\title{
LA FLORA ARBÓREA de MichOACÁN, MÉXICO
}

\author{
Eva M. Cué-Bär¹, José Luis Villaseñor², Libertad Arredondo-Amezcua', Guadalupe \\ CORNEJO-TENORIO'1 Y GUILLERMO IBARRA-MANRÍQUEZ'
}

\author{
${ }^{1}$ Centro de Investigaciones en Ecosistemas, Universidad Nacional Autónoma de México. \\ Antigua carretera a Pátzcuaro No. 8701, Col. San José de la Huerta, C.P. 58190, Morelia, Michoacán, México. \\ Tel. 5623-2730; correo-e: evacue@oikos.unam.mx, gibarra@oikos.unam.mx \\ ${ }^{2}$ Departamento de Botánica, Instituto de Biología, Universidad Nacional Autónoma de México. Apdo. Postal 70-233, \\ Delegación Coyoacán, México 04510, D.F., México. \\ Tel. 5622-9120; correo-e: vrios@ibiologia.unam.mx
}

\begin{abstract}
Resumen: Mediante la revisión de literatura florístico-taxonómica, así como de la consulta del material depositado en los Herbarios del Centro Regional del Bajío (IEB) y del Instituto de Biología (MEXU), se conformó una lista de 845 especies, 352 géneros y 100 familias de árboles para el estado de Michoacán. Asteraceae (82 especies), Fabaceae (74), Mimosaceae (67), Caesalpiniaceae (39) y Burseraceae (38) destacan por su número de especies, mientras que los cinco géneros más importantes al respecto son Bursera (37), Quercus (35), Lonchocarpus (19), Senna (18) y Acacia (15). El género Beiselia (Burseraceae) y 14 especies de árboles (1.8\%) son endémicos del territorio michoacano. Un total de 28 familias (28\%) y 210 géneros $(60 \%)$ están representados por una especie. Los tipos de vegetación más importantes por el número de especies que contienen son el bosque tropical caducifolio $(593,70.2 \%)$, el bosque de coníferas $(336,39.8 \%$ ) y el bosque de Quercus $(332,39.3 \%)$. El $69.9 \%$ de las especies se encuentran en un máximo de cuatro tipos de vegetación; 173 especies $(21.5 \%)$ se distribuyen exclusivamente en una comunidad vegetal, ocupando la primera posición en este grupo el bosque tropical caducifolio con 87 especies (10.3\%). La diversidad florística de Michoacán es explicada principalmente por su complejidad geológica, fisiográfica, climática y de tipos de vegetación, en conjunción con la mezcla de elementos con afinidades holárticas y neotropicales. Se indican los municipios y las especies que se consideran como prioridades para la conservación del componente arbóreo en la entidad.
\end{abstract}

Palabras clave: bosques templados, bosques tropicales, diversidad, endemismo, especies amenazadas, florística, vegetación templada, vegetación tropical.

\begin{abstract}
Based on the review of floristic and taxonomic literature, as well as on the examination of specimens housed at the herbaria of the Centro Regional del Bajío (IEB) and the Instituto de Biología (MEXU), we recorded 845 species, 352 genera and 100 families of trees for the state of Michoacán, Mexico. The largest numbers of species per family were recorded for Asteraceae (82), Fabaceae (74), Mimosaceae (67), Caesalpiniaceae (39) and Burseraceae (38), while at the genus level Bursera (37), Quercus (35), Lonchocarpus (19), Senna (18), and Acacia (16) are the most speciose. The genus Beiselia (Burseraceae) and 14 species $(1.8 \%)$ are strict endemics to the state. A total of 28 families $(28 \%)$ and 210 genera $(60 \%)$ are represented in the state only by one tree species each. The most important vegetation types according to their species richness are tropical deciduous forest (593, $70.2 \%)$, coniferous forest $(336,39.8 \%$ ) and oak forest $(332,39.3 \%)$. A high proportion $(69.9 \%)$ of Michoacán's tree species is located in 2-4 vegetation types; 173 species $(21.5 \%)$ have been found just in one type, mainly in the tropical dry forest (87 species, $10.3 \%$ ). The floristic richness of Michoacán is largely explained by its complex geologic history, its rugged physiography, its diverse climate, and its multiple vegetation types, as well as by its location at the confluence of the Holartic and Neotropical floristic kingdoms. Counties and species on which to focus conservation efforts for trees in the state are pinponted. Key words: diversity, endemism, floristics, temperate forests, temperate vegetation, threatened species, tropical forests, tropical vegetation.
\end{abstract}

$\mathbf{L}$ os árboles son elementos fundamentales para una adecuada caracterización de la composición y la estructura de muchas de las comunidades vegetales, especialmente en los bosques templados y tropicales de México (Miranda y Hernández-X., 1963; Rzedowski, 1978, 1991; Bongers et al., 1988; Meave et al., 1992; Labat, 1995; RamírezMarcial et al., 2001; Sánchez-Sánchez e Islebe, 2002; Giménez de Azcárate et al., 2003; Sánchez-Rodríguez et al., 2003; Mejía-Domínguez et al., 2004; GonzálezEspinosa et al., 2005). Hasta el momento, la única obra 
completa sobre árboles (incluyendo arbustos) del país fue elaborada por Standley (1920-1926) y aunque es una referencia básica sobre el tema, es indiscutible que su información no está actualizada. Posteriormente, Villaseñor e IbarraManríquez (1998) estimaron que al menos 3,639 especies de angiospermas nativas de la flora mexicana son árboles, las cuales se agrupan en 728 géneros y 128 familias; las familias que destacaron por su riqueza de especies fueron Fagaceae (270), Mimosaceae (268) y Fabaceae (205). Estos autores también indicaron que el componente endémico a nivel genérico era poco significativo (3\%), lo que contrastó con lo encontrado a nivel de especie $(42.1 \%)$. Otro trabajo importante a nivel del país sobre el tema es el de Pennington y Sarukhán (1998), quienes describen 200 de las especies arbóreas tropicales más comunes de México, así como los trabajos de Sousa et al. (2001, 2003), en donde se enlistan las 623 especies arbóreas de la familia Leguminosae sensu lato.

En este momento, la posibilidad de contar con un inventario actualizado de la flora arbórea de México no es una tarea sencilla, pues la información que se requiere para su elaboración se encuentra dispersa en numerosas contribuciones florístico-taxonómicas y en los acervos de varios herbarios de México y del extranjero. Una alternativa para avanzar sobre esta tarea es realizar estudios florísticos a nivel estatal. Hasta el momento, sólo Campeche, Colima, Michoacán, Quintana Roo, Sonora y Yucatán cuentan con una lista de sus componentes arbóreos (Ibarra-Manríquez et al., 1995; Felger et al., 2001; Padilla-Velarde et al., en prensa; Carranza-González, 2005) y la realización de estudios similares para los estados con una mayor riqueza florística es un criterio importante para priorizarlos. Villaseñor (2003) indicó que los estados de México con más especies de angiospermas son Chiapas (7,573), Oaxaca (7,399), Veracruz (6,869), Jalisco $(5,105)$ y Michoacán (4,672). Para esta última entidad, los trabajos publicados por Espinosa y Rodríguez-J. (1995, 1996) y Rodríguez-J. y Espinosa (1995, 1996a, b) registran un total de 5,476 especies de plantas vasculares. Recientemente, Carranza-González (2005) publicó una lista de 555 especies arbóreas (incluidas en 85 familias) para Michoacán.

Por otro lado, son varios los estudios que han descrito parcialmente la vegetación de Michoacán, los cuales generalmente aportan información sobre sus componentes florísticos aunque, de manera infortunada, no siempre sobre su forma de crecimiento. Entre los trabajos que se pueden mencionar está el de Leavenworth (1946), quien realizó un estudio entre el cerro Tancítaro y el río Tepalcatepec. Un año después se publicó un estudio donde se describió con detalle la vegetación de la cuenca del río Balsas (Miranda, 1947). Rzedowski y McVaugh (1966), en su obra sobre la vegetación de Nueva Galicia, enlistaron las especies más características de las comunidades vegetales ubicadas en la porción N-NO de Michoacán. Espejo-Serna et al. (1992) describieron la vegetación de la Sierra Chincua y recientemente Genchi (2002), Cornejo-Tenorio et al. (2003) y Giménez de Azcárate et al. (2003) complementaron esta información. Madrigal-Sánchez (1994) describió las comunidades forestales ubicadas en la parte oriental del estado, indicando sus principales componentes florísticos. Un año después, Labat (1995) realizó un trabajo similar, pero enfocándose hacia la porción NO, con información muy detallada de la estructura y la composición de las comunidades que analizó. Estudios florísticos detallados para otras localidades michoacanas incluyen la cuenca del río Chiquito, la cuenca del lago Zirahuén, las comunidades vegetales de la comunidad indígena de Nuevo San Juan Parangaricutiro y el Parque Nacional Pico de Tancítaro (Medina y Rodríguez, 1993; Pérez-Calix, 1996; MedinaGarcía et al., 2000; García-R. et al., 2002). Finalmente, Durán y Sevilla (2004) presentaron información sobre las diez comunidades vegetales que reconocen para Michoacán, señalando sus especies dominantes y un mapa con su distribución a nivel estatal.

Tomando en cuenta que los árboles constituyen un componente muy importante en la composición y la estructura de diversas comunidades vegetales de Michoacán (Miranda, 1947; Rzedoswski, 1978; Espejo et al., 1992; Madrigal-Sánchez, 1994; Labat, 1995; Cornejo-Tenorio et al., 2003; Giménez de Azcárate et al., 2003; Durán y Sevilla, 2004), así como el importante papel que juegan en la realización de estudios biogeográficos y como un grupo indicador para la selección de áreas prioritarias de conservación (Rzedowski, 1978, 1991; Wendt, 1993; IbarraManríquez et al., 2002; Santiago et al., 2002; Villaseñor et al., 2003; Carranza-González, 2005), el presente estudio tiene como principales objetivos la elaboración de una lista actualizada de la flora arbórea de esta entidad, resaltar las familias y los géneros más notables por su riqueza de especies, así como realizar un análisis de la distribución de las especies por tipos de vegetación y su grado de endemismo a nivel estatal.

\section{Área de estudio}

El estado de Michoacán de Ocampo se incluye en la región Centro Occidente de México y se localiza entre las coordenadas 20'23'37' y $17^{\circ} 53^{\prime} 50^{\prime \prime}$ N, y $100^{\circ} 03$ '32" y $103^{\circ} 44^{\prime} 49^{\prime}$ " O (figura 1); cuenta con una superficie de $58,994 \mathrm{~km}^{2}$ y 113 municipios (Durán y Sevilla, 2004). En Michoacán se encuentran dos provincias morfotectónicas (Ferrusquía-Villafranca, 1998): (i) Sierra Madre del Sur (con cinco subprovincias), que destaca por ser la más compleja de México; los registros geológicos más confiables de esta provincia para Michoacán son plutones del Mesozoico y del Cenozoico temprano, así como cuerpos volcánicos andesíticos que se originaron durante el Mesozoico, y (ii) 


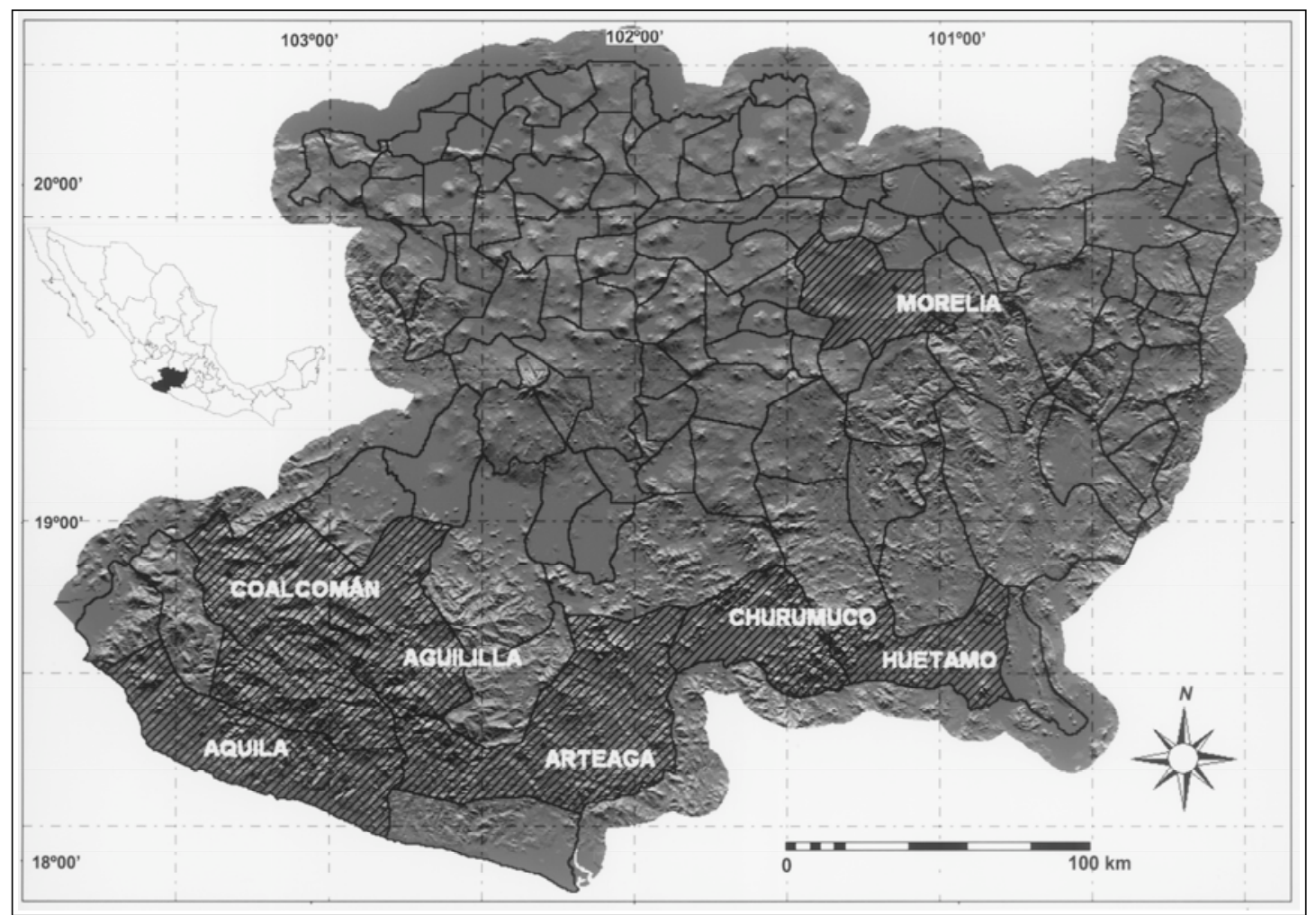

Figura 1. Localización del estado de Michoacán (México) y municipios con mayor número de especies endémicas y cuasiendémicas del estado.

Faja Volcánica Transmexicana, que cubre la mayor parte del territorio de Michoacán y cuya génesis y desarrollo son temas en constante debate, pero que en general se considera que sus inicios datan de mediados del Terciario; esta provincia posee cuerpos volcánicos del Cenozoico Medio (sobre todo en la parte sur y centro de Michoacán) al Tardío, así como sedimentarios clásicos del Cenozoico Tardío. Durán y Sevilla (2004) concuerdan en la existencia de dos provincias geológicas: la Faja Volcánica Transmexicana en el norte del estado, y lo que denominan Complejo Orogénico Guerrero-Colima en su porción sureña.

Durán y Sevilla (2004) dividieron a Michoacán en cinco provincias fisiográficas, las cuales se disponen de N-S con el siguiente orden: (i) Altiplano $\left(3,905 \mathrm{~km}^{2}\right)$, (ii) Cinturón Volcánico Transmexicano $\left(33,492 \mathrm{~km}^{2}\right)$, donde se encuentran las montañas más elevadas del estado, como el Pico Tancítaro (3,850 m), el Cerro de Patamban (3,400 m), el Cerro Paracho (2,220 m) y el volcán Parícutin (2,250 m), (iii) Depresión del Balsas-Tepalcatepec $\left(7,423 \mathrm{~km}^{2}\right)$, (iv) Sierra Madre del Sur $\left(13,929 \mathrm{~km}^{2}\right)$, y (v) Planicie Costera $\left(782 \mathrm{~km}^{2}\right)$. En Michoacán se localizan siete sistemas fluviales (Bocco et al., 1996), tres exorreicos (la cuenca del río Lerma, la cuenca del río Balsas y el Sistema Fluvial Costero) y cuatro endorreicos (el lago de Cuitzeo, el lago de Pátzcuaro, el lago de Zirahuén y el lago de Chapala).
Los tipos de suelos (13 en total) más importantes en el estado son (Correa, 1974; Durán y Sevilla, 2004): (i) leptosoles o litosoles, que son suelos someros, jóvenes, de grises a negros, que se encuentran en todo el estado, sobre todo en los municipios de Arteaga, Huetamo y Apatzingán, (ii) andosoles, que son suelos profundos, bien drenados, negros y pardo rojizos, derivados de cenizas volcánicas, presentes en todo el Eje Neovolcánico y en El Bajío, (iii) regosoles, que son suelos jóvenes, poco desarrollados y de colores claros, muy pobres en materia orgánica, localizados en todas las zonas climáticas pero abundantes al SE del estado, (iv) vertisoles, que son suelos profundos a someros, negros, presentes sobre todo hacia el norte del estado, pero también en su partes central y oriental, y (v) luvisoles, que son suelos profundos de textura arcillosa, con un horizonte B argílico, en su mayoría asociados con vegetación de pino-encino, con las mayo res extensiones en los municipios de Aguililla, Arteaga, Coalcomán, Morelia y Lázaro Cárdenas.

Los tipos de clima predominantes en Michoacán según García (1990) son: (i) Aw, cálido subhúmedo, con la temperatura media del más frío mayor de $18^{\circ} \mathrm{C}$, en la región de la costa y partes más altas de la Depresión del Balsas, (ii) BSw, seco o árido, cálido, con lluvias escasas que predominan en verano; con temperatura media anual superior a $18^{\circ} \mathrm{C}$, (iii) $\mathrm{Cf}$, templado húmedo con lluvias todo el año, 


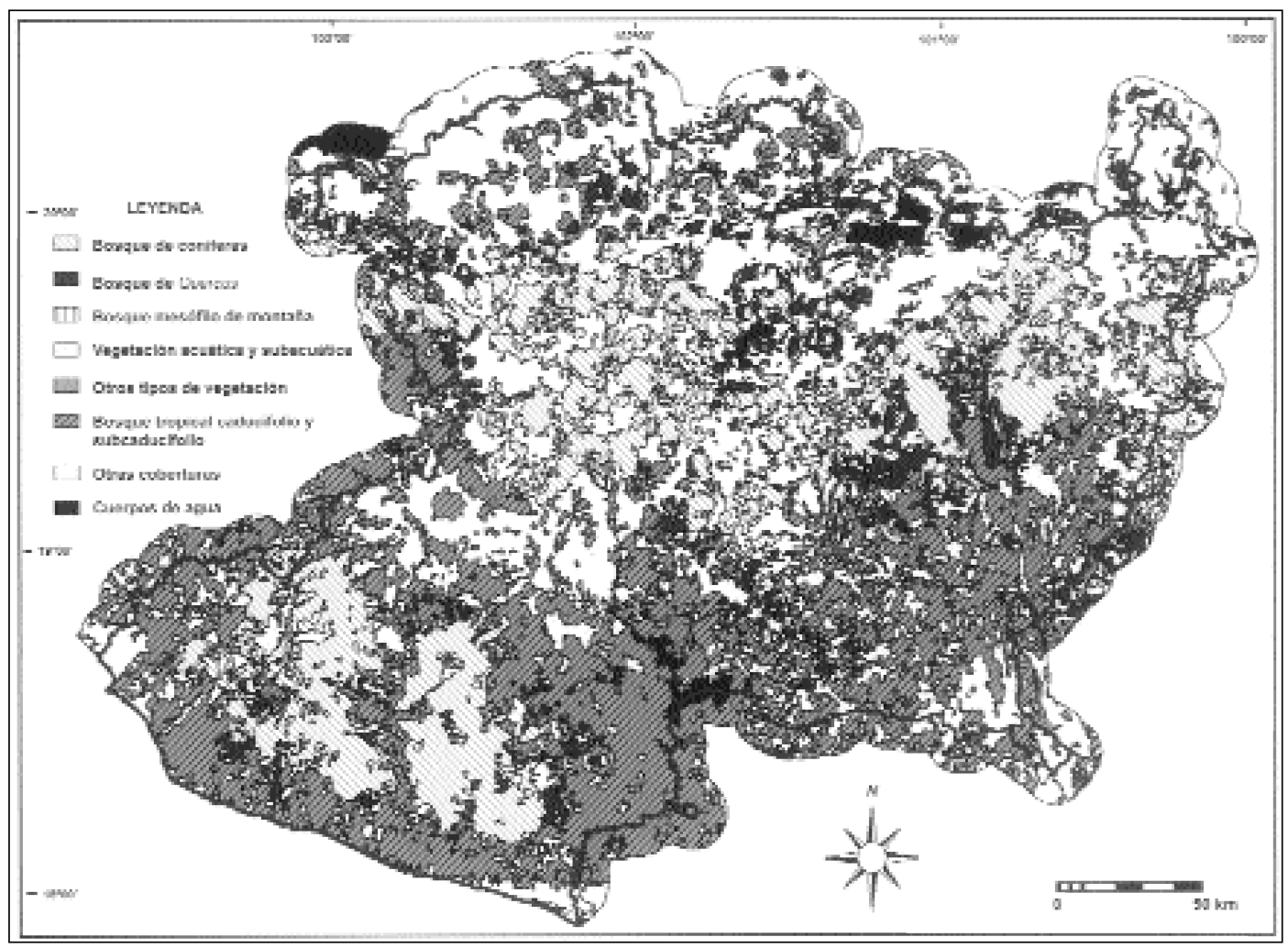

Figura 2. Principales tipos de vegetación en el estado.

propio de las sierras de Tancítaro, Paracho y Patamban en el oeste, y las sierras de Acuitzio, Nahuatzen y Pátzcuaro en el centro del estado, y (iv) $\mathrm{Cw}$, templado subhúmedo con lluvias de verano, que es un clima templado lluvioso, con la temperatura media del mes más frío entre $-3^{\circ}$ y $18^{\circ} \mathrm{C}$ y la del mes más caliente mayor de $10^{\circ} \mathrm{C}$, presente en la mayor parte del sistema Volcánico Transversal.

Finalmente, la delimitación de las comunidades vegetales de Michoacán es un asunto complejo, lo que se refleja en la literatura sinecológica al oscilar sus categorías entre 9 y 17 (Rzedowski, 1978; Madrigal-Sánchez, 1997; Palacio-Prieto et al., 2000; Durán y Sevilla, 2004). PalacioPrieto et al. (2000) reportan los siguientes tipos de vegetación: bosque de Abies $\left(115 \mathrm{~km}^{2}\right)$, bosque de Pinus $\left(3,981 \mathrm{~km}^{2}\right)$, bosque de Pinus-Quercus $\left(8,233 \mathrm{~km}^{2}\right)$, bosque de Quercus $\left(3,114 \mathrm{~km}^{2}\right)$, bosque mesófilo de montaña $\left(85 \mathrm{~km}^{2}\right)$, selva mediana caducifolia y subcaducifolia $\left(1,371 \mathrm{~km}^{2}\right)$, selva baja caducifolia y subcaducifolia $\left(13,707 \mathrm{~km}^{2}\right)$, matorral subtropical $\left(2,197 \mathrm{~km}^{2}\right)$, selva baja espinosa $\left(18 \mathrm{~km}^{2}\right)$, mezquital $\left(2 \mathrm{~km}^{2}\right)$, matorral crasicaule $\left(15 \mathrm{~km}^{2}\right)$, pastizal $\left(16 \mathrm{~km}^{2}\right)$, sabana $\left(7 \mathrm{~km}^{2}\right)$, pastizal inducido $\left(6,149 \mathrm{~km}^{2}\right)$, vegetación acuática y subacuática $\left(123 \mathrm{~km}^{2}\right)$, palmar (33 $\mathrm{km}^{2}$ ) y dunas costeras, vegetación halófila y gipsófila (27 $\mathrm{km}^{2}$ ). La distribución estatal de las comunidades dominadas estructuralmente por especies arbóreas se presenta en la figura 2.

\section{Materiales y métodos}

El criterio para considerar una especie como árbol se basó inicialmente en la propuesta de Whittaker (1975), quien describe a un árbol como una planta leñosa que sobrepasa generalmente una altura de $3 \mathrm{~m}$, y separa esta forma de crecimiento de los arbustos, los cuales generalmente son menores de $3 \mathrm{~m}$. Con el propósito de hacer más precisa la definición empleada en el presente estudio, la definición de árbol se circunscribió a una planta leñosa, con uno o varios troncos desde la base, de porte erecto (es decir, mecánicamente independiente) y cuya altura es $3 \mathrm{~m}$. También se incluyeron algunas especies de monocotiledóneas y de helechos arborescentes, ya que por su apariencia y tamaño semejan el hábito arbóreo.

La compilación de la flora arbórea de Michoacán se centró en el inventario de las especies nativas, así que fueron eliminadas las especies exóticas (e.g. Eucalyptus spp., Myrtaceae) o naturalizadas (e.g. Schinus molle L., Anacardiaceae). Primeramente, se consultó la base de datos del acervo del Herbario del Centro Regional del Bajío, del Instituto de Ecología, A.C. (IEB), a partir de la cual se elaboró una lista preliminar que incluyó las especies de árboles y arbustos $3 \mathrm{~m}$. Estas especies fuer on buscadas en diversos trabajos de tipo florístico-taxonómico y una especie era incluida definitivamente cuando se citaba como 
presente en el estado; un alto porcentaje de estos estudios confirmaba este registro por medio de ejemplares de herbario recolectados en la entidad. La revisión de literatura también permitió detectar especies adicionales que cumplían con el criterio de altura para ser consideradas como árboles, de manera que éstas se añadieron a la lista final.

Las especies cuya presencia en Michoacán no pudo ser verificada por el procedimiento anterior, fueron buscadas en los acervos de los herbarios IEB y MEXU (Herbario Nacional, Instituto de Biología, Unive rsidad Nacional Autónoma de México), que representan las colecciones botánicas a nivel local y nacional más importantes para las plantas michoacanas. Sólo se incluyeron en la lista definitiva especies con ejemplares de herbario determinados por el especialista en la familia o el género (e.g. María de Lourdes Rico Arce para las especies del género Acacia, Mimosaceae) o por botánicos cuya experiencia florística y taxonómica de los árboles mexicanos es ampliamente reconocida (e.g. Jerzy Rzedowski Rotter o Thomas L. Wendt). El conjunto de estas actividades permitió excluir del apéndice 1 a los nombres considerados como sinónimos, a aquellas especies cuyas determinaciones eran dudosas, debido principalmente a que se trata de grupos muy complejos taxonómicamente y para los cuales no se localizaron monografías que permitieran la determinación de sus especies, o a las especies que no cumplían con la altura mínima para considerarlas como árboles. Debido a la dificultad para confirmar la presencia en Michoacán de algunas subespecies o variedades, no fueron incluidas en la lista definitiva.

La literatura consultada incluye diversos trabajos florísticos (González y Labat, 1987; Medina-García y Rodríguez, 1993; Pérez-Calix, 1999; Aguirre, 2000; Medina-García et al., 2000; García-R. et al., 2002; Cornejo-Tenorio et al., 2003; Villaseñor y EspinosaGarcía, 2004), fascículos de floras regionales como la Flora del Bajío y Regiones Adyacentes (Calderón de R., 1991, 1992, 1995, 1996a, 1996b, 2001, 2002; Calderón de R. y Germán, 1993; Carranza-González 1992a, 1992b, 1993, 1994, 1995, 1996, 1999, 2000a, b; CarranzaGonzález y Madrigal-Sánchez, 1995; Carranza-González y Blanco-García, 2000; Rzedowski y Guevara-Fefer, 1992; Zamudio, 1992, 2002; Zamudio y Caranza-González, 1994; Almeda, 1993; Díaz-Barriga, 1993; Fryxell, 1993; López-Ferrari, 1993; Rzedowski y Calderón de R., 1993, 1995a, 1997, 1998, 1999, 2002, 2004; Ballard, 1994; Espinosa y Rodríguez-J-, 1995, 1996; Rodríguez-J. y Espinosa, 1995, 1996a, b; Fernández, 1996; GonzálezVillameal, 1996; Rodríguez-Jiménez, 1996; Carvajal y Peña-Pinela, 1997; van der Werff y Lorea, 1997; PérezCalix, 1999; Pérez-Calix y Camanza-González, 1999; Villarreal-Q., 2000a, b, c; Spellenberg, 2001; Daniel y Acosta-Castellanos, 2003; Ocampo-Acosta, 2003; Lorea-
Hernández, 2004), la Flora de Guerrero (Diego-Pérez, 2004), la Flora Neotropica (Prance, 1972; Pennington et al., 1981; Kaastra, 1982; Sleumer, 1980, 1984; Pennington, 1990; Gentry, 1992a, b; Rohwer, 1993; Luteyn, 1995; Clemants et al., 1995; Farjon y Styles, 1997; Norman, 2000; Berg, 2001; Knapp, 2002), la Flora Novo-Galiciana (McVaugh, 1974, 1983, 1984, 1987, 1992, 2001; Kiger, 2001; Fryxell, 2001a, b, c, d), la Flora del Valle de México (Calderón de R. y Rzedowski, 2001), y la Flora de Veracruz (Soejarto, 1984; Graham, 1991). Además, se consultaron revisiones taxonómicas y publicaciones de especies nuevas para la ciencia (Lay, 1950; McVaugh y Rzedowski, 1965; Bravo-Hollis, 1978; Guevara-Fefer y Rzedowski, 1980; Forman, 1987; Fryxell, 1988; MadrigalSánchez y Rzedowski, 1988; Thomas, 1988; Hernández, 1989; Cannon y Cannon, 1989; Lorence y Dwyer, 1988; Clarke y Seigler, 1989; Ståhl, 1989; Lewis, 1990; Zona, 1990; Barneby, 1991; Perry, 1991; Jiménez y MartínezGordillo, 1991; Ibarra-Manríquez y Wendt, 1992; Sousa y Andrade, 1992; Fernández-N., 1993; González, 1993; Murray, 1993; Villaseñor, 1993; Leeuwenberg 1994; Zárate, 1994; Jiménez-R., 1995; Randall, 1995; Rzedowski y Calderón de R., 1995b, 2000, 2006; Williams, 1996; Farjon et al., 1997; Fritsch, 1997; Lorence, 1999; GarcíaMendoza, 2000; Grether, 2000; Webster, 2001; MartínezGordillo et al., 2002; Steinmann, 2002; Sousa et al., 2001, 2003; Guzmán et al., 2003; Borhidi et al., 2004; ValenciaA., 2004; Rzedowski et al., 2005; Sousa, 2005; Steinmann, 2005a, b).

Los tipos de vegetación citados para las especies fueron obtenidos de la literatura consultada y de los ejemplares de herbario revisados. Debido a la heterogeneidad de las denominaciones dadas a las comunidades vegetales, éstas se adaptaron al sistema de Rzedowski (1978). La lista de especies de angiospermas está arreglada con base en el sistema de familias propuesto por Cronquist (1981). Los nombres de las autoridades de las especies siguen las abreviaturas compiladas por Villaseñor (2001). Finalmente, se consultó la Norma Oficial Mexicana NOM-059-ECOL-2001 (SEMARNAT, 2002) y la lista de la IUCN (Waltery Gillett, 1998) con el fin de ubicar, de acuerdo con sus propuestas, a las especies que se encuentran en alguna de las categorías de riesgo o amenazada.

\section{Resultados}

Se registró para Michoacán un total de 845 especies de árboles, agrupadas en 352 géneros y 100 familias (apéndice 1). Las familias con mayor número de especies son Asteraceae, Fabaceae, Mimosaceae, Caesalpiniaceae y Burseraceae (cuadro 1). Las 13 familias incluidas en el cuadro 1 agrupan 495 especies y 138 géneros que representan, respectivamente, $58.6 \%$ y $39.2 \%$ del total de especies y de géneros del estado. El apéndice 1 muestra que 28 
familias son monoespecíficas y 37 más presentan entre dos y cinco especies; únicamente seis familias tienen más de 10 géneros (cuadro 1). Los cuatro géneros con mayor riqueza de especies son Bursera, Quercus, Lonchocarpus y Senna; los 13 géneros más importantes respecto a este atributo agrupan 227 especies (cuadro 1), es decir, 26.9\% del total de especies citadas en el apéndice $1 ; 60.2 \%$ de los géneros (212) cuentan con una sola especie. El género Beiselia (Burseraceae) y un número muy bajo de especies están restringidos al territorio michoacano (14 especies, 1.8\%), destacando en este sentido Burseraceae (cuatro especies), así como Euphorbiacae y Malvaceae, con dos especies cada una (cuadro 2). El componente endémico se localiza en 18 municipios, sobresaliendo primeramente Morelia (cuatro especies), seguido por Coalcomán y La Huacana (tres), mientras que Arteaga, Aquila y Churumuco cuentan con dos especies cada uno (cuadro 2, figura 1). Otras 20 especies pueden considerarse como cuasiendémicas, pues se comparten sólo con una entidad más del país (cuadro 3). La distribución de estas especies entre los municipios de la zona de estudio ratifica la importancia de aquellos mencionados para el componente endémico, aunque Aguililla y Huetamo aparecen ahora también como relevantes. El apéndice 2 incluye una lista de 106 especies arbóreas cuya presencia en Michoacán no ha sido confirmada, pero que tienen altas probabilidades de encontrarse dentro de sus límites geográficos, ya que han sido citadas en alguno de sus estados vecinos.

El bosque tropical caducifolio es la comunidad vegetal con más especies (70.2\%) en el área de estudio (cuadro 4, figura 2) y en él se albergan seis de las 15 especies endémicas de Michoacán (apéndice 1, cuadro 2). El resto de los
Cuadro 1. Familias y géneros con mayor número de especies de árboles en Michoacán. El número de géneros por familia se indica entre paréntesis.

\begin{tabular}{lclc}
\hline Familia & $\begin{array}{c}\text { Número de } \\
\text { especies } \\
\text { (géneros) }\end{array}$ & $\begin{array}{c}\text { Género } \\
\text { (Familia) }\end{array}$ & $\begin{array}{c}\text { Número de } \\
\text { especies }\end{array}$ \\
\hline Asteraceae & $82(27)$ & Bursera (Burseraceae) & 37 \\
Fabaceae & $74(26)$ & Quercus (Fagaceae) & 35 \\
Mimosaceae & $67(17)$ & Lonchocarpus (Fabaceae) & 19 \\
Caesalpiniaceae & $39(9)$ & Senna (Caesalpiniaceae) & 18 \\
Burseraceae & $38(2)$ & Verbesina (Asteraceae) & 16 \\
Fagaceae & $35(1)$ & Acacia (Mimosaceae) & 15 \\
Euphorbiaceae & $33(14)$ & Mimosa (Mimosaceae) & 15 \\
Rubiaceae & $29(15)$ & Pinus (Pinaceae) & 15 \\
Boraginaceae & $22(5)$ & Cordia (Boraginaceae) & 13 \\
Cactaceae & $23(10)$ & Ficus (Moraceae) & 11 \\
Solanaceae & $18(3)$ & Solanum (Solanaceae) & 11 \\
Moraceae & $17(7)$ & Randia (Rubiaceae) & 11 \\
Pinaceae & $17(2)$ & Vernonia (Asteraceae) & 11 \\
Total & $495(138)$ & Total & 227 \\
\hline
\end{tabular}

tipos de vegetación del cuadro 4 presentan un porcentaje de especies comparativamente más bajo que el correspondiente al bosque tropical caducifolio $(<40 \%)$. Un total de 591 especies (69.9\%) se encuentra en menos de cinco tipos de vegetación y 173 especies se restringen a un tipo de vegetación (cuadro 4), destacando respecto a esta vari able otra vez el bosque tropical caducifolio (87 especies; $10.3 \%$ ); exclusivamente tres especies se localizan en diez tipos de vegetación [Acacia pennatula (Schltdl. et Cham.) Benth., Mimosaceae; Randia aculeata L., Rubiaceae; y

Cuadro 2. Especies endémicas del territorio de Michoacán, indicando la familia a la que pertenecen y los municipios donde se ha registrado su presencia.

\begin{tabular}{|c|c|c|}
\hline Especie & Familia & Municipios \\
\hline Arachnotrhyx michoacana Borhidi & Rubiaceae & Aguililla \\
\hline Beiselia mexicana Forman & Burseraceae & Aquila \\
\hline Bourreria longiflora I.M.Johnst. & Boraginaceae & Coalcomán \\
\hline Bursera madrigalii Rzed. et Calderón & Burseraceae & $\begin{array}{l}\text { Benito Juárez, Jungapeo, Morelia, Tzitzio, } \\
\text { Zitácuaro }\end{array}$ \\
\hline B. occulta McVaugh et Rzed. & Burseraceae & Aquila, Coalcomán \\
\hline B. staphyleoides McVaugh et Rzed. & Burseraceae & Apatzingán \\
\hline Diospyros xolocotzii Madrigal et Rzed. & Ebenaceae & Morelia \\
\hline Gossypium lobatum H.Gentry & Malvaceae & Churumuco, La Huacana, Gabriel Zamora \\
\hline G. schwendimanii Fryxell et S.D.Koch & Malvaceae & Arteaga, Churumuco \\
\hline Jatropha pereziae J.Jiménez Ram. & Euphorbiaceae & Tepalcatepec \\
\hline J. stephani J.Jiménez Ram. et Martínez Gordillo & Euphorbiaceae & Arteaga, La Huacana \\
\hline Pachycereus tepamo S.Gama et S.Arias & Cactaceae & La Huacana \\
\hline Pinus rzedowskii Madrigal et Caball. & Pinaceae & Coalcomán \\
\hline Salix aeruginosa E.Carranza & Salicaceae & $\begin{array}{l}\text { Charo, Indaparapeo, Morelia, Tlalpujahua, } \\
\text { Zinapécuaro }\end{array}$ \\
\hline Vernonia solorzanoana Rzed. et Calderón & Asteraceae & Morelia \\
\hline
\end{tabular}


Cuadro 3. Especies de Michoacán que se comparten exclusivamente con otra entidad estatal, indicando su familia y los municipios michoacanos en donde se han registrado. Abreviaturas de los estados: GRO = Guerrero, JAL = Jalisco, MÉX = Estado de México y PUE = Puebla.

\begin{tabular}{llll}
\hline Especies & Familia & Municipios & Estado \\
\hline Bursera confusa & Burseraceae & Coalcomán, Zitácuaro & JAL \\
B. coyucensis & Burseraceae & Apatzingán & GRO \\
B. fragantissima & Burseraceae & Aguililla & GRO \\
B. paradoxa & Burseraceae & Arteaga, La Huacana & GRO \\
B. ribana & Burseraceae & Aquila & JAL \\
B. sarukhanii & Burseraceae & Arteaga, La Huacana & GRO \\
Casearia elegans & Flacourtiaceae & Aquila, Coalcomán & GRO \\
Magnolia iltisiana & Magnoliaceae & Morelia & JAL \\
Jungia pringlei & Asteraceae & Uruapan & GRO \\
Lonchocarpus balsensis & Fabaceae & Arteaga, Churumuco, Huetamo, Múgica & GRO \\
L. huetamoensis & Fabaceae & Arteaga, Huetamo, La Huacana, Tumbiscatio & GRO \\
L. longipedunculatus & Fabaceae & Aguililla, Arteaga, Buenavista, Carácuaro, & GRO \\
Quercus furfuracea & Churumuco, Huetamo, Múgica & \\
Q. hintonii & Fagaceae & - & PUE \\
Stenocereus chrysocarpus & Fagaceae & - & MÉX \\
Thevetia pinifolia & Cactaceae & - & GRO \\
Triumfetta mexiae & Apocynaceae & Apatzingán, Huetamo & GRO \\
Verbesina furfuracea & Tiliaceae & Zitácuaro & GRO \\
V. heterocarpa & Asteraceae & Aguililla & JAL \\
Vernonia bealliae & Asteraceae & Aguililla & JAL \\
\hline
\end{tabular}

Guazuma ulmifolia Lam., Ulmaceae] y únicamente Dodonaea viscosa Jacq. (Sapindaceae) se encuentra en las 12 comunidades vegetales reconocidas para Michoacán.

De las especies arbóreas de la zona de estudio, se consideraque siete están en peligro de extinción, 13 se dasifican como amenazadas y 18 más están sujetas a protección especial (SEMARNAT, 2002; apéndice 1). En la lista de la IUCN (Walter y Gillett, 1998), 19 especies son reportadas como raras, nueve como vulnerables, seis están consideradas en peligro de extinción y ocho están incluidas en la categoría de indeterminadas (apéndice 1). Solamente Abies guatemalensis Rehder, Bursera arborea (Rose) L.Riley, Diospyros xolocotzii Madrigal et Rzed., Furcraea parmen tieri (Roezl ex Ortgies) García-Mend., Guaiacum coulteri A.Gray, Juglans pyriformis Liebm., Magnolia iltisiana A.Vázquez, Pinus rzedowskii Madrigal et M.Caball., Sabal pumos (Kunth) Burret y Sauraria serrata DC. aparecen en ambas clasificaciones (apéndice 1).

\section{Discusión}

La riqueza de familias, géneros y especies de la flora arbórea de Michoacán es sobresaliente cuando se le compara con la encontrada en otros estados del país (cuadro 5), aunque al realizar este último ejercicio fue necesario considerar que en otros estudios se pueden haber aplicado criterios distintos para definir una especie como árbol. Un elemento que puede explicar la riqueza de la flora de
Cuadro 4. Número de especies arbóreas con distribución restringida a un tipo de vegetación (porcentaje con respecto al total de especies entre paréntesis) para las diferentes agrupaciones vegetales reconocidas en Michoacán.

\begin{tabular}{lcc}
\hline Tipos de vegetación & $\begin{array}{c}\text { Número de } \\
\text { especies (\%) }\end{array}$ & $\begin{array}{c}\text { Especies } \\
\text { restringidas }\end{array}$ \\
\hline Bosque tropical caducifolio & $593(70.2)$ & $87(10.3)$ \\
Bosque de coníferas & $336(39.8)$ & $19(2.2)$ \\
Bosque de Quercus & $332(39.3)$ & $2(0.2)$ \\
Bosque tropical subcaducifolio & $311(36.8)$ & $6(0.7)$ \\
Matorral xerófilo & $299(35.4)$ & $6(0.7)$ \\
Bosque mesófilo de montaña & $295(34.9)$ & $9(1.1)$ \\
Vegetación acuática y subacuática & $223(26.4)$ & $3(0.4)$ \\
Bosque tropical perennifolio & $178(21.1)$ & $2(0.2)$ \\
Bosque espinoso & $154(18.2)$ & $1(0.1)$ \\
Pastizal & $52(6.2)$ & $0(0)$ \\
Vegetación secundaria & $25(3.0)$ & $2(0.2)$ \\
Otros tipos de vegetación primaria & $62(7.3)$ & $1(0.1)$ \\
No determinada & $40(4.7)$ & - \\
\hline
\end{tabular}

Michoacán es su compleja historia geológica (FerrusquíaVillafranca, 1998), el cual ha sido discutido en ese sentido a escala nacional (Rzedowski, 1978, 1991; Wendt, 1993). Además, la accidentada fisiografía de Michoacán, con altitudes que van desde el nivel del mar hasta más de 3,500 m, se traduce en una gran diversidad de climas y tipos de vegetación (Miranda y Hernández-X., 1963; Rzedowski, 1978; García, 1990; Palacio-Prieto et al., 2000; Durán y Sevilla, 2004). 
El menor número de especies de las entidades de la península yucateca puede explicarse parcialmente por su menor relieve (es casi plano, sin sobrepasar 400 m s.n.m.), lo que redunda en que presente una menor variedad de climas y tipos de vegetación, donde se acentúa para estos últimos la ausencia de comunidades templadas y la de bosque mesófilo de montaña (Miranda y Hernández-X., 1963; Rzedowski, 1978). Por otro lado, a pesar de que Sonora también tiene una fisiografía accidentada $(0-2,625 \mathrm{~m}$ s.n.m.) y un territorio mayor, tiene menos especies arbóreas que Michoacán. Una posible explicación podría ser la mayor extensión de climas extremosos que se dan en esta región (García, 1990; Felger et al., 2001). Paralelamente, Michoacán también es la entidad con la mayor densidad de riqueza de especies arbóreas entre los estados incluidos en el cuadro 5, lo que permite afirmar que su mayor riqueza no es una consecuencia de que posea una mayor superficie con respecto a la que presentan Colima o los tres estados de la Península de Yucatán. La comparación en este sentido con Sonora es más clara, ya que su territorio sobrepasa en casi cuatro veces el de Michoacán y, sin embargo, tiene un valor mucho menor de S/logsup.

La familia con más especies arbóreas en Michoacán es Asteraceae, con 82 especies. Esta familia estuvo ubicada en las posiciones quinta y octava por su número de elementos arbóreos en los trabajos de Padilla-Velarde et al. (en prensa) y de Villaseñor e Ibarra-Manríquez (1998). La importancia de Asteraceae obedece a que México es uno de sus principales centros de diversificación y, considerando su número de especies, también ocupa la primera posición a nivel nacional (Rzedowski, 1991; Villaseñor, 2003), además de que Michoacán es la quinta entidad con mayor riqueza de especies de asteráceas en México (Villaseñor, 1993). La mayoría de las asteráceas mexicanas han evolucionado en la Sierra Madre del Sur y en la Faja Volcánica Transmexicana (Turner y Nesom, 1998; Villaseñor, 1993);

Cuadro 5. Riqueza arbórea para familias, géneros y especies en los estados de Michoacán, Colima, Quintana Roo, Campeche, Yucatán y Sonora. Se indica también la densidad de la riqueza a través del cociente de especies por unidad de área, en escala logarítmica (base 10).

\begin{tabular}{lcccrc}
\hline Estado & Familias & Géneros & $\begin{array}{r}\text { Especies } \\
(\mathrm{S})\end{array}$ & $\begin{array}{r}\text { Superficie } \\
\left(\mathrm{km}^{2}\right)\end{array}$ & S/Logsup \\
\hline Michoacán & 100 & 352 & 845 & 58,994 & 176.8 \\
Colima & 88 & 274 & 535 & 5,542 & 142.9 \\
Quintana Roo & 54 & 198 & 351 & 50,212 & 74.7 \\
Campeche & 51 & 177 & 297 & 50,812 & 63.1 \\
Yucatán & 46 & 170 & 287 & 38,402 & 62.6 \\
Sonora & 69 & 160 & 285 & 185,430 & 54.1 \\
\hline
\end{tabular}

ambas provincias biogeográficas se encuentran en Michoacán y junto con la cuenca del río Balsas, forman una zona con alta riqueza de especies para esta familia (Villaseñor, 1987). En contraste, Asteraceae no aparece como un taxón importante para los árboles de la Península de Yucatán ni de Sonora (Ibarra-Manríquez et al., 1995; Felger et al., 2001).

Las siguientes familias más importantes en Michoacán por su riqueza de especies arbóreas son Fabaceae y Mimosaceae (cuadro 1). Mimosaceae es la familia con mayor número de especies en Colima, la Península de Yucatán y Sonora (Ibarra-Manríquez et al., 1995; Felger et al., 2001; Padilla-Velarde et al., en prensa), en tanto que Fabaceae se localiza en las posiciones segunda, tercera y quinta, respectivamente, de dichos trabajos. A nivel nacional, estas familias sólo son superadas por Fagaceae, con 270 especies (Villaseñor e Ibarra-Manríquez, 1998). Una ponderación interesante para Michoacán sería considerar a Fabaceae, Mimosaceae y Caesalpiniaceae como una sola familia (Leguminosae sensu lato), tal y como se hace en varios sistemas de clasificación. En ese caso, Leguminosae superaría con amplitud a Asteraceae, pues agruparía 180 especies (21.3\%). Entre la flora fanerogámica de México, Leguminosae sensu lato es la familia más importante para el componente arbóreo de México, con 579 especies, es decir, el doble de las especies reconocidas para Fagaceae (Villaseñor e Ibarra-Manríquez, 1998). México es considerado como un centro secundario de diferenciación de Leguminosae, con $51.8 \%$ de sus especies restringidas al país (Sousa y Delgado, 1998), y cuyos miembros se distribuyen en la mayoría de sus comunidades vegetales, especialmente en los bosques tropicales (Miranda, 1947; Miranda y Hernández-X., 1963; Rzedowski, 1978; McVaugh, 1987; Sousa-S. y Delgado, 1998); estos últimos ocupan aproximadamente $38.5 \%$ del territorio de Michoacán (Palacio-Prieto et al., 2000).

Respecto a la importancia de Burseraceae en la zona de estudio, existe concordancia con Padilla-Velarde et al. (en prensa), ya que en Colima esta familia se ubica en la cuarta posición por su número de sus especies, siendo superada por Leguminosae, Euphorbiaceae y Rubiaceae. La riqueza de Burseraceae en Michoacán obedece a que el género Bursera ha tenido un importante centro de diversificación en la provincia de la Depresión del Balsas (Miranda, 1947; Rzedowski, 1978, 1991), además de que incluye dos de las seis áreas con alta concentración de especies endémicas de México (Rzedowski et al., 2005). Por el contrario, en la Península de Yucatán sólo está representada por Bursera simaruba (L.) Sarg. y B. sc hlechtendalii Engl. (IbarraManríquez et al., 1995; Rzedowski et al., 2005). Una situación similar existe con Fagaceae para esta última región, ya que su importancia es casi nula, con dos especies registradas por Valencia-A. (2004): Quercus crassipes Humb. et Bonpl. y Q. oleoides Schtldl. et Cham. La impor- 
tancia de Fagaceae para los árboles de Michoacán coincide con su relevancia en Sonora (Felger et al., 2001), Colima (Padilla-Velarde et al., en prensa) y en general en todo el territorio mexicano (Villaseñor e Ibarra-Manríquez, 1998), y se explica porque México también es un centro de especiación del género Quercus (González y Labat, 1987; González, 1993; Nixon, 1998; Valencia-A., 2004), así como por el importante porcentaje de superficie que tienen en Michoacán las comunidades de pino-encino y de encino (Palacio-Prieto et al., 2000).

Después de Bursera y Quercus, Lonchocarpus es el género más destacado por su riqueza de especies (19), y se ubicó entre los cinco más importantes para la flora arbórea de Yucatán (Ibarra-Manríquez et al., 1995) y de Colima (Padilla-Velarde et al., en prensa). Con 62 especies, este taxón despliega en México su mayor centro de diversidad (Sousa et al., 2003), algunas de las cuales son endémicas de la cuenca del río Balsas (Sousa y Soto, 1987). Lonchocarpus, junto con Acacia, Mimosa, Inga y Senna, son los géneros de Leguminosae (sensu lato) más importantes por su número de especies arbóreas en México (Sousa et al., 2001, 2003). Finalmente, la importancia del género Pinus en la flora mexicana ha sido ampliamente discutida, ya que México tiene la mayor diversidad de pinos del mundo, con un importante porcentaje de sus especies distribuidas en la Faja Volcánica Transmexicana y la Sierra Madre del Sur (Perry, 1991; Farjon y Styles, 1997; Farjon et al., 1997; Styles, 1998), ambas provincias presentes en Michoacán.

En relación con las comunidades vegetales que albergan el mayor número de especies en Michoacán, en general son las que presentan la mayor extensión dentro de su territorio. La excepción es el bosque mesófilo de montaña, cuya alta riqueza de especies contrasta con su pequeña extensión en Michoacán $\left(85 \mathrm{~km}^{2}\right)$, lo que concuerda con lo indicado para este tipo de vegetación en todo México (Rzedowski, 1991, 1996). La importancia de los tipos de vegetación respecto a su riqueza de especies arbóreas es similar a lo documentado por Padilla-Velarde et al. (en prensa) para Colima, con la excepción del bosque de coníferas, cuya pequeña área en dicho estado alberga menos de $1 \%$ de especies de árboles. Para los árboles de Sonora, la similitud es únicamente con el bosque tropical caducifolio (Felger et al., 2001). La información del cuadro 4 debe ser tomada con reserva, ya que debido a la complejidad para definir las comunidades vegetales de México, la información contenida en las etiquetas de herbario o en la literatura florística no es totalmente equivalente.

Con respecto a las especies arbóreas consideradas en alguna categoría de riesgo (Walter y Gillett, 1998; SEMARNAT, 2002), sólo Furcraea parmentieri (Agavaceae) y Comarostaphylis discolor (Ericaceae) se encuentran bajo protección en Michoacán, en el territorio de la Reserva de Biosfera de la Mariposa Monarca y en el del Parque Nacional Pico de Tancítaro. Según Walter y Gillet (1998), Quercus martinezii (Fagaceae) está considerada como una especie rara y se le menciona como parte de la flora del volcán Tancítaro (García-R. et al., 2002). De manera infortunada, se carece de información adecuada para la mayoría de las especies de la flora arbórea de Michoacán que permita evaluar su estatus de conservación. Escasos ejemplos son los aportados para cuat ro de sus especies endémicas (Diospyros xolocotzii, Pinus rze dowskii, Salix aeruginosa y Vernonia solorzanoana), señaladas como plantas altamente vulnerables a la extinción debido a su distribución geográfica muy restringida, su baja densidad poblacional y la constante amenaza a sus hábitats por las actividades humanas (Perry, 1991; Rzedowski y Calderón de R., 1995a; Carranza-González, 1995, 2000a).

El grado de amenaza es seguramente más critico para las especies arbóreas localizadas en áreas densamente pobladas, como es el caso del municipio de Morelia, que entre los 113 en los que se divide Michoacán es donde se ha registrado el mayor número de especies endémicas (cuadro 2). Este municipio, en conjunto con Aguililla, Aquila, Coalcomán, Churumuco, La Huacana y Huetamo (figura 1a) deben ser considerados como prioritarios para llevar a cabo acciones de conservación a nivel estatal. En las referencias de la IUCN y de la SEMARNAT existen 10 especies compartidas, las que junto con las especies endémicas conforman un grupo que debe contar con medidas efectivas que aseguren su conservación estatal a largo plazo.

Los resultados del presente trabajo permiten constatar una vez más la importancia florística de Michoacán y pueden ser útiles en la planeación y conducción de los estudios florísticos y ecológicos a desarrollar en su territorio en el futuro inmediato. De hecho, existe consenso entre la comunidad botánica mexicana que la parte meridional del estado no está florísticamente bien caracterizada, y que es necesario realizar actividades más específicas en la Sierra Madre del Sur y la región del Balsas. Es por ello que se justifica incluir en el presente estudio una lista de especies arbóreas cuya presencia en Michoacán es altamente probable, ya que han sido registradas en uno o varios de sus estados vecinos (apéndice 2). Una vez que se cuente con datos más precisos del número de especies y sus patrones de distribución a nivel regional, será posible ubicar con mayor exactitud sitios que destaquen por su riqueza de especies y/o su grado de endemismo. Contar con esta información en un plazo cercano es fundamental para poder aplicar medidas que garanticen la protección del componente arbóreo en Michoacán. Finalmente, se espera que el presente trabajo promueva la realización de proyectos similares en otras regiones de México, que colaboren a incrementar el conocimiento florístico y biogeográfico de los árboles mexicanos. 


\section{Agradecimientos}

Ramón Cuevas Guzmán fungió como revisor del manuscrito y aportó valiosas sugerencias para mejorar su contenido. Un papel similiar fue desempeñado por Thomas L. Wendt, a quien deseamos reconocer su minuciosa revisión, pero sobre todo el compartirnos sus conocimientos sobre la taxonomía y la definición práctica de los árboles, asuntos en los que es experto. También queremos agradecer a Jerzy Rzedowski y a Gerardo Salazar Chávez por las facilidades otorgadas para consultar las colecciones resguardadas en los herbarios de los que son curadores (IEB y MEXU, respectivamente), y a J. Rzedowski y Sergio Zamudio Ruiz por su disposición para facilitarnos la base de datos del herbario IEB. Queremos reconocer la invaluable ayuda de los siguientes taxónomos para precisar la lista de especies de los grupos de su especialidad: Eleazar Carranza González (Convolvulaceae y Ebenaceae), Nelly Diego Pérez (Apocynaceae), Jaime Jiménez Ramírez (Euphorbiaceae), Martha Martínez Gordillo (Euphorbiaceae), Mario Sousa Sánchez (Lonchocarpus, Fabaceae), Rosalinda Medina Lemos (Burseraceae), Jerzy Rzedowski Rotter (Burseraceae) y Susana Valencia Ávalos (Fagaceae). Enrique Ortiz Bermúdez, Jesús Fuentes Junco y Juan Martínez Cruz ap oya ron en la elaboración de las figuras y otros detalles técnicos del manuscrito. Finalmente, reconocemos ampliamente el responsable y cuidadoso trabajo editorial de Jorge A. Meave, particulamente en las últimas fases de la publicación de nuestro trabajo.

\section{Literatura citada}

Aguirre R. 2000. Guía Práctica para los Árboles y Arbustos de la Región Tierra Caliente del Estado de Michoacán, México. The Field Museum, Chicago.

Almeda F. 1993. Melastomataceae. Flora del Bajío y de Regiones Adyacentes 10:1-37.

Ballard Jr. H.E. 1994. Violaceae. Flora del Bajío y de Regiones Adyacentes 31:1-38.

Barneby R.C. 1991. Sensitivae Sensitae: a description of the genus Mimosa Linnaeus (Mimosaceae) in the New World. Memoirs of the New York Botanical Garden 65:1-835.

Berg C.C. 2001. Moreae, Artocarpeae and Dorstenia (Moraceae). Flora Neotropica 83:1-346.

Bocco G., Velázquez A., Mendoza M., Torres M.A. y Torres A. 1996. Regionalización ecológica de los recursos naturales. Informe Técnico. Departamento de Ecología de los Recursos Naturales, Centro de Ecología, Universidad Nacional Autónoma de México, Morelia, 95 p.

Bongers F., Pompa J., Meave J. y Carabias J. 1988. Structure and floristic composition of the lowland rain forest of Los Tuxtlas, Mexico. Vegetatio 74:55-80.

Borhidi A., Darók J., Kócsis M., Stranczinger Sz. y Kaposvári F. 2004. El Rondeletia complejo en México. Acta Botanica Hungarica 46:91-135

Bravo-Hollis H. 1978. Las Cactáceas de México. Vol. 1.
Universidad Nacional Autónoma de México, México, D.F.

Calderón de R. G. 1991. Papaveraceae. Flora del Bajío y de Regiones Adyacentes 1:1-37.

Calderón de R. G. 1992. Coriariaceae. Flora del Bajío y de Regiones Adyacentes 5:1-6.

Calderón de R. G. 1995. Olacaceae. Flora del Bajío y de Regiones Adyacentes 34:1-11.

Calderón de R. G. 1996a. Connaraceae. Flora del Bajío y de Regiones Adyacentes 48:1-7.

Calderón de R. G. 1996b. Flacourtiaceae. Flora del Bajío y de Regiones Adyacentes 41:1-19.

Calderón de R. G. 2001. Aceraceae. Flora del Bajío y de Regiones Adyacentes 94:1-7.

Calderón de R. G. 2002. Muntingiaceae. Flora del Bajío y de Regiones Adyacentes 108:1-6.

Calderón de R. G. y Germán MT. 1993. Meliaceae. Flora del Bajio y de Regiones Adyacentes 11:1-22.

Calderón de R. G. y Rzedowski J. 2001. Flora Fanerogámica del Valle de México. 2a ed., Instituto de Ecología, A.C. y Comisión Nacional para el Conocimiento y Uso de la Biodiversidad, Pátzcuaro.

Cannon M.J. y Cannon J.F.M. 1989. Central American Araliaceae - a precursory study for the Flora Mesoamericana. Bulletin of the British Museum of Natural History (Botany) 19:5-61.

Carvajal S. y Peña-Pinela C. 1997. Cecropiaceae. Flora del Bajío $y$ de Regiones Adyacentes 53:1-7.

Carranza-González E. 1992a. Taxodiaceae. Flora del Bajío y de Regiones Adyacentes 4:1-7.

Carranza-González E. 1992b. Cornaceae. Flora del Bajío y de Regiones Adyacentes 8:1-11.

Carranza-González E. 1993. Styracaceae. Flora del Bajío y de Regiones Adyacentes 21:1-14.

Carranza-González E. 1994. Platanaceae. Flora del Bajío y de Regiones Adyacentes 23:1-7.

Carranza-González E. 1995. Salicaceae. Flora del Bajío y de Regiones Adyacentes 37:1-21.

Carranza-González E. 1996. Garryaceae. Flora del Bajío y de Regiones Adyacentes 49:1-17.

Carranza-González E. 1999. Theaceae. Flora del Bajío y de Regiones Adyacentes 73:1-17.

Carranza-González E. 2000a. Opiliaceae. Flora del Bajío y de Regiones Adyacentes 81:1-7.

Carranza-González E. 2000b. Ebenaceae. Flora del Bajío y de Regiones Adyacentes 83:1-9.

Carranza-González E. 2005. Biodiversidad. Angiospermas. En: Villaseñor-Villaseñor L. Ed. La Biodiversidad en Michoacán. Estudio de Estado, pp. 73-75, Comisión Nacional para el Conocimiento y Uso de la Biodiversidad, Gobierno del Estado de Michoacán, Secretaría de Urbanismo y Medio Ambiente, Universidad Michoacana de San Nicolás de Hidalgo, Morelia.

Carranza-González E. y Blanco-García A. 2000. Bombacaceae. Flora del Bajío y de Regiones Adyacentes 90:1-16.

Carranza-González E. y Madrigal-Sánchez X. 1995. Betulaceae. Flora del Bajío y de Regiones Adyacentes 39:1-23.

Clarke D.H. y Seigler D.S. 1989. Acacia farnesiana (Fabaceae: Mimosoideae) and related species from Mexico, the southwestern U.S., and the Caribbean. Systematic Botany 14:549564.

Clemants S.E., Diggs G.M., Dorr L.J., Judd W.S., Luteyn J.L., Sørensen P.D., Stevens P.F. y Wallace G.D. 1995. Ericaceae 
Part II. Flora Neotropica 66:1-560.

Cornejo-Tenorio G., Casas A., Farfán B., Villaseñor J.L. e IbarraManríquez G. 2003. Flora y vegetación de las zonas núcleo de la Reserva de la Biosfera Mariposa Monarca, México. Boletín de la Sociedad Botánica de México 73:43-62.

Correa G. 1974. Geografía del Estado de Michoacán. Tomo I. Geografía Física. Gobierno del Estado de Michoacán, Morelia.

Cronquist A. 1981. An Integrated System of Classification of Flowering Plants. Columbia University Press, Nueva York.

Daniel T.F. y Acosta-Castellanos S. 2003. Acanthaceae. Flora del Bajio y de Regiones Adyacentes 117:1-173.

Díaz-Barriga H. 1993. Symplocaceae. Flora del Bajío y de Regiones Adyacentes 19:1-6.

Diego-Pérez N. 2004. Apocynaceae. Flora de Guerrero 20:1-117.

Durán C.V. y Sevilla P.F. 2004. Atlas Geográfico del Estado de Michoacán. Universidad Michoacana de San Nicolás de Hidalgo, El Colegio de Michoacán, Secretaría de Educación en el Estado de Michoacán, Editora y Distribuidora EDDISA, S.A. de C.V., Morelia.

Espejo-Serna A., Brunhuber-Menéndez J.L., Segura-Warnholtz G. e Ibarra-Caballero J. 1992. La vegetación de la zona de hibernación de la mariposa monarca (Danaus plexippus L.) en la Sierra Chincua. Tulane Studies in Zoology and Botany. Supplementary Publication 1:79-99.

Espinosa-G. J. y Rodríguez-J. L.S. 1995. Listado Florístico del Estado de Michoacán. Sección II (Angiospermae: Compositae). Flora del Bajío y de Regiones Adyacentes. Fascículo Complementario VII. Instituto de Ecología, A.C., Pátzcuaro.

Espinosa-G. J. y Rodríguez-J. L.S. 1996. Listado Florístico del Estado de Michoacán. Sección IV (Angiospermae: Fagaceae, Gramineae, Krameriaceae y Leguminosae). Flora del Bajio y de Regiones Adyacentes. Fascículo Complementario XII. Instituto de Ecología, A.C., Pátzcuaro.

Farjon A., Pérez de la Rosa J. y Styles B.T. 1997. Guía de Campo de los Pinos de México y América Central. The Royal Botanic Gardens, Kew, Oxford Forestry Institute y Oxford University, Oxford.

Farjon A. y Styles B.T. 1997. Pinus (Pinaceae). Flora Neotropica 75:1-286.

Felger R.S., Johnson M.B. y Wilson M.F. 2001. The Trees of Sonora. Oxford University Press, Nueva York.

Fernández-N. R. 1993. La familia Rhamnaceae en México. Tesis de Doctorado, Escuela Nacional de Ciencias Biológicas, Instituto Politécnico Nacional, México, D.F., 345 pp.

Femández-N. R. 1996. Rhamnaceae. Flora del Bajío y de Regiones Adyacentes 43:1-69.

Ferrusquía-Villafranca I. 1998. Geología de México: una sinopsis. En: Ramamoorthy T.P., B ye R., Lot A. y Fa J. Comp. Diversidad Biológica de México: Orígenes y Distribución, pp. 3-108, Instituto de Biología, Universidad Nacional Autónoma de México, México, D.F.

Forman L.L. 1987. A new genus of Burseraceae from Mexico. Kew Bulletin 42:262.

Fritsch P.W. 1997. A revision of Styrax (Styracaceae) for western Texas, Mexico, and Mesoamerica. Annals of the Missouri Botanical Garden 84:714-749.

Fryxell P.A. 1988. Malvaceae of Mexico. Systematic Botany Monographs 25:1-520.

Fryxell P.A. 1993. Malvaceae. Flora del Bajío y de Regiones
Adyacentes 16:1-175.

Fryxell P.A. 2001a. Tiliaceae. Flora Novo-Galiciana 3:68-109. Fryxell P.A. 2001b. Sterculiaceae. Flora Novo-Galiciana 3:110147.

Fryxell P.A. 2001c. Bombacaceae. Flora Novo-Galiciana 3:148159.

Fryxell P.A. 2001d. Malvaceae. Flora Novo-Galiciana 3:160-305. García E. 1990. Atlas Nacional de México. Carta de Climas (1:4,000,000). Instituto de Geografía, Universidad Nacional Autónoma de México, México, D.F.

García-Mendoza A. 2000. Revisión taxonómica de las especies arborescentes de Furcraea (Agavaceae) en México y Guatemala. Boletín de la Sociedad Botánica de México 66:113-129.

García-R. I., Nava V.J., Flores R.R.E., Cházaro B.M., Machuca N.J.A. y del Río N.E. 2002. Flora del Parque Nacional Pico de Tancítaro, Michoacán. Gobierno del Estado de Michoacán de Ocampo, Morelia.

Genchi L. 2002. The vegetation of Sierra de Chincua, Monarch Butterfly Special Biosphere Reserve, Michoacán, México. Tesis de Maestría, Wageningen University, Wageningen, Holanda, 128 pp.

Gentry A.H. 1992a. Bignoniaceae Part I (Crescentieae and Tourrettieae). Flora Neotropica 25:1-130.

Gentry A.H. 1992b. Bignoniaceae Part II (Tribe Tecomeae). Flora Neotropica 25:1-370.

Giménez de Azcárate J., Ramírez M.I. y Pinto M. 2003. Las comunidades vegetales de la Sierra de Angangueo (estados de Michoacán y México, México): clasificación, composición y distribución. Lazaroa 24:87-111.

González R.R. 1993. La diversidad de los encinos mexicanos. Revista Sociedad Mexicana de Historia Natural 54:125-142.

González M.A. y Labat J.N. 1987. Los Encinos (Quercus) del Estado de Michoacán, México. Cuadernos de Estudios Michoacanos 1. Centre Français d'Études Mexicaines et Centraméricaines, Secretaría de Agricultura y Recursos Hidráulicos e Instituto Nacional de Investigaciones Forestales y Agropecuarias, México, D.F.

González-Espinosa M., Ramírez-Marcial N., Méndez-Dewar G., Galindo-Jaimes L. y Golicher D. 2005. Riqueza de especies de árboles en Chiapas: variación espacial y dimensiones ambientales asociadas al nivel regional. En: González-Espinosa M., Ramírez-Marcial N. y Ruiz-Montoya L. Coord. Diversidad Biológica en Chiapas, pp. 81-125, México, D.F.

González-Villarreal L.M. 1996. Clethraceae. Flora del Bajío y de Regiones Adyacentes 47:1-19.

Graham S.A. 1991. Lythraceae. Flora de Veracruz 66:1-94.

Grether R. 2000. Nomenclature changes in the genus Mimosa (Fabaceae, Mimosoideae) in Southern Mexico and Central America. Novon 10:29-37.

Guevara-Fefer F. y Rzedowski J. 1980. Notas sobre el género Bursera en Michoacán (México). I. Tres especies nuevas de los alrededores de Infiernillo, con algunos datos relativos a la región. Boletín de la Sociedad Botánica de México 39:63-81.

Guzmán U., Arias S. y Dávila P. 2003. Catálogo de Cactáceas Mexicanas. Universidad Nacional Autónoma de México y Comisión Nacional para el Conocimiento y Uso de la Biodiversidad, México, D.F.

Hernández H.M. 1989. Systematics of Zapoteca (Leguminosae). Annals of the Missouri Botanical Garden 76:781-862. 
Ibarra-Manríquez G., Villaseñor J.L. y Durán R. 1995. Riqueza de especies y endemismo del componente arbóreo de la Península de Yucatán, México. Boletín de la Sociedad Botánica de México 57:49-77.

Ibarra-Manríquez G., Villaseñor J.L., Durán R. y Meave J. 2002. Biogeographical analysis of the tree flora of the Yucatan Peninsula. Journal of Biogeography 29:17-29.

Ibarra-Manríquez G. y Wendt T.L. 1992. El género Ficus, subgénero Pharmacosycea (Moraceae) en Veracruz, México. Boletín de la Sociedad Botánica de México 52:3-29.

Jiménez-R. J. 1995. Dos especies nuevas de la sección Loureira Muell. Arg. del género Jatropha (Euphorbiaceae). Acta Botanica Mexicana 30:1-8.

Jiménez-R. J. y Martínez-Gordillo M. 1991. Especie nueva del género Jatropha (Euphorbiaceae) de Michoacán, México. Anales del Instituto de Biología de la Universidad Nacional Autónoma de México, Serie Botánica 61:1-4.

Kaastra R.C. 1982. Pilocarpinae (Rutaceae). Flora Neotropica 33:1-198.

Kiger RW. 2001. Flacourtiaceae. Flora Novo-Galiciana 3:306334.

Knapp S. 2002. Solanum (Solanaceae). Flora Neotropica 84:1404.

Labat J.N. 1995. Végetation du nord-ouest du Michoacán, Mexique. Flora del Bajío y de Regiones Adyacentes. Fascículo Complementario VIII. Instituto de Ecología, A.C., Pátzcuaro.

Lay K.K. 1950. The American species of Triumfetta. Annals of the Missouri Botanical Garden 37:315-395.

Leavenworth W.C. 1946. A preliminary study of the vegetation of the region between Cerro Tancítaro and the Río Tepalcatepec, Michoacán, México. American Midland Naturalist 36:137206.

Leeuwenberg A.J.M. 1994. A Revision of Tabernaemontana. The New World Species and Stemmadenia. Royal Botanic Gardens, Kew y Wageningen Agricultural University, Londres.

Lewis G.P. 1990. Five new taxa of Piptadenia (Leguminosae: Mimosoideae) from Brazil. Kew Bulletin. 46:159-168.

López-Ferrari A.R. 1993. Araliaceae. Flora del Bajío y de Regiones Adyacentes 20:1-17.

Lorea-Hernández F.G. 2004. Capparaceae. Flora del Bajío y de Regiones Adyacentes 130:1-31.

Lorence D.H. 1999. A Nomenclature of Mexican and Central American Rubiaceae. Missouri Botanical Garden, Saint Louis.

Lorence D.H. y Dwyer J.D. 1988. A revision of Deppea (Rubiaceae). Allertonia 4:389-436.

Luteyn J.L. 1995. Ericaceae Part II. The superior-ovaried genera (Monotropoideae, Pyroloideae, Rhododendroideae and Vaccinioideae p.p.). Flora Neotropica 66:1-560.

Madrigal-Sánchez X. 1994. Características Ecológicas Generales de la Región Forestal Oriental del Estado de Michoacán, México. Universidad Michoacana de San Nicolás de Hidalgo, Morelia, Michoacán.

Madrigal-Sánclez X. 1997. Ubicación fisiográfica de la vegetación en Michoacán, México. Ciencia Nicolaita 15:65-75.

Madrigal-Sánchez X. y Rzedowski J. 1988. Una especie nueva de Diospyros (Ebenaceae) del municipio de Morelia, estado de Michoacán (México). Acta Botanica Mexicana 1:3-6.

Martínez-Gordillo M., Jiménez J., Cruz R., Juárez E., García R., Cervantes A. y Mejía R. 2002. Los géneros de la familia Euphorbiaceae en México. Anales del Instituto de Biología de la Universidad Nacional Autónoma de México, Serie Botánica 73:155-281.

McVaugh R. 1974. Fagaceae. Contributions of University of Michigan Herbarium 12:1-93.

McVaugh R. 1983. Gramineae. Flora Novo-Galiciana 14:1-436.

McVaugh R. 1984. Compositae. Flora Novo-Galiciana 12:11157.

McVaugh R. 1987. Leguminosae. Flora Novo-Galiciana 5:1-786.

McVaugh R. 1992. Gymnospermae to Pteridophyte. Flora NovoGaliciana 17:1-467.

McVaugh R. 2001. Ochnaceae to Loasaceae. Flora NovoGaliciana 3:1-751.

McVaugh R. y Rzedowski J. 1965. Synopsis of the genus Burseraceae in western Mexico, with notes on the material of Bursera collected by Sessé \& Mociño. Kew Bulletin 18:317382.

Meave J., Soto-Arenas M.A., Calvo-Irabién L.M., Paz-Hernández H. y Valencia-A. S. 1992. Análisis sinecológico del bosque mesófilo de montaña de Omiltemi, Guerrero. Boletín de la Sociedad Botánica de México 52:31-77.

Medina-García C., Guevara-Féfer F., Martínez-Rodríguez M.A., Silva-Sáenz P., Chávez-Carbajal M.A. y García I. 2000. Estudio florístico en el área de la comunidad indígena de Nuevo San Juan Parangaricutiro, Michoacán, México. Acta Botanica Mexicana 52:5-41.

Medina-García C. y Rodríguez-J. L.S. 1993. Estudio florístico de la cuenca del río Chiquito de Morelia, Michoacán, México. Flora del Bajío y de Regiones Adyacentes. Fascículo Complementario IV. Instituto de Ecología, A.C., Pátzcuaro.

Mejía-Domínguez N.R., Meave J.A. y Ruiz-Jiménez C.A. 2004. Análisis estructural de un bosque mesófilo de montaña en el extremo oriental de la Sierra Madre del Sur (Oaxaca), México. Boletín de la Sociedad Botánica de México 74:13-29.

Miranda F. 1947. Estudios sobre la vegetación de México y rasgos de la vegetación en la cuenca del río Balsas. Revista de la Sociedad Mexicana de Historia Natural 8:95-114.

Miranda F. y Hernández-X. E. 1963. Los tipos de vegetación de México y su clasificación. Boletín de la Sociedad Botánica de México 28:29-178.

Murray N.A. 1993. Revision of Cymbopetalum and Porcelia (Annonaceae). Systematic Botany Monographs 40:1-121.

Nixon K.C. 1998. El género Quercus en México. En: Ramamoorthy T.P., Bye R., Lot A. y Fa J. Comp. Diversidad Biológica de México: Orígenes y Distribución, pp. 435-447, Universidad Nacional Autónoma de México, México, D.F.

Norman E. 2000. Buddlejaceae. Flora Neotropica 81:1-224.

Ocampo-Acosta E. 2003. Buddlejaceae. Flora del Bajío y de Regiones Adyacentes 115:1-31.

Padilla-Velarde E., Cuevas-Guzmán R., Ibarra-Manríquez G. y Moreno-Gómez S. En prensa. Riqueza y biogeografía de la flora arbórea del estado de Colima, México. Revista Mexicana de Biodiversidad.

Palacio-Prieto J.L., Bocco G., Velásquez A., Mas J.F., TakakiTakaki F., Victoria A., Luna-González L., Gómez-Rodríguez G., López-García J., Palma M., Trejo-Vázquez I., Peralta A., Prado-Molina J., Rodríguez-Aguilar A., Mayorga-Saucedo R. y González-Medrano F. 2000. La condición actual de los recursos forestales en México: resultados del Inventario Forestal Nacional 2000. Investigaciones Geográficas, Boletín del Instituto de Geografía UNAM 43:183-203. 
Pennington T.D. 1990. Sapotaceae. Flora Neotropica 52:1-770.

Pennington T.D. y Sarukhán J. 1998. Árboles Tropicales de México. Instituto Nacional de Investigaciones Forestales y Organización de las Naciones Unidas para la Alimentación, México, D.F.

Pennington T.D., Styles B.T. y Taylor D.A.H. 1981. Meliaceae. Flora Neotropica 28:1-470.

Pérez-Calix E. 1996. Flora y Vegetación de la Cuenca del Lago de Zirahuén, Michoacán, México. Flora del Bajio y de Regiones Adyacentes. Fascículo Complementario XIII. Instituto de Ecología, A.C., Pátzcuaro.

Pérez-Calix E. 1999. Phyllonomaceae. Flora del Bajío y de Regiones Adyacentes 74:1-5.

Pérez-Calix E. y Carranza-González E. 1999. Ulmaceae. Flora del Bajío y de Regiones Adyacentes 75:1-30.

Perry J.P. 1991. The Pines of Mexico and Central America. Timber Press, Portland.

Prance G.H. 1972. Chrysobalanaceae. Flora Neotropica 9:1-410.

Ramírez-Marcial N., González-Espinosa M. y Williams-Linera G. 2001. Anthropogenic disturbance and tree diversity in montane rain forest in Chiapas, Mexico. Forest Ecology and Management 154:311-326.

Randall E. 1995. Systematics of Cryosophila (Palmae). Systematic Botany Monographs 46:1-70.

Rodríguez-Jiménez C. 1996. Guttiferae. Flora del Bajío y de Regiones Adyacentes 45:1-27.

Rodríguez-J. L.S. y Espinosa G.J. 1995. Listado Florístico del Estado de Michoacán. Sección I (Gymnospermae; Angiospermae: Acanthaceae-Commelinaceae). Flora del Bajio y de Regiones Adyacentes. Fascículo Complementario VI. Instituto de Ecología, A.C., Pátzcuaro.

Rodríguez-J. L.S. y Espinosa G.J. 1996a. Listado Florístico del Estado de Michoacán. Sección III (Angiospermae: Connaraceae-Myrtaceae, excepto Fagaceae, Gramineae, Krameriaceae y Leguminosae). Flora del Bajío y de Regiones Adyacentes. Fascículo Complementario X. Instituto de Ecología, A.C., Pátzcuaro.

Rodríguez-J. L.S. y Espinosa G.J. 1996b. Listado Florístico del Estado de Michoacán. Sección V (Angiospermae: NajadaceaeZygophyllaceae). Flora del Bajio y de Regiones Adyacentes. Fascículo Complementario XV. Instituto de Ecología, A.C., Pátzcuaro.

Rohwer J.G. 1993. Nectandra: Lauraceae. Flora Neotropica 60:1332.

Rzedowski J. 1978. Vegetación de México. Editorial Limusa, México, D.F.

Rzedowski J. 1991. Diversidad y orígenes de la flora fanerogámica de México. Acta Botanica Mexicana 14:3-21.

Rzedowski J. 1996. Análisis preliminar de la flora vascular de los bosques mesófilos de montaña de México. Acta Botanica Mexicana 35:25-44.

Rzedowski J. y Calderón de R. G. 1993. Bignoniaceae. Flora del Bajio y de Regiones Adyacentes 22:1-44.

Rzedowski J. y Calderón de R. G. 1995a. Compositae, Vernonieae. Flora del Bajío y de Regiones Adyacentes 38:1-50.

Rzedowski J. y Calderón de R. G. 1995b. Tres adiciones a la flora fanerogámica de México. Acta Botanica Mexicana 32:1-10.

Rzedowski J. y Calderón de R. G. 1997. Leguminosae, Caesalpinioideae. Flora del Bajio y de Regiones Adyacentes 51:1-111.
Rzedowski J. y Calderón de R. G. 1998. Apocynaceae. Flora del Bajio y de Regiones Adyacentes 70:1-64.

Rzedowski J. y Calderón de R. G. 1999. Anacardiaceae. Flora del Bajío y de Regiones Adyacentes 78:1-52.

Rzedowski J. y Calderón de R. G. 2000. Tres especies nuevas de Bursera (Burseraceae) de la región costera del occidente de México. Acta Botanica Mexicana 50:47-59.

Rzedowski J. y Calderón de R. G. 2002. Verbenaceae. Flora del Bajio y de Regiones Adyacentes 100:1-145.

Rzedowski J. y Calderón de R. G. 2004. Oleaceae. Flora del Bajío $y$ de Regiones Adyacentes 124:1-37.

Rzedowski J. y Calderón de R. G. 2006. Dos especies de Bursera (Burseraceae) de México. Acta Botanica Mexicana 74:169178.

Rzedowski J. y Guevara-Fefer F. 1992. Burseraceae. Flora del Bajío y de Regiones Adyacentes 3:1-46.

Rzedowski J. y McVaugh R. 1966. La vegetación de Nueva Galicia. Contributions of the University of Michigan Herbarium 9:1-123.

Rzedowski J., Medina L.R. y Calderón de R. G. 2005. Inventario del conocimiento taxonómico, así como de la diversidad y del endemismo regionales de las especies mexicanas de Bursera (Burseraceae). Acta Botanica Mexicana 70:85-111.

Sánchez-Rodríguez E.V., López-Mata L., García-Moya E. y Cuevas-Guzmán R. 2003. Estructura, composición florística y diversidad de especies leñosas de un bosque mesófilo de montaña en la Sierra de Manantlán, Jalisco. Boletín de la Sociedad Botánica de México 73:17-34.

Sánchez-Sánchez O. e Islebe G. A. 2002. Tropical forest communities in southeastern Mexico. Plant Ecology 158:183-200.

Santiago A.L., Jardel E. y Cuevas-Guzmán R. 2002. Rareza y estado de conservación de especies arbóreas del bosque mesófilo de montaña en la Reserva de la Biosfera Sierra de Manantlán, México. Boletín del Instituto de Botánica de la Universidad de Guadalajara 10:5-22.

SEMARNAT [Secretaría del Medio Ambiente y Recursos Naturales]. 2002. Norma Oficial Mexicana NOM-059-ECOL2001, Protección ambiental - Especies nativas de México de flora y fauna silvestres - Categorías de riesgo y especificaciones para su inclusión, exclusión o cambio - Lista de especies en riesgo. Diario Oficial de la Federación. 2a Sección, 6 de marzo de 2002.

Sleumer H.O. 1980. Flacourtiaceae. Flora Neotropica 22:1-499.

Sleumer H.O. 1984. Olacaceae. Flora Neotropica 38:1-159.

Soejarto D.D. 1984. Actinidiaceae. Flora de Veracruz 35:1-25.

Sousa S.M. 2005. Heteroflorum: un nuevo género del grupo Peltophorum (Leguminosae: Caesalpinioideae: Caesalpinieae), endémico de México. Novon 15:213-218.

Sousa S.M. y Andrade M.G. 1992. Identidad de Microlobius y Goldmania (Leguminosae: Mimosoideae: Mimoseae) y nuevas combinaciones. Anales del Instituto de Biología, Universidad Nacional Autónoma de México, Serie Botánica 63:101-107.

Sousa-S. M. y Delgado A. 1998. Leguminosas mexicanas: fitogeografía, endemismo y orígenes. En: Ramamoorthy T.P., Bye R., Lot A. y Fa J. Comp. Diversidad Biológica de México: Orígenes y Distribución, pp. 449-500, Universidad Nacional Autónoma de México, México, D.F.

Sousa-S. M. y Soto J.C. 1987. Nuevos taxa de Lonchocarpus (Leguminosae) de las cuencas baja y media del río Balsas, México. Anales del Instituto de Biología, Universidad 
Nacional Autónoma de México, Serie Botánica 58:68-86.

Sousa-S. M., Ricker M. y Hernández H. 2001. Tree species of the family Leguminosae in Mexico. Harvard Papers in Botany 6:339-365

Sousa-S. M., Ricker M. y Hernández H. 2003. An index for the tree species of the family Leguminosae in Mexico. Harvard Papers in Botany 7:381-198.

Spellenberg R. 2001. Nyctaginaceae. Flora del Bajío y de Regiones Adyacentes 93:1-98.

Ståhl B. 1989. A synopsis of Central American Theophrastaceae. Nordic Journal of Botany 9:15-30.

Standley P.C. 1920-1926. Trees and shrubs of Mexico. Contributions of the United States National Herbarium 23:11721.

Steinmann V.W. 2002. Diversidad y endemismo de la familia Euphorbiaceae en México. Acta Botanica Mexicana 61:61-84.

Steinmann V.W. 2005a. Four new neotropical species and a new combination of Urera (Urticaceae). Acta Botanica Mexicana 71:19-43.

Steinmann V.W. 2005b. Urticaceae. Flora del Bajío y de Regiones Adyacentes 134:1-74.

Styles B.T. 1998. El género Pinus: su panorama en México. En: Ramamoorthy T.P., Bye R., Lot A. y Fa J. Comp. Diversidad Biológica de México: Orígenes y Distribución, pp. 385-408, Universidad Nacional Autónoma de México, México, D.F.

Thomas W.W. 1988. A conspectus of Mexican and Central American Picramnia (Simaroubaceae). Brittonia 40:89-105.

Turner B.L. y Nesom G.L. 1998. Biogeografía, diversidad y situación de peligro o amenaza de Asteraceae de México. En: Ramamoorthy T.P., Bye R., Lot A. y Fa J. Comp. Diversidad Biológica de México: Orígenes y Distribución, pp. 545-561, Universidad Nacional Autónoma de México, México, D.F.

Valencia-A. S. 2004. Diversidad del género Quercus (Fagaceae) en México. Boletín de la Sociedad Botánica de México 75:33-53.

van der Werff H. y Lorea F. 1997. Lauraceae. Flora del Bajío y de Regiones Adyacentes 56:1-58.

Villarreal-Q. J.Á. 2000a. Sambucaceae. Flora del Bajío y de Regiones Adyacentes 85:1-5.

Villarreal-Q. J.Á. 2000b. Viburnaceae. Flora del Bajío y de Regiones Adyacentes 86:1-9.

Villarreal-Q. J.Á. 2000c. Caprifoliaceae. Flora del Bajío y de Regiones Adyacentes 88:1-17.

Villaseñor J.L. 1987. Clave genérica para las compuestas de la cuenca del río Balsas. Boletín de la Sociedad Botánica de México 47:65-86.

Villaseñor J.L. 1993. La familia Asteraceae en México. Revista de la Sociedad Mexicana de Historial Natural 44:117-124.
Villaseñor J.L. 2001. Catálogo de Autores de Plantas Vasculares de México. Universidad Nacional Autónoma de México y Comisión Nacional para el Conocimiento y Uso de la Biodiversidad, México, D.F.

Villaseñor J.L. 2003. Diversidad y distribución de las Magnoliophyta de México. Interciencia 28:160-167.

Villaseñor J.L. y Espinosa-García F. 2004. The allien flowering plants of Mexico. Diversity and Distributions 10:113-123.

Villaseñor J.L. e Ibarra-Manríquez G. 1998. La riqueza arbórea de México. Boletín del Insituto de Biologia de la Universidad de Guadalajara 5:95-105.

Villaseñor J.L., Meave J.A, Ortiz-Bermúdez E. e IbarraManríquez G. 2003. Bioge ografía y conservación de los bosques tropicales húmedos de México. En: Morrone J.J. y Llorente-Bousquets J. Eds. Una Perspectiva Latinoamericana de la Biogeografía, pp. 209-216, Las Prensas de Ciencias, Universidad Nacional Autónoma de México, México, D.F.

Walter K.S. y Gillett H.J. Eds. 1998. Red List of Threatened Plants. Compiled by the World Conservation Monitoring Centre, IUCN, The World Conservation Union, Gland, Suiza y Cambridge, Reino Unido.

Webster G.L. 2001. Synopsis of Croton and Phyllanthus (Euphorbiaceae) in western tropical Mexico. Contribution of the University Michigan Herbarium 23:353-388.

Wendt T. 1993. Composition, floristic affinities, and origins of the canopy tree flora of the Mexican Atlantic slope rain forest. En: Ramamoorthy T.P., Bye R., Lot A. y Fa J. Eds. Biological Diversity of Mexico: Origins and Distribution, pp. 595-680, Oxford University Press, Nueva York.

Whittaker R.H. 1975. Communities and Ecosystems. 2a ed., Macmillan Publishing Co., Nueva York.

Williams J.K. 1996. A new combination in Thevetia (Apocynaceae). Sida 7:185-190.

Zamudio S. 1992. Taxaceae. Flora del Bajío y de Regiones Adyacentes 9:1-7.

Zamudio S. 2002. Podocarpaceae. Flora del Bajío y de Regiones Adyacentes 105:1-7.

Zamudio S. y Carranza-González E. 1994. Cupressaceae. Flora del Bajio y de Regiones Adyacentes 29:1-21.

Zárate S. 1994. Revisión del género Leucaena en México. Anales del Instituto de Biología, Universidad Nacional Autónoma de México, Serie Botánica 65:83-162.

Zona S. 1990. A monograph of Sabal (Arecaceae: Coryphoideae). Aliso 12:583-666.

Fecha de recepción: 15 de octubre de 2004

Versión corregida: 18 de abril de 2006

Aceptado: 19 de abril de 2006 
Apéndice 1. Lista de especies de los árboles nativos de Michoacán. Los números de géneros y especies que contiene cada familia se indican entre paréntesis después de su nombre, separadas estas cifras por una diagonal. Abreviaturas de los tipos de vegetación: $\mathrm{BC}=$ bosque de coníferas, $\mathrm{BE}=$ bosque espinoso, $\mathrm{BM}=$ bosque mesófilo de montaña, $\mathrm{BQ}=$ bosque de Quercus, $\mathrm{MX}=$ matorral xerófilo, $\mathrm{OV}=$ otros tipos de vegetación, $\mathrm{PA}=$ pastizal, $\mathrm{TC}=$ bosque tropical caducifolio, $\mathrm{TP}=$ bosque tropical perennifolio, TS = bosque tropical subcaducifolio, VA = vegetación acuática y subacuática, VS = vegetación secundaria. Las categorías en riesgo se indican con abreviaturas (como un superíndice, en negritas y entre paréntesis), después del nombre de la autoridad de cada especie, considerando las propuestas de la SEMARNAT (2002) (A = amenazada, P = en peligro de extinción, Pr = sujeta a protección especial) o la de la IUCN (Walter y Gillett, 1998) ( $E=$ en peligro de extinción, $V=$ vulnerable, $R=$ rara, $\mathrm{I}=$ indeterminada).

Taxa Tipos de vegetación

\section{DIVISIÓN PILICOPHYTA}

\section{CYATHEACEAE (1/1)}

Cyathea costaricensis (Mett. ex Kuhn) Domin ${ }^{(P)}$

\section{DIVISIÓN CONIFEROPHYTA}

\author{
CUPRESSACEAE (2/5) \\ Cupressus lusitanica Mill. ${ }^{(\mathrm{Pr})}$ \\ Juniperus blancoi Martínez (1) \\ J. deppeana Steud. \\ J. flaccida Schltdl. \\ J. monticola Martínez ${ }^{(\mathrm{Pr})}$
}

PINACEAE (2/17)

Abies guatemalensis Rehder ${ }^{(P, V)}$

A. religiosa (Kunth) Schltdl. et Cham.

Pinus ayacahuite C.Ehrenb. ex Schltdl.

P. devoniana Lindl.

P. douglasiana Martínez

P. durangensis Martínez ${ }^{(\mathrm{R})}$

P. hartwegii Lindl.

$P$. herrerae Martínez ${ }^{(\mathbf{R})}$

P. lawsonii Roezl ex Gordon ${ }^{(\mathrm{R})}$

P. leiophylla Schiede ex Schltdl. et Cham.

$P$. maximinoi H.E.Moore

P. montezumae Lamb.

P. oocarpa Schiede ex Schltdl.

$P$. pringlei Shaw

$P$. pseudostrobus Lindl.

P. rzedowskii Madrigal et M.Caball. (E, ${ }^{(\mathbf{P r})}$

$P$. teocote Schltdl. et Cham.

PODOCARPACEAE (1/1)

Podocarpus reichei J.Buchholz et N.E.Gray

TAXODIACEAE (1/1)

Taxodium mucronatum Ten. ${ }^{(\mathbf{R})}$

\section{DIVISIÓN MAGNOLIOPHYTA}

\section{CLASE MAGNOLIOPSIDA}

ACANTHACEAE (2/3)

Bravaisia integerrima (Spreng.) Standl. ${ }^{\text {(A) }}$

Odontonema callistachyum (Schltdl. et Cham.) Kuntze

O. cuspidatum (Nees) Kuntze

ACERACEAE (1/1)

Acer negundo $\mathrm{L}$.

\author{
$B C, B M, B Q, P A, V A$ \\ $\mathrm{BC}$ \\ $\mathrm{BC}, \mathrm{BM}, \mathrm{BQ}, \mathrm{MX}, \mathrm{PA}, \mathrm{TC}$ \\ $B C, B M, B Q, M X, O V, T C, V A$ \\ $\mathrm{BC}, \mathrm{BQ}, \mathrm{MX}, \mathrm{PA}$ \\ $B C, B M, B Q$ \\ $B C, B M, P A$ \\ $B C, B M$ \\ $B C, B M, B Q$ \\ $B C, B Q$ \\ $\mathrm{BC}$ \\ $B C, B Q, P A$ \\ $\mathrm{BM}, \mathrm{BQ}$ \\ $B C, B Q$ \\ $B C, B M, B Q, M X$ \\ $B C, B M, B Q, T C$ \\ $B C, B M, B Q, P A$ \\ $\mathrm{BC}, \mathrm{BE}, \mathrm{BM}, \mathrm{BQ}, \mathrm{TC}$ \\ $B C, B M, B Q$ \\ $B C, B M, B Q, M X$ \\ $\mathrm{BC}$ \\ $B C, B M, B Q, M X, P A$ \\ $B C, B M, B Q, V A$ \\ $\mathrm{BC}, \mathrm{BE}, \mathrm{MX}, \mathrm{TC}, \mathrm{VA}$
}

TC, TP, TS, VA

$\mathrm{BQ}, \mathrm{TS}$

$B M, B Q, T S$

BC, BM, VA 


\begin{tabular}{|c|c|}
\hline Taxa & Tipos de vegetación \\
\hline \multicolumn{2}{|l|}{ ACATOCHARPACEAE (1/1) } \\
\hline Achatocarpus gracilis H.Walter & TC, TS, VA \\
\hline \multicolumn{2}{|l|}{ ACTINIDIACEAE (1/2) } \\
\hline Saurauia leucocarpa Schltdl. & $B Q, T S, V A, V S$ \\
\hline S. serrata DC. ${ }^{\left(\mathrm{Pr}_{\mathrm{r}, \mathrm{R}}\right.}$ & $\mathrm{BC}, \mathrm{BM}, \mathrm{TC}, \mathrm{TP}, \mathrm{TS}$ \\
\hline \multicolumn{2}{|l|}{ ANACARDIACEAE $(7 / 8)$} \\
\hline Astronium graveolens Jacq. ${ }^{\text {(A) }}$ & $\mathrm{MX}, \mathrm{TC}, \mathrm{TP}, \mathrm{TS}$ \\
\hline Comocladia engleriana Loes. & $\mathrm{MX}, \mathrm{TC}, \mathrm{TS}$ \\
\hline C. mollissima Kunth & $\mathrm{TC}$ \\
\hline Cyrtocarpa procera Kunth & $\mathrm{BC}, \mathrm{MX}, \mathrm{TC}, \mathrm{TS}$ \\
\hline Pistacia mexicana Kunth & $\mathrm{BC}, \mathrm{MX}, \mathrm{TC}, \mathrm{VA}$ \\
\hline Pseudosmodingium perniciosum (Kunth) Engl. & $\mathrm{BC}, \mathrm{TC}, \mathrm{TS}$ \\
\hline Spondias purpurea L. & $\mathrm{BC}, \mathrm{BE}, \mathrm{TC}, \mathrm{TP}, \mathrm{TS}, \mathrm{VS}$ \\
\hline Toxicodendron radicans (L.) Kuntze & $\mathrm{BC}, \mathrm{BE}, \mathrm{BM}, \mathrm{VA}$ \\
\hline \multicolumn{2}{|l|}{ ANNONACEAE $(4 / 7)$} \\
\hline Annona diversifolia Saff. & $\mathrm{TC}$ \\
\hline A. purpurea Moc. et Sessé ex Dunal & TC, TP, TS, VA \\
\hline A. reticulata $\mathrm{L}$. & $\mathrm{BC}, \mathrm{BM}, \mathrm{TC}, \mathrm{TP}, \mathrm{TS}$ \\
\hline A. squamosa L. & $\mathrm{BC}, \mathrm{TC}, \mathrm{TS}, \mathrm{VA}$ \\
\hline Cymbopetalum hintonii Lundell & $\mathrm{TC}$ \\
\hline Desmopsis mexicana R.E.Fr. & TS \\
\hline Oxandra lanceolata (Sw.) Baill. & TS \\
\hline \multicolumn{2}{|l|}{ APOCYNACEAE $(7 / 14)$} \\
\hline Alstonia longifolia (A.DC.) Pichon & TC \\
\hline A. pittieri (Donn.Sm.) A.H.Gentry & $\mathrm{BM}, \mathrm{MX}, \mathrm{TC}, \mathrm{TP}$ \\
\hline Plumeria rubra L. & $\mathrm{BE}, \mathrm{BQ}, \mathrm{MX}, \mathrm{OV}, \mathrm{TC}, \mathrm{TP}, \mathrm{TS}$ \\
\hline Rauvolfia tetraphylla L. & $\mathrm{BC}, \mathrm{BE}, \mathrm{MX}, \mathrm{OV}, \mathrm{TC}, \mathrm{TS}, \mathrm{VA}$ \\
\hline Stemmadenia donnell-smithii (Rose) Woodson & $\mathrm{BC}, \mathrm{BQ}, \mathrm{TC}, \mathrm{TP}, \mathrm{TS}, \mathrm{VA}$ \\
\hline S. obovata K.Schum. & $\mathrm{BC}, \mathrm{TC}, \mathrm{TP}, \mathrm{TS}, \mathrm{VA}$ \\
\hline S. tomentosa Greenm. & $\mathrm{BE}, \mathrm{TC}, \mathrm{TS}, \mathrm{VA}$ \\
\hline Tabernaemontana alba Mill. & $\mathrm{BM}, \mathrm{TC}, \mathrm{TP}, \mathrm{TS}$ \\
\hline T. amygdalifolia Jacq. & $\mathrm{BE}, \mathrm{BQ}, \mathrm{TC}, \mathrm{VA}$ \\
\hline Thevetia ovata (Cav.) A.DC. & $\mathrm{BC}, \mathrm{BE}, \mathrm{BQ}, \mathrm{MX}, \mathrm{TC}, \mathrm{TP}, \mathrm{TS}, \mathrm{VA}$ \\
\hline T. peruviana (Pers.) K.Schum. & $\mathrm{BE}, \mathrm{BM}, \mathrm{MX}, \mathrm{TC}, \mathrm{TP}, \mathrm{TS}, \mathrm{VA}$ \\
\hline T. pinifolia (Standl. et Steyerm.) J.K.Williams & $\mathrm{TC}, \mathrm{VA}, \mathrm{VS}$ \\
\hline T. thevetioides (Kunth) K.Schum. & $\mathrm{BC}, \mathrm{BE}, \mathrm{MX}, \mathrm{TC}, \mathrm{VA}$ \\
\hline Vallesia glabra (Cav.) Link & $\mathrm{BE}, \mathrm{MX}, \mathrm{TC}, \mathrm{TS}, \mathrm{VA}$ \\
\hline \multicolumn{2}{|l|}{ AQUIFOLIACEAE (1/3) } \\
\hline Ilex brandegeana Loes. & $\mathrm{BC}, \mathrm{BM}, \mathrm{BQ}$ \\
\hline I. mexicana (Turcz.) Black ex Hemsl. & $\mathrm{BC}, \mathrm{BM}, \mathrm{BQ}$ \\
\hline I. tolucana Hemsl. & $\mathrm{BC}, \mathrm{BM}, \mathrm{BQ}, \mathrm{VA}$ \\
\hline \multicolumn{2}{|l|}{ ARALIACEAE (3/5) } \\
\hline Aralia humilis Cav. & $\mathrm{BC}, \mathrm{BM}, \mathrm{BQ}, \mathrm{MX}, \mathrm{TC}$ \\
\hline Dendropanax arboreus (L.) Decne. et Planch. & $\mathrm{BC}, \mathrm{BM}, \mathrm{BQ}, \mathrm{TC}, \mathrm{TP}, \mathrm{TS}, \mathrm{VA}$ \\
\hline Oreopanax echinops (Cham. et Schltdl.) Decne. et Planch. & $\mathrm{BC}, \mathrm{BM}$ \\
\hline O. peltatus Linden & $\mathrm{BC}, \mathrm{BM}, \mathrm{BQ}, \mathrm{TC}, \mathrm{TP}, \mathrm{VA}$ \\
\hline O. xalapensis (Kunth) Decne. et Planch. & $\mathrm{BC}, \mathrm{BM}, \mathrm{BQ}, \mathrm{TP}, \mathrm{TS}$ \\
\hline \multicolumn{2}{|l|}{ ASTERACEAE $(27 / 82)$} \\
\hline Ageratina areolaris (DC.) Gage ex B.L.Turner & $\mathrm{BC}, \mathrm{BM}, \mathrm{VS}$ \\
\hline A. chiapensis (B.L.Rob.) R.M.King et H.Rob. & $\mathrm{BC}, \mathrm{BM}$ \\
\hline A. crassiramea (B.L.Rob.) R.M.King et H.Rob. & $\mathrm{TC}$ \\
\hline A. cremasta (B.L.Rob.) R.M.King et H.Rob. & $\mathrm{BC}$ \\
\hline A. cylindrica (McVaugh) R.M.King et H.Rob. & $\mathrm{BC}, \mathrm{TC}$ \\
\hline A. ligustrina (DC.) R.M.King et H.Rob. & $\mathrm{BC}, \mathrm{BM}, \mathrm{BQ}, \mathrm{MX}, \mathrm{TC}$ \\
\hline A. mairetiana (DC.) R.M.King et H.Rob. & $\mathrm{BC}, \mathrm{BM}, \mathrm{MX}, \mathrm{TC}, \mathrm{VA}$ \\
\hline
\end{tabular}




\begin{tabular}{|c|c|}
\hline Taxa & Tipos de vegetación \\
\hline Archibaccharis auriculata (Hemsl.) G.L.Nesom & $\mathrm{BC}, \mathrm{TC}$ \\
\hline Baccharis heterophylla Kunth & BC, VS \\
\hline B. salicifolia (Ruiz et Pav.) Pers. & $\mathrm{BC}, \mathrm{BE}, \mathrm{BQ}, \mathrm{MX}, \mathrm{PA}, \mathrm{TC}, \mathrm{TP}, \mathrm{VA}$ \\
\hline B. thesioides Kunth & $\mathrm{BC}, \mathrm{VS}$ \\
\hline Barkleyanthus salicifolius (Kunth) H.Rob. et Brettell & $\mathrm{BC}, \mathrm{MX}$ \\
\hline Bartlettina cronquistii R.M.King et H.Rob. & $\mathrm{BM}, \mathrm{TS}$ \\
\hline Calea urticifolia (Mill.) DC. & $\mathrm{BC}, \mathrm{BM}, \mathrm{BQ}, \mathrm{MX}, \mathrm{TC}, \mathrm{TP}, \mathrm{TS}, \mathrm{VA}$ \\
\hline Chromolaena collina (DC.) R.M.King et H.Rob. & $\mathrm{BC}, \mathrm{BQ}, \mathrm{OV}, \mathrm{VS}$ \\
\hline Critonia hebebotrya DC. & $\mathrm{BM}, \mathrm{BQ}, \mathrm{TS}$ \\
\hline Jungia pringlei Greenm. & $\mathrm{BC}, \mathrm{BQ}$ \\
\hline Koanophyllon albicaulis (Sch.Bip. ex Klatt) R.M.King et H.Rob. & $\mathrm{BE}, \mathrm{BM}, \mathrm{MX}, \mathrm{TC}, \mathrm{TP}, \mathrm{TS}$ \\
\hline Kyrsteniopsis nelsonii (B.L.Rob.) R.M.King et H.Rob. & TC \\
\hline Lagascea decipiens Hemsl. & $\mathrm{TC}$ \\
\hline Lasianthaea ceanothifolia (Willd.) K.M.Becker & $\mathrm{BC}, \mathrm{BQ}, \mathrm{TC}, \mathrm{TP}$ \\
\hline L. fruticosa (L.) K.M.Becker & $\mathrm{BM}, \mathrm{BQ}, \mathrm{TC}, \mathrm{TP}, \mathrm{TS}$ \\
\hline L. helianthoides DC. & $\mathrm{BC}, \mathrm{BQ}, \mathrm{OV}, \mathrm{TC}$ \\
\hline L. macrocephala (Hook. et Arn.) K.M.Becker & $\mathrm{BC}, \mathrm{BQ}, \mathrm{TC}$ \\
\hline Montanoa andersonii McVaugh & $\mathrm{BC}, \mathrm{BM}, \mathrm{BQ}$ \\
\hline M. bipinnatifida (Kunth) K.Koch & $\mathrm{BC}, \mathrm{BQ}, \mathrm{TC}$ \\
\hline M. frutescens (Mairet ex DC.) Hemsl. & $\mathrm{BC}, \mathrm{BM}, \mathrm{MX}, \mathrm{PA}$ \\
\hline M. grandiflora Alaman ex DC. & $\mathrm{BC}, \mathrm{BM}, \mathrm{TC}$ \\
\hline M. hibiscifolia Benth. & $\mathrm{TP}$ \\
\hline M. karwinskii DC. & $\mathrm{BQ}, \mathrm{TC}$ \\
\hline M. leucantha (Lag.) S.F.Blake & $\mathrm{BC}, \mathrm{BQ}, \mathrm{MX}, \mathrm{PA}, \mathrm{TC}$ \\
\hline M. tomentosa Cerv. & $\mathrm{BM}, \mathrm{MX}, \mathrm{TC}$ \\
\hline Perymenium hintonii McVaugh & $\mathrm{BC}, \mathrm{TC}$ \\
\hline Pittocaulon bombycophole (Bullock) H.Rob. et Brettell & $\mathrm{MX}, \mathrm{TC}$ \\
\hline P. praecox (Cav.) H.Rob. et Brettell & $\mathrm{BC}, \mathrm{BQ}, \mathrm{MX}, \mathrm{TC}$ \\
\hline P. velatum (Greenm.) H.Rob. et Brettell & $\mathrm{BQ}, \mathrm{MX}, \mathrm{TC}$ \\
\hline Pluchea carolinensis (Jacq.) G.Don & $\mathrm{TC}$ \\
\hline Podachaenium eminens (Lag.) Sch.Bip. & $\mathrm{BC}, \mathrm{BM}, \mathrm{MX}, \mathrm{TP}, \mathrm{TS}$ \\
\hline Porophyllum viridiflorum (Kunth) DC. & TC \\
\hline Roldana albonervia (Greenm.) H.Rob. et Brettell & $\mathrm{BC}$ \\
\hline R. angulifolia (DC.) H.Rob. et Brettell & $\mathrm{BC}$ \\
\hline R. aschenborniana (Schauer) H.Rob. et Brettell & $\mathrm{BC}, \mathrm{BM}, \mathrm{BQ}, \mathrm{MX}, \mathrm{VA}$ \\
\hline R. barba-johannis (DC.) H.Rob. et Brettell & $\mathrm{BC}$ \\
\hline R. chapalensis (S.Watson) H.Rob. et Brettell & $\mathrm{BC}, \mathrm{BM}$ \\
\hline R. lobata La Llave & $\mathrm{BC}, \mathrm{TS}$ \\
\hline Rumfordia floribunda DC. & $B C, V S$ \\
\hline Sinclairia glabra (Hemsl.) Rydb. & $\mathrm{BQ}, \mathrm{TC}$ \\
\hline S. liebmannii (Klatt) Sch.Bip. ex Rydb. & $\mathrm{BC}, \mathrm{TC}$ \\
\hline Stevia nelsonii B.L.Rob. & $\mathrm{BC}$ \\
\hline Telanthophora andrieuxii (DC.) H.Rob. et Brettell & $\mathrm{BC}, \mathrm{BM}, \mathrm{BQ}$ \\
\hline T. standleyi (Greenm.) H.Rob. et Brettell & $\mathrm{BM}$ \\
\hline Verbesina breedlovei B.L.Turner & ND \\
\hline V. crocata (Cav.) Less. & $\mathrm{TC}$ \\
\hline V. furfuracea McVaugh & $\mathrm{TC}$ \\
\hline V. greenmanii Urb. & $\mathrm{BC}$ \\
\hline V. heterocarpa S.F.Blake & $\mathrm{BC}$ \\
\hline V. klattii B.L.Rob. et Greenm. & $\mathrm{BC}$ \\
\hline V. langlassei B.L.Rob. & $\mathrm{BC}, \mathrm{BQ}$ \\
\hline V. montanoifolia B.L.Rob. et Greenm. & $\mathrm{BC}, \mathrm{BM}, \mathrm{BQ}$ \\
\hline V. myriocephala Sch.Bip. ex Klatt & $M X, T C, T P, V A, V S$ \\
\hline V. oligantha B.L.Rob. & $\mathrm{TC}, \mathrm{TS}$ \\
\hline V. oncophora B.L.Rob. et Seaton & $B C, V S$ \\
\hline
\end{tabular}




\begin{tabular}{|c|c|}
\hline Taxa & Tipos de vegetación \\
\hline V. perymenioides Sch.Bip. ex Klatt & $B C, B Q, M X, T C$ \\
\hline V. platyptera Sch.Bip. ex Klatt & $\mathrm{TC}, \mathrm{TS}$ \\
\hline V. serrata Cav. & $B Q, V S$ \\
\hline V. spharocephala A.Gray & $\mathrm{BC}, \mathrm{BQ}, \mathrm{TC}$ \\
\hline V. turbacensis Kunth & $\mathrm{BC}, \mathrm{BM}, \mathrm{BQ}, \mathrm{TC}, \mathrm{TP}, \mathrm{TS}$ \\
\hline Vernonia baadii (McVaugh) S.B.Jones & $\mathrm{BC}, \mathrm{BQ}, \mathrm{VA}$ \\
\hline V. bealliae McVaugh & $\mathrm{BQ}, \mathrm{TC}$ \\
\hline V. canescens Kunth & $\mathrm{BM}, \mathrm{BQ}, \mathrm{TC}$ \\
\hline V. cordata Kunth & $\mathrm{BC}, \mathrm{BQ}, \mathrm{TC}, \mathrm{VA}$ \\
\hline V. liatroides DC. & $\mathrm{BC}, \mathrm{BM}, \mathrm{BQ}, \mathrm{MX}, \mathrm{TC}$ \\
\hline V. paniculata DC. & $\mathrm{BC}, \mathrm{BM}, \mathrm{BQ}, \mathrm{MX}, \mathrm{TC}$ \\
\hline V. patens Kunth & $\mathrm{BC}, \mathrm{BM}, \mathrm{BQ}, \mathrm{TP}, \mathrm{TS}, \mathrm{VA}$ \\
\hline V. triflosculosa Kunth & $\mathrm{BE}, \mathrm{BM}, \mathrm{BQ}, \mathrm{MX}, \mathrm{TC}, \mathrm{TP}, \mathrm{TS}$ \\
\hline V. villaregalis Carvajal & $\mathrm{MX}, \mathrm{TC}$ \\
\hline V. solorzanoana Rzed. et Calderón & $\mathrm{BM}$ \\
\hline Viguiera buddleiiformis (DC.) Hemsl. & $\mathrm{BQ}, \mathrm{MX}, \mathrm{TC}$ \\
\hline V. puruana Paray & $\mathrm{TC}$ \\
\hline V. quinqueradiata (Cav.) A.Gray & $\mathrm{TC}$ \\
\hline V. sphareocephala (DC.) Hemsl. & $\mathrm{TC}$ \\
\hline V. splendens Panero et E.E.Schill. ${ }^{(1)}$ & ND \\
\hline \multicolumn{2}{|l|}{ BETULACEAE (3/4) } \\
\hline Alnus acuminata Kunth & $\mathrm{BC}, \mathrm{BM}, \mathrm{BQ}$ \\
\hline A. jorullensis Kunth & $\mathrm{BC}, \mathrm{BQ}$ \\
\hline Carpinus caroliniana Walter ${ }^{(\mathrm{A})}$ & $\mathrm{BM}, \mathrm{BQ}$ \\
\hline Ostrya virginiana (Mill.) K.Koch ${ }^{(\mathrm{Pr})}$ & $\mathrm{BM}, \mathrm{BQ}$ \\
\hline \multicolumn{2}{|l|}{ BIGNONIACEAE $(6 / 9)$} \\
\hline Asthianthus viminalis (Kunth) Baill. & VA \\
\hline Crescentia alata Kunth & OV \\
\hline Godmania aesculifolia (Kunth) Standl. & $\mathrm{BE}, \mathrm{TC}$ \\
\hline Parmentiera aculeata (Kunth) Seem. & BM, TP, TS \\
\hline Tabebuia chrysantha (Jacq.) G.Nicholson & $\mathrm{BE}, \mathrm{TC}$ \\
\hline T. donnell-smithii Rose & $\mathrm{TC}$ \\
\hline T. impetiginosa (Mart. ex DC.) Standl. & $\mathrm{BE}, \mathrm{MX}, \mathrm{TC}, \mathrm{TS}$ \\
\hline T. rosea (Bertol.) A.DC. & $\mathrm{BE}, \mathrm{BM}, \mathrm{TC}, \mathrm{TP}, \mathrm{TS}, \mathrm{VA}$ \\
\hline Tecoma stans (L.) Juss. ex Kunth & $\mathrm{BC}, \mathrm{BM}, \mathrm{MX}, \mathrm{PA}, \mathrm{TC}, \mathrm{TP}, \mathrm{TS}$ \\
\hline \multicolumn{2}{|l|}{ BIXACEAE (2/2) } \\
\hline Bixa orellana L. & $\mathrm{BC}, \mathrm{TC}, \mathrm{TP}, \mathrm{TS}$ \\
\hline Cochlospermum vitifolium (Willd.) Spreng. & $\mathrm{BE}, \mathrm{BM}, \mathrm{BQ}, \mathrm{TC}, \mathrm{TP}, \mathrm{TS}, \mathrm{VA}$ \\
\hline \multicolumn{2}{|l|}{ BOMBACACEAE $(3 / 5)$} \\
\hline Bernoullia flammea Oliv. & $\mathrm{TC}, \mathrm{TP}, \mathrm{VA}$ \\
\hline Ceiba acuminata (S.Watson) Rose & $\mathrm{BE}, \mathrm{MX}, \mathrm{TC}, \mathrm{TS}$ \\
\hline C. aesculifolia (Kunth) Britton et Baker $\mathrm{f}$. & $\mathrm{BC}, \mathrm{BQ}, \mathrm{MX}, \mathrm{TC}, \mathrm{TP}, \mathrm{TS}$ \\
\hline C. pentandra (L.) Gaertn. & $\mathrm{BE}, \mathrm{TC}, \mathrm{TS}, \mathrm{VA}$ \\
\hline Pseudobombax ellipticum (Kunth) Dugand & $\mathrm{BC}, \mathrm{BQ}, \mathrm{TC}, \mathrm{TP}, \mathrm{TS}$ \\
\hline \multicolumn{2}{|l|}{ BORAGINACEAE $(5 / 23)$} \\
\hline Bourreria andrieuxii (DC.) Hemsl. & ND \\
\hline B. huanita (Lex.) Hemsl. & ND \\
\hline B. longiflora I.M.Johnst. & ND \\
\hline B. purpusii Brandegee & TC \\
\hline B. spathulata (Miers) Hemsl. & ND \\
\hline B. superba I.M.Johnst. ${ }^{(\mathrm{R})}$ & $\mathrm{BQ}, \mathrm{TC}, \mathrm{TS}$ \\
\hline Cordia alliodora (Ruiz et Pav.) Oken & $\mathrm{BE}, \mathrm{TC}, \mathrm{TP}, \mathrm{TS}, \mathrm{VA}$ \\
\hline C. dentata Poir. & $\mathrm{TC}, \mathrm{TP}, \mathrm{TS}, \mathrm{VA}$ \\
\hline C. elaeagnoides DC. & $\mathrm{BE}, \mathrm{PA}, \mathrm{TC}, \mathrm{TS}, \mathrm{VA}$ \\
\hline C. globosa (Jacq.) Kunth & $\mathrm{NA}$ \\
\hline
\end{tabular}




\begin{tabular}{|c|c|}
\hline Taxa & Tipos de vegetación \\
\hline C. globulifera I.M.Johnst. ${ }^{(\mathrm{R})}$ & $\mathrm{TC}$ \\
\hline C. macvaughii James S.Miller ${ }^{(\mathrm{R})}$ & ND \\
\hline C. morelosana Standl. & $\mathrm{TC}$ \\
\hline C. oaxacana DC. & $M X, P A, T C$ \\
\hline C. pringlei B.L.Rob. & $\mathrm{MX}$ \\
\hline C. salvadorensis Standl. & $\mathrm{TC}$ \\
\hline C. seleriana Fernald & $\mathrm{TC}$ \\
\hline C. sonorae Rose & $\mathrm{BE}, \mathrm{OV}, \mathrm{TC}$ \\
\hline C. spinescens L. & ND \\
\hline Ehretia latifolia DC. & $\mathrm{BM}, \mathrm{BQ}, \mathrm{MX}, \mathrm{TC}, \mathrm{TP}$ \\
\hline Lepidocordia williamsii (I.M.Johnst.) James M.Mill. ${ }^{(\mathrm{R})}$ & $\mathrm{TC}$ \\
\hline Tournefortia glabra L. & $\mathrm{BC}, \mathrm{BM}, \mathrm{BQ}, \mathrm{TC}, \mathrm{TP}, \mathrm{TS}, \mathrm{VA}$ \\
\hline T. petiolaris DC. & $\mathrm{BM}$ \\
\hline \multicolumn{2}{|l|}{ BUDDLEJACEAE $(1 / 5)$} \\
\hline Buddleja americana L. & $\mathrm{BC}, \mathrm{BM}, \mathrm{TC}$ \\
\hline B. cordata Kunth & $\mathrm{BC}, \mathrm{BM}, \mathrm{BQ}, \mathrm{MX}, \mathrm{PA}, \mathrm{VA}$ \\
\hline B. crotonoides A.Gray & $\mathrm{BC}$ \\
\hline B. parviflora Kunth & $\mathrm{BC}, \mathrm{BM}, \mathrm{BQ}, \mathrm{MX}, \mathrm{PA}, \mathrm{TC}$ \\
\hline B. sessiliflora Kunth & $\mathrm{BC}, \mathrm{BM}, \mathrm{BQ}, \mathrm{MX}, \mathrm{TC}, \mathrm{VA}$ \\
\hline \multicolumn{2}{|l|}{ BURSERACEAE $(2 / 38)$} \\
\hline Beiselia mexicana Forman ${ }^{(\mathrm{R})}$ & $\mathrm{TC}$ \\
\hline Bursera arborea (Rose) L. Riley ${ }^{(\mathrm{A}, \mathrm{V})}$ & $\mathrm{TC}, \mathrm{TS}$ \\
\hline B. ariensis (Kunth) McVaugh et Rzed. & $\mathrm{BQ}, \mathrm{TC}$ \\
\hline B. bicolor (Willd. ex Schltdl.) Engl. & $\mathrm{BQ}, \mathrm{MX}, \mathrm{TC}$ \\
\hline B. bipinnata (DC.) Engl. & $\mathrm{BC}, \mathrm{BQ}, \mathrm{MX}, \mathrm{TC}, \mathrm{TS}$ \\
\hline B. citronella McVaugh et Rzed. & $\mathrm{BQ}, \mathrm{TC}$ \\
\hline B. confusa (Rose) Engl. & $\mathrm{TC}$ \\
\hline B. copallifera (DC.) Bullock & $\mathrm{BC}, \mathrm{BQ}, \mathrm{TC}$ \\
\hline B. coyucensis Bullock ${ }^{(\mathrm{Pr})}$ & $\mathrm{TC}$ \\
\hline B. crenata Paul G.Wilson & $\mathrm{TC}$ \\
\hline B. cuneata (Schltdl.) Engl. & $\mathrm{BQ}, \mathrm{MX}, \mathrm{TC}$ \\
\hline B. denticulata McVaugh et Rzed. & $\mathrm{TC}, \mathrm{TS}$ \\
\hline B. discolor Rzed. & $\mathrm{TC}$ \\
\hline B. excelsa (Kunth) Engl. & $\mathrm{BC}, \mathrm{BE}, \mathrm{BQ}, \mathrm{MX}, \mathrm{TC}, \mathrm{VA}$ \\
\hline B. fagaroides (Kunth) Engl. & $\mathrm{BC}, \mathrm{BQ}, \mathrm{MX}, \mathrm{PA}, \mathrm{TC}, \mathrm{TS}$ \\
\hline B. fragrantissima Bullock & $\mathrm{TC}, \mathrm{TS}$ \\
\hline B. glabrifolia (Kunth) Engl. & $\mathrm{BQ}, \mathrm{MX}, \mathrm{TC}$ \\
\hline B. grandifolia (Schltdl.) Engl. & $\mathrm{BC}, \mathrm{BE}, \mathrm{BM}$ \\
\hline B. heteresthes Bullock & $\mathrm{TC}, \mathrm{TS}$ \\
\hline B. hintonii Bullock & $\mathrm{TC}$ \\
\hline B. infernidialis Guevara et Rzed. & $\mathrm{TC}$ \\
\hline B. instabilis McVaugh et Rzed. & $\mathrm{TC}, \mathrm{TS}$ \\
\hline B. kerberi Engl. & $\mathrm{TC}$ \\
\hline B. madrigalii Rzed. et Calderón & $\mathrm{BC}, \mathrm{BQ}, \mathrm{TC}$ \\
\hline B. multijuga Engl. & $\mathrm{BC}, \mathrm{TC}$ \\
\hline B. occulta McVaugh et Rzed. & $\mathrm{TC}$ \\
\hline B. palmeri S.Watson & $\mathrm{MX}, \mathrm{TC}$ \\
\hline B. paradoxa Guevara et Rzed. & $\mathrm{TC}$ \\
\hline B. penicillata (DC.) Engl. & $\mathrm{BE}, \mathrm{MX}, \mathrm{TC}$ \\
\hline B. ribana Rzed. et Calderón & $\mathrm{TC}$ \\
\hline B. sarcopoda Paul G.Wilson & $\mathrm{TC}$ \\
\hline B. sarukhanii Guevara et Rzed. & $\mathrm{TC}$ \\
\hline B. simaruba (L.) Sarg. & $\mathrm{BE}, \mathrm{BM}, \mathrm{BQ}, \mathrm{MX}, \mathrm{TC}, \mathrm{TP}, \mathrm{TS}, \mathrm{VA}$ \\
\hline B. staphyleoides McVaugh et Rzed. & TC \\
\hline B. submoniliformis Engl. & $\mathrm{MX}, \mathrm{TC}$ \\
\hline
\end{tabular}




\begin{tabular}{|c|c|}
\hline Taxa & Tipos de vegetación \\
\hline B. trifoliolata Bullock & TC \\
\hline B. trimera Bullock & TC \\
\hline B. velutina Bullock & $\mathrm{BQ}, \mathrm{TC}$ \\
\hline \multicolumn{2}{|l|}{ CACTACEAE (10/23) } \\
\hline Backerbergia militaris (Audot) Bravo ex Sánchez-Mej. ${ }^{\left({ }^{(P r}\right)}$ & TC \\
\hline Escontria chiotilla (F.A.C.Weber) Rose & $\mathrm{MX}, \mathrm{TC}$ \\
\hline Marginatocereus marginatus (DC.) Brackeb. & $\mathrm{BC}, \mathrm{MX}, \mathrm{TC}, \mathrm{VA}$ \\
\hline Myrtillocactus geometrizans (Mart. ex Pfeiff.) Console & $\mathrm{BC}, \mathrm{BQ}, \mathrm{MX}, \mathrm{PA}, \mathrm{TC}, \mathrm{VA}$ \\
\hline Neobuxbaumia mezcalensis (Bravo) Backeb. & $\mathrm{MX}, \mathrm{TC}$ \\
\hline N. squamulosa Scheinvar et Sánchez-Mej. & $\mathrm{TC}$ \\
\hline Opuntia atropes Rose & ND \\
\hline O. bensonii Sánchez-Mej. & ND \\
\hline O. fuliginosa Griffiths ${ }^{(v)}$ & $M X, P A, T C$ \\
\hline O. jaliscana Bravo & ND \\
\hline O. karwinskiana Salm-Dyck & $\mathrm{BE}, \mathrm{MX}, \mathrm{TC}, \mathrm{VA}$ \\
\hline O. tomentosa Salm-Dyck & $\mathrm{BC}, \mathrm{BQ}, \mathrm{MX}, \mathrm{PA}, \mathrm{TC}$ \\
\hline Pachycereus grandis Rose & ND \\
\hline P. pecten-aboriginum (Engelm. ex S.Watson) Britton et Rose & $\mathrm{BE}, \mathrm{MX}, \mathrm{TC}, \mathrm{VA}$ \\
\hline P. tepamo S.Gama et S.Arias & ND \\
\hline P. weberi (J.M.Coult.) Backeb. & $\mathrm{MX}, \mathrm{TC}$ \\
\hline Pereskiopsis blakeana J.G.Ortega & ND \\
\hline P. diguetii (F.A.C.Weber) Britton et Rose & ND \\
\hline Pilosocereus alensis (F.A.C.Weber) Byles et G.D.Rowley & ND \\
\hline P. purpusii (Britton et Rose) Byles et G.D.Rowley & ND \\
\hline Stenocereus chrysocarpus Sánchez-Mej. & TC \\
\hline S. fricii Sánchez-Mej. & ND \\
\hline S. queretaroensis (F.A.C.Weber) Buxb. & $\mathrm{MX}, \mathrm{TC}$ \\
\hline \multicolumn{2}{|l|}{ CAESALPINIACEAE $(9 / 39)$} \\
\hline Bauhinia andrieuxii Hemsl. & TC, TS \\
\hline B. cookii Rose & TC, TS, VA \\
\hline B. divaricata $\mathrm{L}$. & $\mathrm{BM}, \mathrm{BQ}, \mathrm{MX}, \mathrm{TC}, \mathrm{TP}, \mathrm{TS}, \mathrm{VA}$ \\
\hline B. pauletia Pers. & $\mathrm{BE}, \mathrm{TC}, \mathrm{TS}$ \\
\hline B. pringlei S.Watson & $\mathrm{BE}, \mathrm{MX}, \mathrm{TC}$ \\
\hline B. subrotundifolia Cav. & $\mathrm{TC}$ \\
\hline B. ungulata $\mathrm{L}$. & $\mathrm{BC}, \mathrm{TC}, \mathrm{TP}, \mathrm{TS}$ \\
\hline Caesalpinia cacalaco Bonpl. & $\mathrm{BE}, \mathrm{BQ}, \mathrm{MX}, \mathrm{OV}, \mathrm{TC}, \mathrm{VA}$ \\
\hline C. caladenia Standl. & $\mathrm{TC}, \mathrm{TS}$ \\
\hline C. coriaria (Jacq.) Willd. & $\mathrm{BC}, \mathrm{OV}, \mathrm{TC}, \mathrm{TS}, \mathrm{VA}$ \\
\hline C. eriostachys Benth. & $\mathrm{BE}, \mathrm{OV}, \mathrm{TC}, \mathrm{TS}$ \\
\hline C. mexicana A.Gray & $\mathrm{BQ}, \mathrm{MX}, \mathrm{TC}, \mathrm{TS}$ \\
\hline C. platyloba S.Watson & $\mathrm{BE}, \mathrm{MX}, \mathrm{TC}, \mathrm{TS}, \mathrm{VS}$ \\
\hline Cassia hintonii Sandwith & $\mathrm{BC}, \mathrm{TC}$ \\
\hline Conzattia multiflora (B.L.Rob.) Standl. & $\mathrm{BC}, \mathrm{BQ}, \mathrm{MX}, \mathrm{TC}, \mathrm{TS}$ \\
\hline Haematoxylum brasiletto H.Karst. & $\mathrm{BE}, \mathrm{BQ}, \mathrm{MX}, \mathrm{TC}, \mathrm{TS}, \mathrm{VA}$ \\
\hline Heteroflorum sclerocarpum M.Sousa & TC, TS, VA \\
\hline Parkinsonia aculeata L. & $\mathrm{BE}, \mathrm{MX}, \mathrm{TC}, \mathrm{VA}$ \\
\hline P. praecox (Ruiz et Pav.) Hawkins & $\mathrm{BQ}, \mathrm{MX}, \mathrm{TC}, \mathrm{TS}, \mathrm{VA}$ \\
\hline P. $\times$ carterae Hawkins & $\mathrm{TC}$ \\
\hline Poeppigia procera C.PresI & TC, TS \\
\hline Senna alata (L.) Roxb. & $\mathrm{BC}, \mathrm{TS}, \mathrm{VA}$ \\
\hline S. atomaria (L.) H.S.Irwin et Barneby & $\mathrm{BC}, \mathrm{BE}, \mathrm{BQ}, \mathrm{MX}, \mathrm{TC}, \mathrm{TS}$ \\
\hline S. centranthera H.S.Irwin et Barneby & $\mathrm{OV}, \mathrm{TC}$ \\
\hline S. didymobotrya (Fresen.) H.S.Irwin et Barneby & $\mathrm{MX}, \mathrm{TC}$ \\
\hline S. foetidissima (G.Don) H.S.Irwin et Barneby & $\mathrm{BQ}$ \\
\hline S. fruticosa (Mill.) H.S.Irwin et Barneby & $\mathrm{BC}, \mathrm{BE}, \mathrm{TC}, \mathrm{TP}, \mathrm{TS}, \mathrm{VA}$ \\
\hline
\end{tabular}




\begin{tabular}{|c|c|}
\hline Taxa & Tipos de vegetación \\
\hline S. holwayana (Rose) H.S.Irwin et Barneby & $\mathrm{BC}, \mathrm{BQ}, \mathrm{MX}, \mathrm{TC}, \mathrm{VA}$ \\
\hline S. mollissima (Willd.) H.S.Irwin et Barneby & $\mathrm{BE}, \mathrm{TC}, \mathrm{TS}, \mathrm{VA}$ \\
\hline S. multifoliolata (Paul G.Wilson) H.S.Irwin et Barneby & $\mathrm{BC}, \mathrm{VA}$ \\
\hline S. multijuga (Rich.) H.S.Irwin et Barneby & $\mathrm{TP}$ \\
\hline S. pallida (Vahl) H.S.Irwin et Barneby & $\mathrm{BC}, \mathrm{BE}, \mathrm{BM}, \mathrm{MX}, \mathrm{OV}, \mathrm{TC}, \mathrm{TP}, \mathrm{TS}$ \\
\hline S. pendula (Willd.) H.S.Irwin et Barneby & $\mathrm{TC}, \mathrm{TS}$ \\
\hline S. polyantha (Collad.) H.S.Irwin et Barneby & $\mathrm{MX}, \mathrm{TC}$ \\
\hline S. quinquangulata (Rich.) H.S.Irwin et Barneby & $\mathrm{BC}, \mathrm{BQ}, \mathrm{TC}$ \\
\hline S. racemosa (Mill.) H.S.Irwin et Barneby & $\mathrm{BQ}, \mathrm{TC}, \mathrm{TS}$ \\
\hline S. septemtrionalis (Viv.) H.S.Irwin et Barneby & $\mathrm{BC}, \mathrm{BM}, \mathrm{BQ}, \mathrm{MX}, \mathrm{TC}$ \\
\hline S. skinneri (Benth.) H.S.Irwin et Barneby & $\mathrm{BC}, \mathrm{OV}, \mathrm{TC}$ \\
\hline S. wislizenii (A.Gray) H.S.Irwin et Barneby & $\mathrm{MX}, \mathrm{TC}, \mathrm{VA}$ \\
\hline \multicolumn{2}{|l|}{ CAPPARACEAE $(4 / 8)$} \\
\hline Capparis angustifolia Kunth & ND \\
\hline C. asperifolia C.Pres| & OV, TC \\
\hline C. flexuosa (L.) L. & $\mathrm{BE}, \mathrm{MX}, \mathrm{TC}, \mathrm{TS}, \mathrm{VA}$ \\
\hline C. incana Kunth & MX, OV, PA, TC, TS, VA \\
\hline C. verrucosa Jacq. & $\mathrm{BE}, \mathrm{TC}, \mathrm{TS}$ \\
\hline Crateva tapia L. & $\mathrm{BE}, \mathrm{OV}, \mathrm{TC}, \mathrm{TP}, \mathrm{TS}, \mathrm{VA}$ \\
\hline Forchhammeria pallida Liebm. & $\mathrm{OV}, \mathrm{TC}, \mathrm{TS}$ \\
\hline Morisonia americana L. & $\mathrm{BE}, \mathrm{MX}, \mathrm{TC}, \mathrm{TP}, \mathrm{TS}$ \\
\hline \multicolumn{2}{|l|}{ CAPRIFOLIACEAE (3/9) } \\
\hline Sambucus nigra L. & $\mathrm{BC}, \mathrm{BM}, \mathrm{BQ}, \mathrm{MX}, \mathrm{TC}, \mathrm{TP}, \mathrm{VA}$ \\
\hline Shymphoricarpos microphyllus Kunth & $\mathrm{BC}$ \\
\hline Viburnum acutifolium Benth. & $\mathrm{BC}$ \\
\hline V. amatenangense Lundell & TS \\
\hline V. dispar C.V.Morton ${ }^{(\mathbf{R})}$ & $\mathrm{BC}$ \\
\hline V. elatum Benth. & $\mathrm{BC}, \mathrm{BM}, \mathrm{BQ}, \mathrm{VA}$ \\
\hline V. loeseneri Graebn. & $\mathrm{BC}, \mathrm{BM}$ \\
\hline V. microphyllum (Oerst.) Hemsl. & $\mathrm{BC}, \mathrm{BM}$ \\
\hline V. stenocalyx (Oerst.) Hemsl. & $\mathrm{BC}, \mathrm{BM}$ \\
\hline \multicolumn{2}{|l|}{ CARICACEAE $(1 / 1)$} \\
\hline Jacaratia mexicana A.DC. & $\mathrm{BM}, \mathrm{MX}, \mathrm{TC}, \mathrm{TP}$ \\
\hline \multicolumn{2}{|l|}{ CECROPIACEAE (1/1) } \\
\hline Cecropia obtusifolia Bertol. & $\mathrm{BM}, \mathrm{BQ}, \mathrm{TP}, \mathrm{TS}$ \\
\hline \multicolumn{2}{|l|}{ CELASTRACEAE $(3 / 3)$} \\
\hline Crossopetalum managuatillo (Loes.) Lundell & TC \\
\hline Wimmeria lanceolata Rose & $\mathrm{TC}, \mathrm{TS}$ \\
\hline Zinowiewia concinna Lundell ${ }^{(\mathbf{P})}$ & $\mathrm{BC}, \mathrm{BM}, \mathrm{BQ}, \mathrm{TC}$ \\
\hline \multicolumn{2}{|l|}{ CHLORANTHACEAE $(1 / 1)$} \\
\hline Hedyosmum mexicanum C.Cordem. & $\mathrm{BC}, \mathrm{BM}, \mathrm{TP}, \mathrm{TS}, \mathrm{VA}$ \\
\hline \multicolumn{2}{|l|}{ CHRYSOBALANACEAE $(3 / 4)$} \\
\hline Couepia polyandra (Kunth) Rose & $\mathrm{TC}, \mathrm{TP}, \mathrm{TS}$ \\
\hline Hirtella racemosa Lam. & OV, VA, VS \\
\hline Licania arborea Seem. ${ }^{(A)}$ & TC, TS, VA \\
\hline L. retifolia S.F.Blake & TS \\
\hline \multicolumn{2}{|l|}{ CLETHRACEAE (1/4) } \\
\hline Clethra hartwegii Britton & $\mathrm{BC}, \mathrm{BM}, \mathrm{BQ}, \mathrm{MX}, \mathrm{TC}, \mathrm{VA}$ \\
\hline C. lanata M.Martens et Galeotti & ND \\
\hline C. mexicana DC. & $\mathrm{BC}, \mathrm{BM}, \mathrm{BQ}, \mathrm{TS}, \mathrm{VA}$ \\
\hline C. pringlei S.Watson & $\mathrm{BC}, \mathrm{BM}, \mathrm{BQ}, \mathrm{MX}, \mathrm{TC}, \mathrm{TP}, \mathrm{VA}$ \\
\hline \multicolumn{2}{|l|}{ CLUSIACEAE $(3 / 3)$} \\
\hline Calophyllum brasiliense Cambess. & $\mathrm{BC}, \mathrm{BM}, \mathrm{TC}, \mathrm{TP}, \mathrm{TS}, \mathrm{VA}$ \\
\hline Clusia salvinii Donn.Sm. & $\mathrm{BC}, \mathrm{BM}, \mathrm{BQ}, \mathrm{TC}, \mathrm{TP}, \mathrm{TS}$ \\
\hline Garcinia intermedia (Pittier) Hammel & $\mathrm{BC}, \mathrm{BM}, \mathrm{TC}, \mathrm{TP}, \mathrm{TS}, \mathrm{VA}$ \\
\hline
\end{tabular}




\begin{tabular}{|c|c|}
\hline Taxa & Tipos de vegetación \\
\hline \multicolumn{2}{|l|}{ COMBRETACEAE $(2 / 2)$} \\
\hline Conocarpus erectus L. ${ }^{(\mathrm{Pr})}$ & $\mathrm{MX}, \mathrm{OV}, \mathrm{TC}, \mathrm{TS}, \mathrm{VA}$ \\
\hline Laguncularia racemosa (L.) C.F.Gaertn. ${ }^{\left({ }^{\prime}\right)}$ & $\mathrm{OV}, \mathrm{TC}, \mathrm{VA}$ \\
\hline \multicolumn{2}{|l|}{ CONVOLVULACEAE $(1 / 4)$} \\
\hline Ipomoea arborescens (Humb. et Bonpl. ex Willd.) G.Don & $\mathrm{BE}, \mathrm{BQ}, \mathrm{MX}, \mathrm{TC}$ \\
\hline I. murucoides Roem. et Schult. & $\mathrm{BC}, \mathrm{BE}, \mathrm{BQ}, \mathrm{MX}, \mathrm{PA}, \mathrm{TC}$ \\
\hline I. pauciflora M.Martens et Galeotti & $\mathrm{MX}, \mathrm{TC}, \mathrm{TS}$ \\
\hline I. wolcottiana Rose & $\mathrm{MX}, \mathrm{TC}$ \\
\hline \multicolumn{2}{|l|}{ CORIARIACEAE $(1 / 1)$} \\
\hline Coriaria ruscifolia L. & $\mathrm{BC}, \mathrm{BM}, \mathrm{BQ}$ \\
\hline \multicolumn{2}{|l|}{ CORNACEAE $(1 / 2)$} \\
\hline Cornus disciflora DC. & $\mathrm{BC}, \mathrm{BM}, \mathrm{BQ}, \mathrm{MX}, \mathrm{VA}$ \\
\hline C. excelsa Kunth & $\mathrm{BC}, \mathrm{BM}, \mathrm{BQ}, \mathrm{TC}, \mathrm{VA}$ \\
\hline \multicolumn{2}{|l|}{ DILLENIACEAE (1/1) } \\
\hline Curatella americana L. & $\mathrm{BC}, \mathrm{OV}, \mathrm{TC}, \mathrm{TP}, \mathrm{TS}$ \\
\hline \multicolumn{2}{|l|}{ EBENACEAE $(1 / 3)$} \\
\hline Diospyros digyna Jacg. & $\mathrm{BM}, \mathrm{MX}, \mathrm{TC}, \mathrm{TP}, \mathrm{TS}, \mathrm{VA}$ \\
\hline D. oaxacana Standl. & $\mathrm{MX}, \mathrm{TC}, \mathrm{TS}$ \\
\hline D. xolocotzii Madrigal et Rzed. ${ }^{\left(\mathrm{Pr}_{\mathrm{r}} \mathrm{R}\right)}$ & $M X$ \\
\hline \multicolumn{2}{|l|}{ ERICACEAE $(6 / 9)$} \\
\hline Arbutus tessellata P.D.Sorensen & $\mathrm{BC}, \mathrm{BQ}$ \\
\hline A. xalapensis Kunth & $\mathrm{BC}, \mathrm{BM}, \mathrm{BQ}, \mathrm{MX}$ \\
\hline Arctostaphylos pungens Kunth & $\mathrm{BC}, \mathrm{BM}, \mathrm{BQ}, \mathrm{MX}$ \\
\hline Comarostaphylis discolor (Hook.) Diggs ${ }^{\left({ }^{r}\right)}$ & $\mathrm{BC}, \mathrm{BM}, \mathrm{MX}$ \\
\hline C. glaucescens (Kunth) Zucc. ex Klotzsch & $\mathrm{BM}, \mathrm{BQ}, \mathrm{MX}, \mathrm{TC}$ \\
\hline C. longifolia (Benth.) Klotzsch & $\mathrm{BC}, \mathrm{BM}, \mathrm{BQ}$ \\
\hline Gaultheria erecta Vent. & $B C, V A, V S$ \\
\hline Pernettya prostrata (Cav.) DC. & $\mathrm{BC}, \mathrm{BM}, \mathrm{BQ}, \mathrm{MX}, \mathrm{PA}$ \\
\hline Vaccinium leucanthum Schltdl. & $\mathrm{BM}$ \\
\hline \multicolumn{2}{|l|}{ ERYTHROXYLACEAE $(1 / 5)$} \\
\hline Erythroxylum compactum Rose & $\mathrm{MX}, \mathrm{TC}$ \\
\hline E. havanense Jacq. & $\mathrm{BM}, \mathrm{TC}, \mathrm{TS}$ \\
\hline E. mexicanum Kunth & $\mathrm{BE}, \mathrm{BQ}, \mathrm{MX}, \mathrm{TC}, \mathrm{VA}$ \\
\hline E. pallidum Rose & $\mathrm{BM}, \mathrm{TC}, \mathrm{TS}$ \\
\hline E. rotundifolium Lunan & $\mathrm{MX}, \mathrm{TC}, \mathrm{TS}$ \\
\hline \multicolumn{2}{|l|}{ EUPHORBIACEAE $(14 / 33)$} \\
\hline Bernardia mexicana (Hook. et Arn.) Müll.Arg. ${ }^{(\mathrm{A})}$ & $\mathrm{BM}, \mathrm{BQ}, \mathrm{MX}, \mathrm{TC}, \mathrm{TS}, \mathrm{VA}$ \\
\hline Cnidoscolus aconitifolius (Mill.) I.M.Johnst. & $\mathrm{BM}, \mathrm{BQ}, \mathrm{MX}, \mathrm{TC}, \mathrm{TS}$ \\
\hline C. multilobus (Pax) I.M.Johnst. & $\mathrm{BM}, \mathrm{MX}, \mathrm{TC}, \mathrm{TP}, \mathrm{TS}$ \\
\hline Croton draco Schltdl. et Cham. & $\mathrm{BC}, \mathrm{BM}, \mathrm{BQ}, \mathrm{TC}, \mathrm{TP}$ \\
\hline C. flavescens Greenm. & $\mathrm{BC}, \mathrm{BE}, \mathrm{BQ}, \mathrm{MX}, \mathrm{TC}, \mathrm{TS}$ \\
\hline C. morifolius Willd. & $\mathrm{BC}, \mathrm{BE}, \mathrm{BQ}, \mathrm{MX}, \mathrm{TC}$ \\
\hline C. niveus Jacq. & $\mathrm{BE}, \mathrm{BM}, \mathrm{MX}, \mathrm{TC}, \mathrm{TS}$ \\
\hline C. xalapensis Kunth & $\mathrm{BC}, \mathrm{BQ}, \mathrm{TC}, \mathrm{TP}$ \\
\hline Dalembertia populifolia Baill. & $\mathrm{BE}, \mathrm{BQ}, \mathrm{MX}, \mathrm{TC}$ \\
\hline Ditaxis heterantha Zucc. & $M X$ \\
\hline Euphorbia calyculata Kunth & $\mathrm{MX}, \mathrm{TC}$ \\
\hline E. colletioides Benth. & $\mathrm{BC}, \mathrm{BE}, \mathrm{MX}, \mathrm{TC}, \mathrm{TS}$ \\
\hline E. schlechtendalii Boiss. & $\mathrm{BE}, \mathrm{BM}, \mathrm{BQ}, \mathrm{MX}, \mathrm{TC}, \mathrm{TS}$ \\
\hline E. tanquahuete Sessé et Moc. & $\mathrm{BC}, \mathrm{BQ}, \mathrm{TC}, \mathrm{TP}$ \\
\hline Gymnanthes actinostemoides Müll.Arg. & $\mathrm{BM}, \mathrm{BQ}, \mathrm{TC}, \mathrm{TP}$ \\
\hline Hippomane mancinella L. & $\mathrm{MX}, \mathrm{TC}, \mathrm{TP}, \mathrm{TS}, \mathrm{VA}$ \\
\hline Hura polyandra Baill. & $\mathrm{BE}, \mathrm{MX}, \mathrm{TC}, \mathrm{TP}, \mathrm{TS}$ \\
\hline Jatropha cordata (Ortega) Müll.Arg. & $\mathrm{BE}, \mathrm{MX}, \mathrm{TC}$ \\
\hline J. galvanii J.Jiménez Ram. et L.M.Contr. & $\mathrm{TC}$ \\
\hline
\end{tabular}




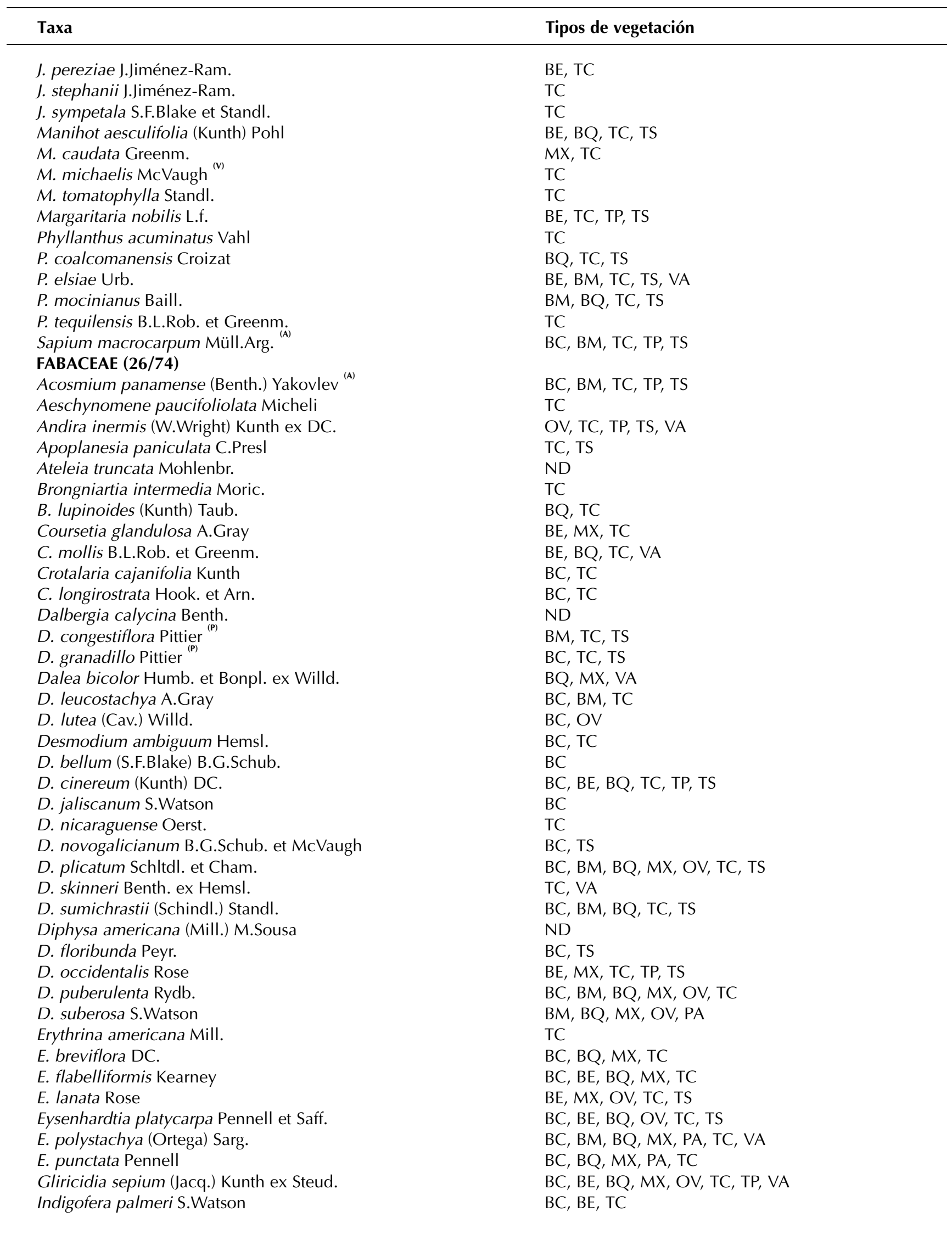




\begin{tabular}{|c|c|}
\hline Taxa & Tipos de vegetación \\
\hline I. platycarpa Rose & $\mathrm{TC}$ \\
\hline I. thibaudiana DC. & $\mathrm{BC}, \mathrm{BM}, \mathrm{MX}, \mathrm{TC}, \mathrm{TS}$ \\
\hline Lonchocarpus balsensis M.Sousa et J.C.Soto & TC \\
\hline L. caudatus Pittier & $\mathrm{BM}, \mathrm{TC}, \mathrm{TS}$ \\
\hline L. cochleatus Pittier & $\mathrm{TC}, \mathrm{TP}, \mathrm{TS}$ \\
\hline L. constrictus Pittier & MX, TC, TS \\
\hline L. epigaeus M.Sousa & $\mathrm{TC}$ \\
\hline L. eriocarinalis Micheli & TC, TS \\
\hline L. eriophyllus Benth. & $\mathrm{TC}$ \\
\hline L. guatemalensis Benth. & $\mathrm{BE}, \mathrm{TC}, \mathrm{TP}, \mathrm{TS}, \mathrm{VA}$ \\
\hline L. hintonii Sandwith & $\mathrm{TC}, \mathrm{TS}, \mathrm{VA}$ \\
\hline L. huetamoensis M.Sousa et J.C.Soto & $\mathrm{TC}$ \\
\hline L. lanceolatus Benth. & $\mathrm{BE}, \mathrm{TC}, \mathrm{TS}$ \\
\hline L. longipedunculatus M.Sousa et J.C.Soto & $\mathrm{TC}$ \\
\hline L. magallanesii M.Sousa & $\mathrm{TC}$ \\
\hline L. mutans M.Sousa & TC, TS \\
\hline L. pittieri M.Sousa & $\mathrm{BC}, \mathrm{TC}, \mathrm{TS}$ \\
\hline L. rugosus Benth. & $\mathrm{BQ}, \mathrm{TC}, \mathrm{TS}, \mathrm{VA}$ \\
\hline L. salvadorensis Pittier & $\mathrm{BM}, \mathrm{TC}, \mathrm{TS}$ \\
\hline L. schubertiae M.Sousa & $\mathrm{TC}$ \\
\hline L. sericeus (Poir.) Kunth ex DC. & $\mathrm{BE}, \mathrm{TC}, \mathrm{TP}, \mathrm{TS}, \mathrm{VA}$ \\
\hline Lupinus reflexus Rose & $\mathrm{BC}$ \\
\hline Machaerium biovulatum Micheli & $\mathrm{TC}$ \\
\hline M. salvadorense (Donn.Sm.) Rudd & TC, TS \\
\hline Myrospermum frutescens Jacq. & $\mathrm{TC}$ \\
\hline Myroxylon balsamum (L.) Harms & TC, TP, TS \\
\hline Piscidia carthagenensis Jacq. & $\mathrm{TC}, \mathrm{TS}$ \\
\hline P. grandifolia (Donn.Sm.) I.M.Johnst. & $\mathrm{BQ}, \mathrm{TC}, \mathrm{TS}$ \\
\hline P. piscipula (L.) Sarg. & $\mathrm{TC}$ \\
\hline Platymiscium lasiocarpum Sandwith ${ }^{(\mathbf{P})}$ & $\mathrm{TC}, \mathrm{TS}, \mathrm{VA}$ \\
\hline Pterocarpus acapulcensis Rose & $\mathrm{TC}, \mathrm{TS}, \mathrm{VA}$ \\
\hline P. orbiculatus DC. & $\mathrm{TC}, \mathrm{TP}$ \\
\hline Sesbania longifolia DC. & $M X, T C, V A$ \\
\hline Swartzia simplex (Sw.) Spreng. & TC, TP, TS, VA \\
\hline \multicolumn{2}{|l|}{ FAGACEAE $(1 / 35)$} \\
\hline Quercus acutifolia Née & $\mathrm{BC}, \mathrm{BM}, \mathrm{BQ}, \mathrm{MX}, \mathrm{TC}$ \\
\hline Q. candicans Née & $\mathrm{BC}, \mathrm{BM}, \mathrm{TC}$ \\
\hline Q. castanea Née & $\mathrm{BC}, \mathrm{BM}, \mathrm{MX}, \mathrm{TC}, \mathrm{TS}$ \\
\hline Q. conspersa Benth. & $\mathrm{BC}, \mathrm{BM}, \mathrm{BQ}$ \\
\hline Q. crassifolia Humb. et Bonpl. & $\mathrm{BC}, \mathrm{BM}, \mathrm{BQ}, \mathrm{MX}$ \\
\hline Q. crassipes Humb. et Bonpl. & $\mathrm{BC}, \mathrm{BM}, \mathrm{BQ}, \mathrm{MX}$ \\
\hline Q. deserticola Trel. & $\mathrm{BQ}, \mathrm{MX}, \mathrm{TC}$ \\
\hline Q. eduardii Trel. & $\mathrm{BC}, \mathrm{BQ}$ \\
\hline Q. elliptica Née & $\mathrm{BC}, \mathrm{BM}, \mathrm{BQ}, \mathrm{VA}$ \\
\hline Q. frutex Trel. & $\mathrm{BC}, \mathrm{BQ}, \mathrm{MX}$ \\
\hline Q. furfuracea Liebm. & $\mathrm{BQ}, \mathrm{MX}$ \\
\hline Q. gentryi C.H.Mull. & $\mathrm{BC}, \mathrm{BM}, \mathrm{BQ}, \mathrm{MX}, \mathrm{TC}$ \\
\hline Q. glabrescens Benth. & $\mathrm{BC}, \mathrm{BM}, \mathrm{BQ}, \mathrm{MX}$ \\
\hline Q. glaucescens Humb. et Bonpl. & $\mathrm{BC}, \mathrm{BM}, \mathrm{BQ}, \mathrm{OV}, \mathrm{TC}, \mathrm{VA}$ \\
\hline Q. glaucoides M.Martens et Galeotti & $\mathrm{BC}, \mathrm{BM}, \mathrm{BQ}, \mathrm{MX}, \mathrm{TC}$ \\
\hline Q. greggii (A.DC.) Trel. & $\mathrm{BC}, \mathrm{BM}, \mathrm{BQ}, \mathrm{MX}$ \\
\hline Q. hintonii E.F.Warb. ${ }^{(\mathrm{E})}$ & $\mathrm{BC}, \mathrm{BQ}$ \\
\hline Q. laeta Liebm. & $\mathrm{BC}, \mathrm{BM}, \mathrm{BQ}, \mathrm{MX}, \mathrm{TC}$ \\
\hline Q. laurina Humb. et Bonpl. & $\mathrm{BC}, \mathrm{BM}, \mathrm{BQ}, \mathrm{MX}, \mathrm{PA}, \mathrm{TP}$ \\
\hline Q. laxa Liebm. & $\mathrm{BC}, \mathrm{BQ}$ \\
\hline
\end{tabular}




\begin{tabular}{|c|c|}
\hline Taxa & Tipos de vegetación \\
\hline Q. magnoliifolia Née & $\mathrm{BC}, \mathrm{BE}, \mathrm{BM}, \mathrm{BQ}, \mathrm{MX}, \mathrm{TC}$ \\
\hline Q. martinezii C.H.Mull. ${ }^{(\mathrm{R})}$ & $\mathrm{BC}, \mathrm{BM}, \mathrm{BQ}$ \\
\hline Q. obtusata Humb. et Bonpl. & $\mathrm{BC}, \mathrm{BM}, \mathrm{BQ}, \mathrm{MX}, \mathrm{TC}, \mathrm{VA}$ \\
\hline Q. peduncularis Née & $\mathrm{BC}, \mathrm{BM}, \mathrm{BQ}, \mathrm{MX}$ \\
\hline Q. planipocula Trel. ${ }^{(\mathrm{R})}$ & $\mathrm{BC}, \mathrm{BM}$ \\
\hline Q. resinosa Liebm. & $\mathrm{BC}, \mathrm{BQ}, \mathrm{MX}, \mathrm{TC}$ \\
\hline Q. rugosa Née & $\mathrm{BC}, \mathrm{BM}, \mathrm{BQ}, \mathrm{MX}, \mathrm{TC}, \mathrm{TS}$ \\
\hline Q. salicifolia Née & $\mathrm{BC}, \mathrm{BM}, \mathrm{BQ}, \mathrm{VA}$ \\
\hline Q. scytophylla Liebm. & $\mathrm{BC}, \mathrm{BM}, \mathrm{BQ}$ \\
\hline Q. sideroxylla Humb. et Bonpl. & $\mathrm{BC}, \mathrm{BQ}$ \\
\hline Q. splendens Née & $\mathrm{BC}, \mathrm{BQ}, \mathrm{MX}, \mathrm{TC}, \mathrm{VA}$ \\
\hline Q. subspathulata Trel. ${ }^{(1)}$ & $\mathrm{BM}, \mathrm{TC}$ \\
\hline Q. tuberculata Liebm. & $\mathrm{BQ}, \mathrm{MX}, \mathrm{TC}$ \\
\hline Q. uxoris McVaugh $^{(\mathrm{R})}$ & $\mathrm{BM}$ \\
\hline Q. $\times d y$ sophylla Benth. & $\mathrm{BC}, \mathrm{BM}, \mathrm{BQ}, \mathrm{MX}$ \\
\hline \multicolumn{2}{|l|}{ FLACOURTIACEAE (4/7) } \\
\hline Casearia arguta Kunth & $\mathrm{BC}, \mathrm{BM}, \mathrm{BQ}, \mathrm{OV}, \mathrm{TC}, \mathrm{TP}, \mathrm{TS}, \mathrm{VA}$ \\
\hline C. corymbosa Kunth & $\mathrm{TC}$ \\
\hline C. elegans Standl. & ND \\
\hline C. tremula (Griseb.) Griseb. ex C.Wright & $\mathrm{TC}, \mathrm{TS}$ \\
\hline Muntingia calabura L. & $\mathrm{BC}, \mathrm{BM}, \mathrm{BQ}, \mathrm{MX}, \mathrm{TC}, \mathrm{TP}, \mathrm{TS}, \mathrm{VA}$ \\
\hline Prockia crucis P.Browne ex L. & $\mathrm{MX}, \mathrm{TC}, \mathrm{TS}$ \\
\hline Xylosma flexuosum (Kunth) Hemsl. & $\mathrm{BC}, \mathrm{BM}, \mathrm{BQ}, \mathrm{MX}, \mathrm{TC}, \mathrm{TP}, \mathrm{TS}, \mathrm{VA}$ \\
\hline \multicolumn{2}{|l|}{ FOUQUERIACEAE $(1 / 1)$} \\
\hline Fouquieria formosa Kunth & $\mathrm{MX}, \mathrm{TC}$ \\
\hline \multicolumn{2}{|l|}{ GARRYACEAE $(1 / 2)$} \\
\hline Garrya laurifolia Hartw. ex Benth. & $\mathrm{BC}, \mathrm{BM}, \mathrm{BQ}, \mathrm{MX}, \mathrm{VA}$ \\
\hline G. longifolia Rose & $\mathrm{BC}, \mathrm{BM}, \mathrm{BQ}, \mathrm{TC}, \mathrm{VA}$ \\
\hline \multicolumn{2}{|l|}{ GROSSULARIACEAE (1/1) } \\
\hline Phyllonoma laticuspis (Turcz.) Engl. & $\mathrm{BC}, \mathrm{BM}, \mathrm{TP}$ \\
\hline \multicolumn{2}{|l|}{ HERNANDIACEDAE $(1 / 1)$} \\
\hline Gyrocarpus jatrophifolius Domin & $\mathrm{BE}, \mathrm{BM}, \mathrm{BQ}, \mathrm{TC}$ \\
\hline \multicolumn{2}{|l|}{ HYDROPHYLLACEAE $(1 / 1)$} \\
\hline Wigandia urens (Ruiz et Pav.) Kunth & $\mathrm{BC}, \mathrm{BE}, \mathrm{BM}, \mathrm{BQ}, \mathrm{MX}, \mathrm{TC}, \mathrm{TP}, \mathrm{TS}, \mathrm{VA}$ \\
\hline \multicolumn{2}{|l|}{ JUGLANDACEAE $(1 / 2)$} \\
\hline Juglans major (Torr.) A.Heller ${ }^{(A)}$ & $\mathrm{BC}, \mathrm{BM}, \mathrm{BQ}, \mathrm{MX}, \mathrm{PA}, \mathrm{TC}, \mathrm{VA}$ \\
\hline J. pyriformis Liebm. ${ }^{(\mathrm{A}, \mathrm{V})}$ & $\mathrm{BM}, \mathrm{TP}, \mathrm{VA}$ \\
\hline \multicolumn{2}{|l|}{ JULIANIACEAE (1/1) } \\
\hline Amphipterygium adstringens (Schltdl.) Standl. & $\mathrm{MX}, \mathrm{TC}$ \\
\hline \multicolumn{2}{|l|}{ LAURACEAE $(4 / 6)$} \\
\hline Cinnamomum pachypodium (Nees) Kostermans & $\mathrm{BC}, \mathrm{BM}, \mathrm{BQ}, \mathrm{MX}, \mathrm{TC}, \mathrm{TS}$ \\
\hline Litsea glaucescens Kunth $^{(\mathbf{P})}$ & $\mathrm{BC}, \mathrm{BM}, \mathrm{BQ}, \mathrm{MX}, \mathrm{TC}, \mathrm{TP}$ \\
\hline Nectandra hihua (Ruiz et Pav.) Rohwer & $\mathrm{BM}, \mathrm{MX}, \mathrm{TC}, \mathrm{TS}, \mathrm{VA}$ \\
\hline N. nitida Mez & $\mathrm{TC}, \mathrm{TP}$ \\
\hline N. salicifolia (Kunth) Nees & $\mathrm{BC}, \mathrm{BM}, \mathrm{BQ}, \mathrm{TC}, \mathrm{TP}, \mathrm{TS}$ \\
\hline Ocotea veraguensis (Meisn.) Mez & $\mathrm{BM}, \mathrm{TP}, \mathrm{TS}$ \\
\hline \multicolumn{2}{|l|}{ LYTHRACEAE $(3 / 3)$} \\
\hline Adenaria floribunda Kunth & $\mathrm{BC}, \mathrm{TP}, \mathrm{TS}$ \\
\hline Ginoria nudiflora (Hemsl.) Koehne ${ }^{(1)}$ & $\mathrm{TC}, \mathrm{TP}, \mathrm{TS}, \mathrm{VA}$ \\
\hline Heimia salicifolia Link & VA \\
\hline \multicolumn{2}{|l|}{ MAGNOLIACEAE (1/2) } \\
\hline Magnolia iltisiana A.Vázquez ${ }^{(\mathrm{A}, \mathrm{E})}$ & $\mathrm{BM}, \mathrm{BQ}$ \\
\hline M. schiedeana Schltdl. & $\mathrm{BM}, \mathrm{BQ}$ \\
\hline \multicolumn{2}{|l|}{ MALPIGHIACEAE (3/5) } \\
\hline Bunchosia lindeniana A.Juss. & $\mathrm{BE}, \mathrm{BM}, \mathrm{BQ}, \mathrm{TC}, \mathrm{TP}, \mathrm{TS}, \mathrm{VA}$ \\
\hline
\end{tabular}




\begin{tabular}{|c|c|}
\hline Taxa & Tipos de vegetación \\
\hline B. palmeri S.Watson & $\mathrm{BC}, \mathrm{BE}, \mathrm{TC}$ \\
\hline Byrsonima crassifolia (L.) Kunth & $\mathrm{BC}, \mathrm{BE}, \mathrm{BM}, \mathrm{BQ}, \mathrm{OV}, \mathrm{TC}, \mathrm{TP}, \mathrm{TS}, \mathrm{VA}$ \\
\hline Malpighia mexicana A.Juss. & $\mathrm{MX}, \mathrm{TC}$ \\
\hline M. ovata Rose & $\mathrm{BC}, \mathrm{TC}$ \\
\hline \multicolumn{2}{|l|}{ MALVACEAE $(9 / 15)$} \\
\hline Abutilon ellpticum Schltdl. & $\mathrm{BC}, \mathrm{BM}, \mathrm{TC}, \mathrm{VS}$ \\
\hline A. haenkeanum C.Presl & $\mathrm{BE}, \mathrm{TC}$ \\
\hline Bastardia bivalvis (Cav.) Kunth ex Griseb. & $\mathrm{MX}, \mathrm{TC}$ \\
\hline Gossypium aridum (Rose et Standl.) Skovst. & $\mathrm{BE}, \mathrm{TC}$ \\
\hline G. lobatum Gentry & $\mathrm{TC}$ \\
\hline G. schwendimanii Fryxell et S.D.Koch & $\mathrm{TC}$ \\
\hline G. trilobum (DC.) Skovst. ${ }^{(\mathbf{R})}$ & $\mathrm{BC}, \mathrm{TC}$ \\
\hline Hampea tomentosa (C.Presl) Standl. & $\mathrm{TC}, \mathrm{TS}$ \\
\hline Hibiscus pernambucensis Arruda & OV, VA \\
\hline Malvaviscus arboreus Cav. (E) & $\mathrm{BC}, \mathrm{BM}, \mathrm{BQ}, \mathrm{MX}, \mathrm{OV}, \mathrm{TC}, \mathrm{TP}, \mathrm{TS}, \mathrm{VA}$ \\
\hline Neobrittonia acerifolia (G.Don) Hochr. & $\mathrm{BC}, \mathrm{BM}$ \\
\hline Pavonia candida (DC.) Fryxell & $\mathrm{MX}, \mathrm{TC}$ \\
\hline P. oxyphylla (DC.) Fryxell & $M X, T C$ \\
\hline P. pleuranthera (DC.) Fryxell & $\mathrm{BC}$ \\
\hline Phymosia rosea (DC.) Kearney ${ }^{\left({ }^{(r)}\right)}$ & $\mathrm{BC}, \mathrm{BM}, \mathrm{BQ}, \mathrm{TC}, \mathrm{VA}$ \\
\hline \multicolumn{2}{|l|}{ MELASTOMATACEAE $(\mathbf{1} / \mathbf{1})$} \\
\hline Leandra subseriata (Naudin) Cogn. & $\mathrm{BC}, \mathrm{BM}$ \\
\hline \multicolumn{2}{|l|}{ MELIACEAE (4/8) } \\
\hline Cedrela odorata L. & $\mathrm{BM}, \mathrm{BQ}, \mathrm{MX}, \mathrm{TC}, \mathrm{TP}, \mathrm{TS}, \mathrm{VA}$ \\
\hline C. salvadorensis Standl. & $\mathrm{BE}, \mathrm{MX}, \mathrm{TC}$ \\
\hline Guarea glabra Vahl & $\mathrm{BM}, \mathrm{BQ}, \mathrm{TC}, \mathrm{TP}, \mathrm{TS}, \mathrm{VA}$ \\
\hline Swietenia humilis Zucc. & $\mathrm{BE}, \mathrm{OV}, \mathrm{TC}, \mathrm{TS}$ \\
\hline Trichilia americana (Sessé et Moc.) T.D.Penn. & $\mathrm{BC}, \mathrm{BE}, \mathrm{BQ}, \mathrm{TC}, \mathrm{TS}, \mathrm{VA}$ \\
\hline T. havanensis Jacq. & $\mathrm{BE}, \mathrm{BM}, \mathrm{BQ}, \mathrm{MX}, \mathrm{TC}, \mathrm{TP}, \mathrm{TS}, \mathrm{VA}$ \\
\hline T. hirta L. & $\mathrm{BC}, \mathrm{BE}, \mathrm{BM}, \mathrm{BQ}, \mathrm{MX}, \mathrm{TC}, \mathrm{TP}, \mathrm{TS}, \mathrm{VA}$ \\
\hline T. trifolia L. & $\mathrm{MX}, \mathrm{TC}, \mathrm{TP}, \mathrm{TS}, \mathrm{VA}$ \\
\hline \multicolumn{2}{|l|}{ MENISPERMACEAE (1/1) } \\
\hline Hyperbaena ilicifolia Standl. & TC, TS \\
\hline \multicolumn{2}{|l|}{ MIMOSACEAE $(17 / 67)$} \\
\hline Acacia acatlensis Benth. & $\mathrm{BE}, \mathrm{MX}, \mathrm{TC}$ \\
\hline A. cochliacantha Humb. et Bonpl. ex Willd. & $\mathrm{BE}, \mathrm{BM}, \mathrm{BQ}, \mathrm{MX}, \mathrm{TC}, \mathrm{TS}$ \\
\hline A. coulteri Benth. ex A.Gray & $\mathrm{BQ}, \mathrm{MX}, \mathrm{TC}, \mathrm{VA}$ \\
\hline A. farnesiana (L.) Willd. & $\mathrm{BC}, \mathrm{BE}, \mathrm{BQ}, \mathrm{MX}, \mathrm{OV}, \mathrm{PA}, \mathrm{TC}, \mathrm{TS}, \mathrm{VA}$ \\
\hline A. hindsii Benth. & $\mathrm{OV}, \mathrm{TC}, \mathrm{TP}, \mathrm{TS}, \mathrm{VS}$ \\
\hline A. macilenta Rose & $\mathrm{TC}$ \\
\hline A. macracantha Humb. et Bonpl. ex Willd. & $\mathrm{BC}, \mathrm{BE}, \mathrm{BQ}, \mathrm{OV}, \mathrm{PA}, \mathrm{TC}$ \\
\hline A. pennatula (Schltdl. et Cham.) Benth. & $\mathrm{BC}, \mathrm{BE}, \mathrm{BM}, \mathrm{BQ}, \mathrm{MX}, \mathrm{PA}, \mathrm{TC}, \mathrm{TP}, \mathrm{TS}, \mathrm{VA}$ \\
\hline A. picachensis Brandegee & $\mathrm{MX}, \mathrm{TC}, \mathrm{TS}$ \\
\hline A. polyphyla DC. & $\mathrm{MX}, \mathrm{TC}$ \\
\hline A. pringlei Rose & $\mathrm{MX}, \mathrm{TC}$ \\
\hline A. riparia Kunth & $\mathrm{BE}, \mathrm{BQ}, \mathrm{TC}, \mathrm{TP}, \mathrm{TS}, \mathrm{VA}$ \\
\hline A. schaffneri (S.Watson) F.J.Herm. & $\mathrm{BC}, \mathrm{BM}, \mathrm{BQ}, \mathrm{MX}, \mathrm{PA}, \mathrm{TC}$ \\
\hline A. sphaerocephala Cham. et Schltdl. & $\mathrm{OV}, \mathrm{TC}$ \\
\hline A. tenuifolia (L.) Willd. & $\mathrm{BM}, \mathrm{TC}, \mathrm{TS}$ \\
\hline Acaciella angustissima (Mill.) Britton et Rose & $\mathrm{TC}$ \\
\hline Albizia occidentalis Brandegee & $\mathrm{BE}, \mathrm{BQ}, \mathrm{TC}, \mathrm{VA}$ \\
\hline A. tomentosa (Micheli) Standl. & $\mathrm{TC}, \mathrm{TP}, \mathrm{TS}$ \\
\hline Calliandra bijuga Rose & $B C, B Q, V A$ \\
\hline C. caeciliae Harms & $\mathrm{MX}, \mathrm{TC}$ \\
\hline C. calothyrsus Meisn. & $\mathrm{TC}, \mathrm{TP}$ \\
\hline
\end{tabular}




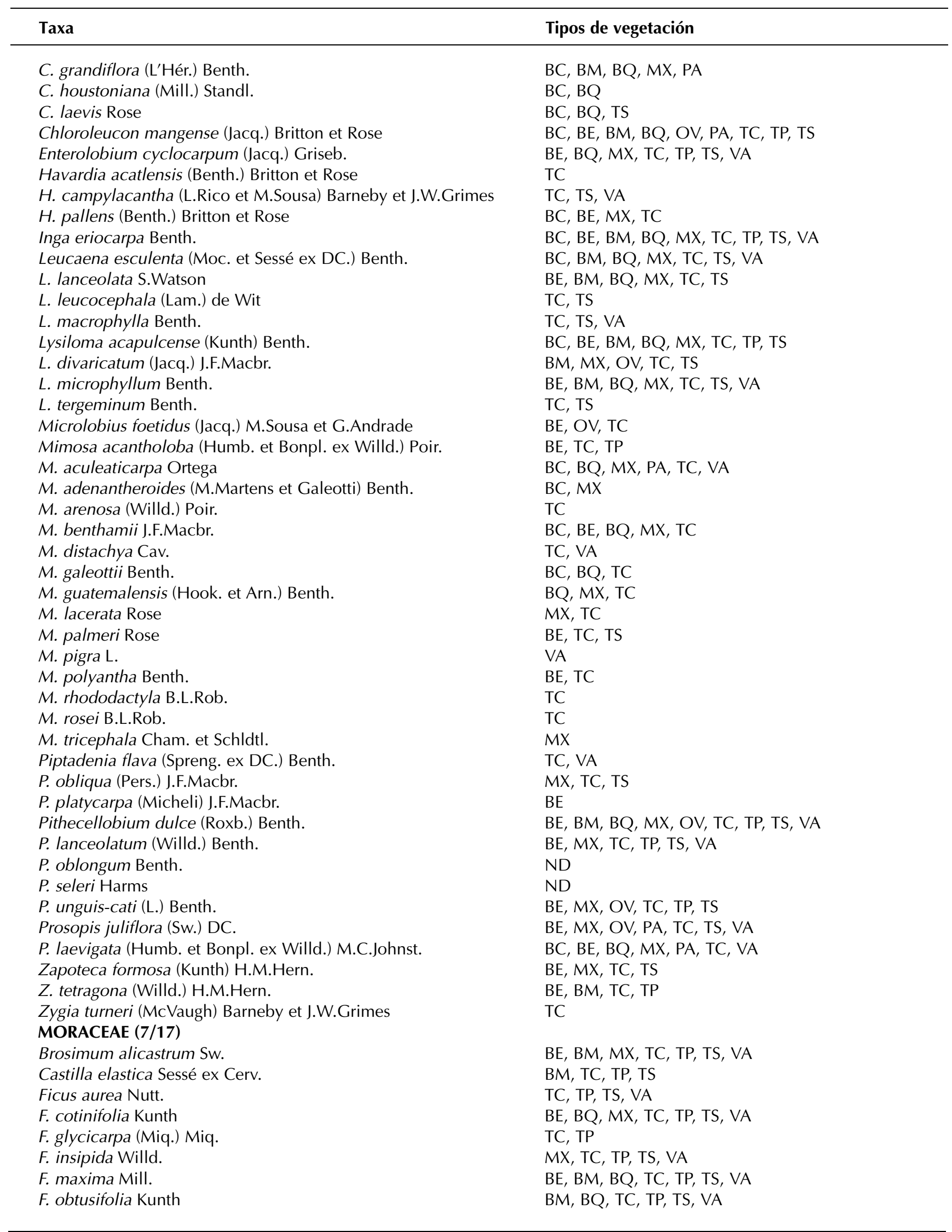




\begin{tabular}{|c|c|}
\hline Taxa & Tipos de vegetación \\
\hline F. pertusa L.f. & $\mathrm{BC}, \mathrm{BE}, \mathrm{BM}, \mathrm{MX}, \mathrm{TC}, \mathrm{TP}, \mathrm{TS}, \mathrm{VA}$ \\
\hline F. petiolaris Kunth & $\mathrm{BC}, \mathrm{BE}, \mathrm{TC}$ \\
\hline F. pringlei S.Watson & $\mathrm{TC}$ \\
\hline F. trigonata L. & $\mathrm{BC}, \mathrm{BQ}, \mathrm{TC}, \mathrm{TP}, \mathrm{TS}, \mathrm{VA}$ \\
\hline F. turrialbana W.C.Burger & $T C, T P, V A, V S$ \\
\hline Maclura tinctoria (L.) Steud. & $\mathrm{BE}, \mathrm{MX}, \mathrm{TC}, \mathrm{TP}, \mathrm{TS}, \mathrm{VA}$ \\
\hline Morus celtidifolia Kunth & $\mathrm{BM}, \mathrm{BQ}, \mathrm{MX}, \mathrm{PA}, \mathrm{VA}$ \\
\hline Pseudolmedia glabrata (Liebm.) C.C.Berg & $\mathrm{BM}, \mathrm{TP}, \mathrm{TS}$ \\
\hline Trophis racemosa (L.) Urb. & $\mathrm{BM}, \mathrm{BQ}, \mathrm{MX}, \mathrm{TC}, \mathrm{TP}, \mathrm{TS}, \mathrm{VA}$ \\
\hline \multicolumn{2}{|l|}{ MYRICACEAE $(1 / 1)$} \\
\hline Myrica lindeniana C.DC. & $\mathrm{BC}, \mathrm{BM}$ \\
\hline \multicolumn{2}{|l|}{ MYRSINACEAE $(4 / 7)$} \\
\hline Ardisia escallonioides Schltdl. et Cham. & $\mathrm{BM}, \mathrm{BQ}, \mathrm{MX}, \mathrm{TC}, \mathrm{TS}$ \\
\hline A. revoluta Kunth & $\mathrm{BC}, \mathrm{BM}, \mathrm{TC}, \mathrm{TS}, \mathrm{VA}$ \\
\hline Myrsine coriacea (Sw.) R.Br. ex Roem. et Schult. & $\mathrm{BM}, \mathrm{BQ}$ \\
\hline M. juergensenii (Mez) Ricketson et Pipoly & $\mathrm{BC}, \mathrm{BM}, \mathrm{BQ}, \mathrm{TS}$ \\
\hline Parathesis melanosticta (Schltdl.) Hemsl. & $\mathrm{BC}, \mathrm{BM}, \mathrm{BQ}$ \\
\hline P. villosa Lundell & $\mathrm{BM}, \mathrm{BQ}, \mathrm{TS}$ \\
\hline Synardisia venosa (Mast.) Lundell & $\mathrm{BM}$ \\
\hline \multicolumn{2}{|l|}{ MYRTACEAE (3/6) } \\
\hline Eugenia acapulcensis Steud. & $\mathrm{BM}, \mathrm{TC}, \mathrm{TP}, \mathrm{TS}, \mathrm{VA}$ \\
\hline E. capuli (Schltdl. et Cham.) Hook et Arn. & $\mathrm{BC}, \mathrm{BM}, \mathrm{BQ}, \mathrm{MX}, \mathrm{TC}, \mathrm{TP}, \mathrm{TS}, \mathrm{VA}$ \\
\hline Myrcianthes fragrans (Sw.) McVaugh & $\mathrm{BM}, \mathrm{BQ}, \mathrm{MX}, \mathrm{TC}, \mathrm{TS}, \mathrm{VA}$ \\
\hline Psidium guajava $\mathrm{L}$. & $\mathrm{BC}, \mathrm{BE}, \mathrm{BM}, \mathrm{BQ}, \mathrm{MX}, \mathrm{TC}, \mathrm{TP}, \mathrm{VA}$ \\
\hline P. guineense Sw. & $\mathrm{BC}, \mathrm{BE}, \mathrm{BM}, \mathrm{BQ}, \mathrm{TC}, \mathrm{TS}, \mathrm{VA}$ \\
\hline P. sartorianum (O.Berg) Nied. & $\mathrm{BE}, \mathrm{BM}, \mathrm{BQ}, \mathrm{TC}, \mathrm{TP}, \mathrm{TS}, \mathrm{VA}$ \\
\hline \multicolumn{2}{|l|}{ NYCTAGINACEAE $(1 / 1)$} \\
\hline $\begin{array}{l}\text { Pisoniella arborescens (Lag. et Rodr.) Standl. }{ }^{(R)} \\
\text { OCHNACEAE }(\mathbf{1 / 2})\end{array}$ & $\mathrm{MX}, \mathrm{PA}, \mathrm{TC}, \mathrm{TS}$ \\
\hline Ouratea madrensis L.Riley & TS \\
\hline O. mexicana (Humb. et Bonpl.) Engl. & $\mathrm{BQ}, \mathrm{OV}, \mathrm{TC}, \mathrm{VA}$ \\
\hline \multicolumn{2}{|l|}{ OLACACEAE $(2 / 2)$} \\
\hline Schoepfia pringlei B.L.Rob. ${ }^{(1)}$ & $\mathrm{BQ}$ \\
\hline Ximenia parviflora Benth. & $\mathrm{BQ}, \mathrm{MX}, \mathrm{TC}$ \\
\hline \multicolumn{2}{|l|}{ OLEACEAE $(2 / 2)$} \\
\hline Forestiera phillyreoides (Benth.) Torr. & $\mathrm{BC}, \mathrm{BQ}, \mathrm{MX}, \mathrm{PA}, \mathrm{TC}$ \\
\hline Fraxinus uhdei (Wenz.) Lingelsh. & $\mathrm{BC}, \mathrm{BM}, \mathrm{BQ}, \mathrm{MX}, \mathrm{PA}, \mathrm{TC}, \mathrm{VA}$ \\
\hline \multicolumn{2}{|l|}{ ONAGRACEAE $(2 / 3)$} \\
\hline Fuchsia arborescens Sims & $\mathrm{BC}, \mathrm{BM}, \mathrm{BQ}, \mathrm{TP}$ \\
\hline F. michoacanensis Sessé et Moc. & $\mathrm{BC}, \mathrm{BM}$ \\
\hline Hauya elegans DC. & $\mathrm{BC}, \mathrm{BM}, \mathrm{TC}, \mathrm{TP}, \mathrm{VA}$ \\
\hline \multicolumn{2}{|l|}{ OPILIACEAE $(1 / 1)$} \\
\hline Agonandra racemosa (DC.) Standl. & $\mathrm{BE}, \mathrm{BM}, \mathrm{BQ}, \mathrm{MX}, \mathrm{TC}, \mathrm{VA}$ \\
\hline \multicolumn{2}{|l|}{ PAPAVERACEAE $(1 / 2)$} \\
\hline Bocconia arborea S.Watson & $\mathrm{BC}, \mathrm{BM}, \mathrm{MX}, \mathrm{TC}$ \\
\hline B. frutescens $\mathrm{L}$. & $\mathrm{BC}, \mathrm{BM}, \mathrm{BQ}, \mathrm{TP}$ \\
\hline \multicolumn{2}{|l|}{ PIPERACEAE (1/2) } \\
\hline Piper aduncum L. & $\mathrm{BC}, \mathrm{BM}, \mathrm{BQ}, \mathrm{MX}, \mathrm{TC}, \mathrm{TP}, \mathrm{TS}, \mathrm{VA}$ \\
\hline P. tuberculatum Jacq. & TS, VA \\
\hline \multicolumn{2}{|l|}{ POLYGONACEAE $(2 / 3)$} \\
\hline Coccoloba barbadensis Jacq. & $\mathrm{BC}, \mathrm{BM}, \mathrm{MX}, \mathrm{OV}, \mathrm{TC}, \mathrm{TP}, \mathrm{TS}, \mathrm{VA}$ \\
\hline Ruprechtia fusca Fernald & $\mathrm{MX}, \mathrm{TC}, \mathrm{TS}$ \\
\hline R. pallida Standl. & $\mathrm{TC}, \mathrm{TP}, \mathrm{TS}$ \\
\hline \multicolumn{2}{|l|}{ RHAMNACEAE $(6 / 12)$} \\
\hline Ceanothus coeruleus Lag. & $\mathrm{BC}, \mathrm{BM}, \mathrm{BQ}, \mathrm{MX}, \mathrm{VA}$ \\
\hline
\end{tabular}




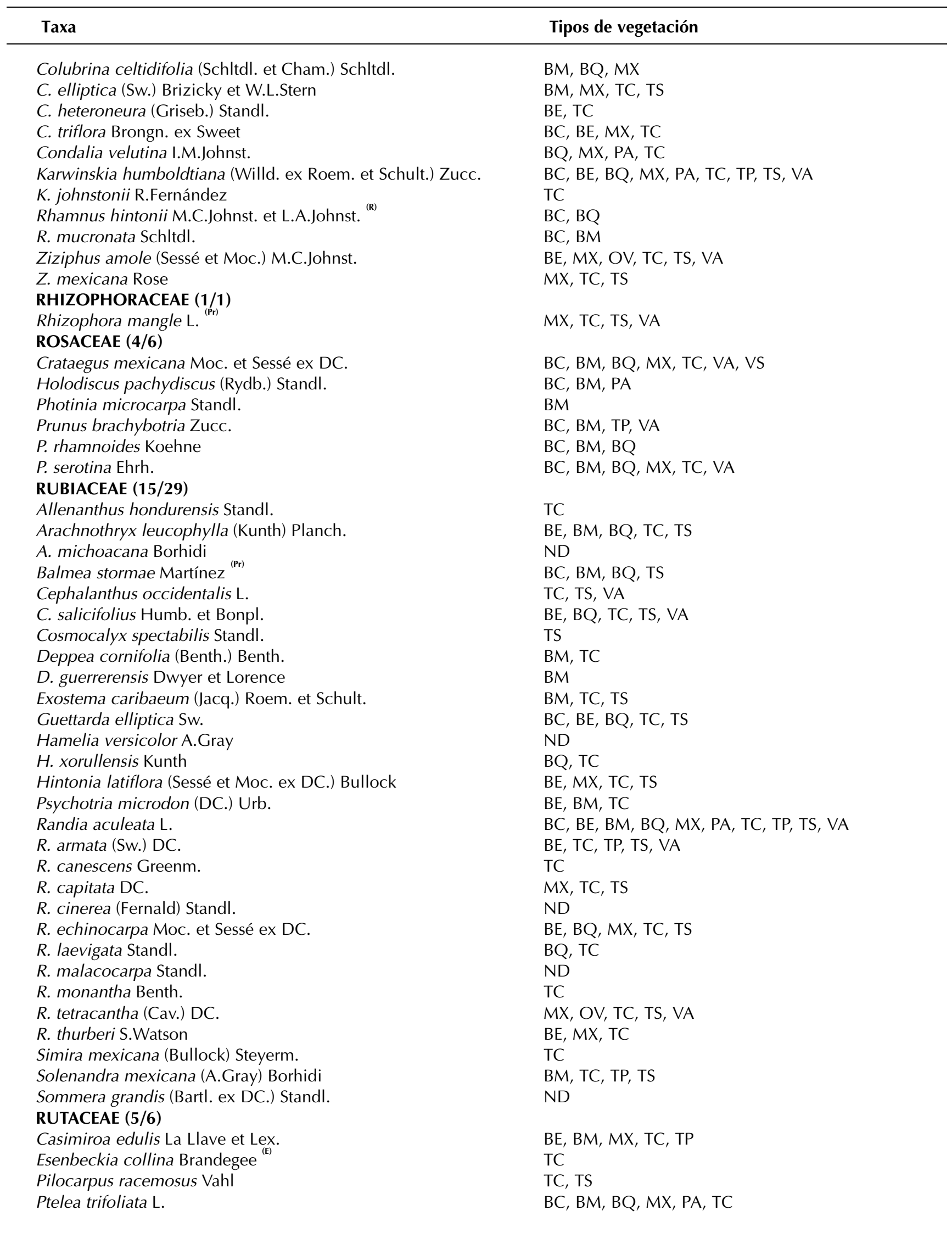




\begin{tabular}{|c|c|}
\hline Taxa & Tipos de vegetación \\
\hline Zanthoxylum affine Kunth & $M X$ \\
\hline Z. fagara (L.) Sarg. & $\mathrm{BC}, \mathrm{BM}, \mathrm{BQ}, \mathrm{MX}, \mathrm{TC}, \mathrm{TS}$ \\
\hline \multicolumn{2}{|l|}{ SABIACEAE $(1 / 1)$} \\
\hline Meliosma dentata (Liebm.) Urb. & $\mathrm{BC}, \mathrm{BM}, \mathrm{BQ}, \mathrm{TP}$ \\
\hline \multicolumn{2}{|l|}{ SALICACEAE $(2 / 8)$} \\
\hline Populus simaroa Rzed. ${ }^{\left({ }^{(r)}\right)}$ & $\mathrm{BC}, \mathrm{BM}, \mathrm{BQ}$ \\
\hline P. tremuloides Michx. & $B C, B Q, M X, V A$ \\
\hline Salix aeruginosa E.Carranza & $\mathrm{BC}, \mathrm{BQ}, \mathrm{VA}$ \\
\hline S. bonplandiana Kunth & $\mathrm{BC}, \mathrm{BM}, \mathrm{BQ}, \mathrm{MX}, \mathrm{PA}, \mathrm{VA}$ \\
\hline S. humboldtiana Willd. & $\mathrm{BM}, \mathrm{BQ}, \mathrm{MX}, \mathrm{TC}, \mathrm{TP}, \mathrm{TS}, \mathrm{VA}$ \\
\hline S. jaliscana M.E.Jones & $\mathrm{BM}, \mathrm{BQ}$ \\
\hline S. paradoxa Kunth & $\mathrm{BC}, \mathrm{BM}, \mathrm{BQ}, \mathrm{MX}, \mathrm{VA}$ \\
\hline S. taxifolia Kunth & $\mathrm{BC}, \mathrm{BM}, \mathrm{BQ}, \mathrm{MX}, \mathrm{PA}, \mathrm{TC}, \mathrm{TP}, \mathrm{TS}, \mathrm{VA}$ \\
\hline \multicolumn{2}{|l|}{ SAPINDACEAE $(6 / 8)$} \\
\hline Cupania glabra Sw. & TC, TP, TS \\
\hline Dodonaea viscosa Jacq. & $\mathrm{BC}, \mathrm{BE}, \mathrm{BM}, \mathrm{BQ}, \mathrm{MX}, \mathrm{OV}, \mathrm{PA}, \mathrm{TC}, \mathrm{TP}, \mathrm{TS}, \mathrm{VA}, \mathrm{VS}$ \\
\hline Exothea paniculata (Juss.) Radlk. & $\mathrm{BM}, \mathrm{MX}, \mathrm{TC}, \mathrm{TP}, \mathrm{TS}$ \\
\hline Sapindus saponaria L. & $\mathrm{BC}, \mathrm{BE}, \mathrm{BM}, \mathrm{BQ}, \mathrm{MX}, \mathrm{TP}, \mathrm{TS}, \mathrm{VA}$ \\
\hline Thouinia acuminata S.Watson & $\mathrm{TC}, \mathrm{TS}$ \\
\hline T. paucidentata Radlk. & TC, TP, TS \\
\hline T. villosa DC. & $\mathrm{BM}, \mathrm{BQ}, \mathrm{MX}, \mathrm{TC}$ \\
\hline Thouinidium decandrum (Humb. et Bonpl.) Radlk. & $\mathrm{BE}, \mathrm{BQ}, \mathrm{TC}, \mathrm{TS}, \mathrm{VA}$ \\
\hline \multicolumn{2}{|l|}{ SAPOTACEAE $(3 / 5)$} \\
\hline Manilkara zapota (L.) P.Royen & OV, TC, TP, TS, VA \\
\hline Pouteria campechiana (Kunth) Baehni & $\mathrm{BM}, \mathrm{TC}, \mathrm{TP}, \mathrm{TS}, \mathrm{VA}$ \\
\hline Sideroxylon capiri (A.DC.) Pittier ${ }^{(1)}$ & $\mathrm{BC}, \mathrm{BQ}, \mathrm{TC}, \mathrm{TP}, \mathrm{TS}, \mathrm{VA}$ \\
\hline S. cartilagineum (Cronquist) T.D.Penn. (1) & $\mathrm{TC}, \mathrm{TS}, \mathrm{VA}$ \\
\hline S. persimile (Hemsl.) T.D.Penn. & $\mathrm{BQ}, \mathrm{TP}, \mathrm{TS}$ \\
\hline \multicolumn{2}{|l|}{ SIMAROUBACEAE $(4 / 4)$} \\
\hline Alvaradoa amorphoides Liebm. & $\mathrm{BE}, \mathrm{MX}, \mathrm{TC}, \mathrm{TS}, \mathrm{VA}$ \\
\hline Picramnia guerrerensis W.W.Thomas & $\mathrm{BM}, \mathrm{BQ}$ \\
\hline Quassia amara L. & $\mathrm{TC}, \mathrm{TP}$ \\
\hline Recchia mexicana Moc. et Sessé ex DC. & OV, TC, TS, VA \\
\hline \multicolumn{2}{|l|}{ SOLANACEAE $(3 / 18)$} \\
\hline Acnistus arborescens (L.) Schltdl. & $M X$ \\
\hline Cestrum flavescens Greenm. & $\mathrm{BM}$ \\
\hline C. fulvescens Fernald & $\mathrm{BC}, \mathrm{BM}, \mathrm{MX}$ \\
\hline C. lanatum M.Martens et Galeotti & $\mathrm{BC}, \mathrm{BM}, \mathrm{BQ}, \mathrm{MX}, \mathrm{TC}, \mathrm{TP}, \mathrm{TS}, \mathrm{VA}$ \\
\hline C. nitidum M.Martens et Galeotti & ND \\
\hline C. nocturnum L. & $\mathrm{TC}$ \\
\hline C. roseum Kunth & ND \\
\hline Solanum aligerum Schltdl. & $\mathrm{BC}, \mathrm{BM}, \mathrm{MX}, \mathrm{TP}$ \\
\hline S. aphyodendron S.Knapp & $\mathrm{BC}, \mathrm{BM}, \mathrm{BQ}, \mathrm{TP}$ \\
\hline S. chrysotrichum Schltdl. & $\mathrm{BC}, \mathrm{BM}, \mathrm{BQ}, \mathrm{MX}$ \\
\hline S. erianthum D.Don & $\mathrm{BC}, \mathrm{BE}, \mathrm{BM}, \mathrm{BQ}, \mathrm{MX}, \mathrm{TC}, \mathrm{TP}, \mathrm{TS}, \mathrm{VA}$ \\
\hline S. hispidum Pers. & ND \\
\hline S. laurifolium L.f. & ND \\
\hline S. nigricans M.Martens et Galeotti & $\mathrm{BC}, \mathrm{BM}, \mathrm{BQ}, \mathrm{MX}, \mathrm{TC}, \mathrm{TP}$ \\
\hline S. nudum Dunal & $\mathrm{BC}, \mathrm{BM}, \mathrm{BQ}, \mathrm{TC}, \mathrm{TP}, \mathrm{TS}$ \\
\hline S. pubigerum Dunal & ND \\
\hline S. torvum Sw. & $\mathrm{TC}$ \\
\hline S. umbellatum Mill. & $\mathrm{BC}, \mathrm{BM}, \mathrm{BQ}, \mathrm{MX}, \mathrm{PA}, \mathrm{TC}, \mathrm{TP}, \mathrm{TS}$ \\
\hline \multicolumn{2}{|l|}{ STERCULIACEAE (4/7) } \\
\hline Ayenia mexicana Turcz. & $\mathrm{MX}, \mathrm{TC}$ \\
\hline A. micrantha Standl. & $\mathrm{BE}, \mathrm{TC}$ \\
\hline
\end{tabular}




\begin{tabular}{|c|c|}
\hline Taxa & Tipos de vegetación \\
\hline Guazuma ulmifolia Lam. & $\mathrm{BC}, \mathrm{BE}, \mathrm{BM}, \mathrm{BQ}, \mathrm{MX}, \mathrm{TC}, \mathrm{TP}, \mathrm{TS}, \mathrm{VA}, \mathrm{VS}$ \\
\hline Melochia nudiflora Standl. et L.O.Williams & $\mathrm{BC}, \mathrm{TC}, \mathrm{VS}$ \\
\hline M. pyramidata L. & VS \\
\hline M. tomentosa L. & VS \\
\hline Physodium adenodes (Goldberg) Fryxell & $\mathrm{BE}, \mathrm{TC}$ \\
\hline \multicolumn{2}{|l|}{ STYRACACEAE $(1 / 1)$} \\
\hline Styrax argenteus C.Presl & $\mathrm{BC}, \mathrm{BM}, \mathrm{TC}, \mathrm{TP}, \mathrm{TS}, \mathrm{VA}$ \\
\hline \multicolumn{2}{|l|}{ SYMPLOCACEAE (1/1) } \\
\hline \multicolumn{2}{|l|}{ THEACEAE $(2 / 2)$} \\
\hline Cleyera integrifolia (Benth.) Choisy & $\mathrm{BC}, \mathrm{BM}$ \\
\hline Ternstroemia lineata DC. & $\mathrm{BC}, \mathrm{BM}, \mathrm{BQ}, \mathrm{TC}, \mathrm{TS}$ \\
\hline \multicolumn{2}{|l|}{ THEOPHRASTACEAE $(1 / 2)$} \\
\hline Jacquinia macrocarpa Cav. & $\mathrm{BE}, \mathrm{MX}, \mathrm{OV}, \mathrm{TC}, \mathrm{TP}, \mathrm{TS}, \mathrm{VA}$ \\
\hline J. nervosa C.Pres| & $\mathrm{BE}, \mathrm{TC}$ \\
\hline \multicolumn{2}{|l|}{ THYMELAEACEAE (1/1) } \\
\hline $\begin{array}{l}\text { Daphnopsis americana (Mill.) J.R.Johnst. } \\
\text { TILIACEAE }(\mathbf{5 / 1 1})\end{array}$ & $\mathrm{BQ}, \mathrm{TC}, \mathrm{VA}$ \\
\hline Heliocarpus occidentalis Rose & $\mathrm{BC}, \mathrm{BQ}, \mathrm{TC}, \mathrm{TS}$ \\
\hline H. pallidus Rose & $\mathrm{BM}, \mathrm{BQ}, \mathrm{MX}, \mathrm{TC}, \mathrm{VA}$ \\
\hline H. terebinthinaceus (DC.) Hochr. & $\mathrm{BQ}, \mathrm{MX}, \mathrm{TC}, \mathrm{VA}$ \\
\hline Luehea candida (Moc. et Sessé ex DC.) Mart. & OV, TC, TP, TS, VA \\
\hline Tilia americana L. & $\mathrm{BC}, \mathrm{BM}, \mathrm{BQ}, \mathrm{TC}, \mathrm{TS}$ \\
\hline Trichospermum mexicanum (DC.) Baill. & $\mathrm{BQ}, \mathrm{TC}$ \\
\hline Triumfetta galeottiana Turcz. & $\mathrm{BQ}, \mathrm{OV}, \mathrm{TC}$ \\
\hline T. goldmanii Rose & $\mathrm{BC}, \mathrm{BM}, \mathrm{BQ}$ \\
\hline T. mexiae C.V.Morton et Lay & $\mathrm{TC}$ \\
\hline T. paniculata Hook. et Arn. & $\mathrm{BQ}, \mathrm{TC}$ \\
\hline T. simplicifolia (Sessé et Moc.) Fryxell & $\mathrm{BQ}, \mathrm{TC}$ \\
\hline \multicolumn{2}{|l|}{ ULMACEAE $(3 / 5)$} \\
\hline Aphananthe monoica (Hemsl.) J.F.Leroy & $\mathrm{BM}, \mathrm{TP}, \mathrm{TS}$ \\
\hline Celtis caudata Planch. & $\mathrm{BM}, \mathrm{BQ}, \mathrm{MX}, \mathrm{TC}, \mathrm{TS}$ \\
\hline C. iguanaea (Jacq.) Sarg. & $\mathrm{BE}, \mathrm{BM}, \mathrm{BQ}, \mathrm{MX}, \mathrm{TC}, \mathrm{TP}, \mathrm{TS}, \mathrm{VA}$ \\
\hline C. pallida Torr. & $\mathrm{BE}, \mathrm{BQ}, \mathrm{MX}, \mathrm{PA}, \mathrm{TC}, \mathrm{TS}$ \\
\hline Trema micrantha (L.) Blume & $\mathrm{BC}, \mathrm{BE}, \mathrm{BM}, \mathrm{BQ}, \mathrm{MX}, \mathrm{TC}, \mathrm{TP}, \mathrm{TS}, \mathrm{VA}$ \\
\hline \multicolumn{2}{|l|}{ URTICACEAE $(5 / 10)$} \\
\hline Discocnide mexicana (Liebm.) Chew & TS, BM \\
\hline Myriocarpa brachystachys S.Watson & ND \\
\hline M. longipes Liebm. & $\mathrm{BM}, \mathrm{TP}, \mathrm{TS}$ \\
\hline Phenax hirtus (Sw.) Wedd. & $\mathrm{BM}, \mathrm{VA}$ \\
\hline P. mexicanus Wedd. & $\mathrm{BM}$ \\
\hline Pouzolzia guatemala (Blume) Wedd. & $\mathrm{TC}$ \\
\hline P. occidentalis (Liebm.) Wedd. & $\mathrm{BQ}, \mathrm{BM}, \mathrm{TC}, \mathrm{TS}, \mathrm{VA}$ \\
\hline Urera corallina (Liebm.) Wedd. & $\mathrm{BM}, \mathrm{TC}$ \\
\hline U. pacifica V.W.Steinm. & $\mathrm{BC}, \mathrm{BM}, \mathrm{TC}, \mathrm{VA}$ \\
\hline U. verrucosa (Liebm.) V.W.Steinm. & $\mathrm{TC}, \mathrm{VA}$ \\
\hline \multicolumn{2}{|l|}{ VERBENACEAE $(7 / 16)$} \\
\hline Avicennia germinans (L.) L. ${ }^{(\mathrm{Pr})}$ & $\mathrm{MX}, \mathrm{OV}, \mathrm{TC}, \mathrm{TS}, \mathrm{VA}$ \\
\hline Callicarpa acuminata Kunth & $\mathrm{BM}, \mathrm{MX}, \mathrm{OV}, \mathrm{TC}, \mathrm{TP}, \mathrm{TS}$ \\
\hline Citharexylum affine D.Don & $\mathrm{BE}, \mathrm{BM}, \mathrm{BQ}, \mathrm{MX}, \mathrm{TC}, \mathrm{TP}, \mathrm{TS}, \mathrm{VA}$ \\
\hline C. hidalgense Moldenke & $\mathrm{BC}, \mathrm{BM}, \mathrm{MX}$ \\
\hline C. racemosum Sessé et Moc. & $\mathrm{MX}, \mathrm{TC}$ \\
\hline Duranta repens $\mathrm{L}$. & $\mathrm{TC}$ \\
\hline Lantana camara L. & $\mathrm{BQ}, \mathrm{MX}, \mathrm{TC}, \mathrm{TS}$ \\
\hline L. hirta Graham & $\mathrm{BC}, \mathrm{BQ}, \mathrm{MX}, \mathrm{TC}$ \\
\hline
\end{tabular}




\begin{tabular}{|c|c|}
\hline Taxa & Tipos de vegetación \\
\hline Lippia graveolens Kunth & $\mathrm{MX}, \mathrm{TC}$ \\
\hline L. inopinata Moldenke & ND \\
\hline L. mexicana Grieve & $\mathrm{BM}, \mathrm{BQ}$ \\
\hline L. myriocephala Schltdl. et Cham. & $\mathrm{BC}, \mathrm{BM}, \mathrm{TC}, \mathrm{TP}, \mathrm{VA}$ \\
\hline L. umbellata Cav. & $\mathrm{BC}, \mathrm{BE}, \mathrm{BM}, \mathrm{BQ}, \mathrm{MX}, \mathrm{TC}, \mathrm{TS}$ \\
\hline Vitex hemsleyi Briq. & $\mathrm{BC}, \mathrm{OV}, \mathrm{TC}, \mathrm{TS}, \mathrm{VA}$ \\
\hline V. mollis Kunth & $\mathrm{BE}, \mathrm{BQ}, \mathrm{MX}, \mathrm{OV}, \mathrm{TC}, \mathrm{TS}, \mathrm{VA}$ \\
\hline V. pyramidata Rob. & $\mathrm{BE}, \mathrm{BQ}, \mathrm{TC}, \mathrm{TS}$ \\
\hline \multicolumn{2}{|l|}{ VIOLACEAE (1/1) } \\
\hline Hybanthus mexicanus Ging. & MX, TC \\
\hline \multicolumn{2}{|l|}{ ZYGOPHYLLACEAE $(\mathbf{1} / \mathbf{1})$} \\
\hline Guaiacum coulteri A.Gray ${ }^{(1, \mathrm{Pr})}$ & $\mathrm{BQ}, \mathrm{MX}, \mathrm{TC}, \mathrm{TS}$ \\
\hline \multicolumn{2}{|l|}{ DIVISIÓN MAGNOLIOPHYTA } \\
\hline \multicolumn{2}{|l|}{ CLASE LILIOPSIDA } \\
\hline \multicolumn{2}{|l|}{ AGAVACEAE $(3 / 3)$} \\
\hline Furcraea parmentieri (Roezl ex Ortgies) García-Mend. ${ }^{(A, v)}$ & $\mathrm{BC}, \mathrm{PA}$ \\
\hline Nolina parviflora (Kunth) Hemsl. & $\mathrm{BC}, \mathrm{BQ}, \mathrm{MX}, \mathrm{TC}$ \\
\hline Yucca filifera Chabaud & $\mathrm{BC}, \mathrm{MX}, \mathrm{PA}, \mathrm{TC}$ \\
\hline \multicolumn{2}{|l|}{ ARECACEAE $(6 / 9)$} \\
\hline Acrocomia aculeata (Jacq.) Lodd. ex Mart. & $\mathrm{BQ}, \mathrm{OV}, \mathrm{TP}, \mathrm{TS}$ \\
\hline Attalea cohune Mart. & $M X, T C, T P, T S, V A, V S$ \\
\hline Brahea dulcis (Kunth) Mart. & $\mathrm{BC}, \mathrm{BM}, \mathrm{MX}, \mathrm{TC}, \mathrm{TS}$ \\
\hline B. nitida André & $\mathrm{BC}, \mathrm{BQ}, \mathrm{MX}, \mathrm{TC}$ \\
\hline B. pimo Becc. ${ }^{(v)}$ & $\mathrm{BC}, \mathrm{TS}$ \\
\hline Chamaedorea pochutlensis Liebm. ${ }^{(\mathrm{A}, \mathrm{V})}$ & $\mathrm{BM}, \mathrm{BQ}, \mathrm{TC}, \mathrm{TS}$ \\
\hline Cryosophila nana (Kunth) Blume ex Salomon ${ }^{(A, v)}$ & $\mathrm{BQ}, \mathrm{TC}, \mathrm{TS}, \mathrm{VA}$ \\
\hline Sabal mexicana Mart. & $\mathrm{BQ}, \mathrm{OV}, \mathrm{TC}, \mathrm{TP}, \mathrm{TS}, \mathrm{VS}$ \\
\hline S. pumos (Kunth) Burret ${ }^{(\mathrm{R}, \mathrm{Pr})}$ & $\mathrm{BQ}, \mathrm{OV}$ \\
\hline \multicolumn{2}{|l|}{ POACEAE $(2 / 2)$} \\
\hline Chusquea circinata Soderstr. et C.E.Calderón & $\mathrm{BQ}, \mathrm{TC}$ \\
\hline Otatea acuminata (Munro) C.E.Calderón et Soderstr. & $\mathrm{BQ}, \mathrm{TC}$ \\
\hline
\end{tabular}


Apéndice 2. Especies arbóreas no registradas para Michoacán, pero con una alta probabilidad de encontrarse en su territorio debido a su presencia en estados vecinos. Abreviaturas de los estados: $\mathrm{COL}=$ Colima, $\mathrm{GTO}=\mathrm{Guanajuato}, \mathrm{GRO}=\mathrm{Guerrero}$, $\mathrm{JAL}=$ Jalisco y MÉX = Estado de México.

\begin{tabular}{|c|c|c|c|c|c|}
\hline Taxa & COL & GTO & GRO & JAL & MÉX \\
\hline \multicolumn{6}{|l|}{ ACHATOCARPACEAE } \\
\hline Achatocarpus nigricans Triana & & & * & & \\
\hline \multicolumn{6}{|l|}{ ACTINIDIACEAE } \\
\hline Saurauia buscalioniana S.F.Blake & & & $*$ & & \\
\hline \multicolumn{6}{|l|}{ AGAVACEAE } \\
\hline Furcraea guerrerensis Matuda & $*$ & & * & * & \\
\hline Yucca jaliscensis (Trel.) Trel. & $*$ & * & & * & \\
\hline \multicolumn{6}{|l|}{ ANACARDIACEAE } \\
\hline Cyrtocarpa kruseana R.M.Fonseca & & & * & * & \\
\hline \multirow{2}{*}{\multicolumn{6}{|c|}{ ANNONACEAE }} \\
\hline & & & & & \\
\hline Annona longiflora S.Watson & & & & * & \\
\hline A. palmeri Saff. & & & * & $*$ & \\
\hline Mosannona depressa (Baill.) Chatrou & & & * & & \\
\hline \multicolumn{6}{|l|}{ APOCYNACEAE } \\
\hline Plocosperma buxifolium Benth. & & & $*$ & $*$ & \\
\hline \multicolumn{6}{|l|}{ BOMBACACEAE } \\
\hline Ceiba parvifolia Rose & & & * & & * \\
\hline Pachira aquatica Aubl. & & & * & & \\
\hline \multicolumn{6}{|l|}{ BORAGINACEAE } \\
\hline Cordia gerascanthus L. & & & & * & * \\
\hline \multicolumn{6}{|l|}{ BURSERACEAE } \\
\hline Bursera morelensis Ramirez & & * & * & & \\
\hline \multicolumn{6}{|l|}{ CAESALPINIACEAE } \\
\hline Caesalpinia colimensis F.J.Herm. & * & & * & * & \\
\hline C. exostemma DC. & * & & & $*$ & \\
\hline C. sclerocarpa Standl. & * & & * & $*$ & \\
\hline C. velutina (Britton et Rose) Standl. & & & * & & \\
\hline Hymenaea courbaril L. & * & & * & * & \\
\hline \multirow{2}{*}{\multicolumn{6}{|c|}{$\begin{array}{l}\text { CAPPARACEAE } \\
\text { CA. }\end{array}$}} \\
\hline & & & & & \\
\hline Capparis indica (L.) Druce & * & $*$ & $*$ & $*$ & \\
\hline \multicolumn{6}{|l|}{ CAPRIFOLIACEAE } \\
\hline Viburnum hartwegii Benth. & & & & * & \\
\hline \multicolumn{6}{|l|}{ CELASTRACEAE } \\
\hline Perrottetia longistylis Rose & * & & * & * & \\
\hline Wimmeria persicifolia Radlk. & * & & $*$ & * & $*$ \\
\hline \multicolumn{6}{|l|}{ CLETHRACEAE } \\
\hline Clethra alcoceri Greenm. & & & & * & \\
\hline C. rosei Britton & * & & $*$ & * & \\
\hline \multicolumn{6}{|l|}{ CLUSIACEAE } \\
\hline Clusia pringlei Lundell & $*$ & & & & \\
\hline C. rosea Jacq. & & & $*$ & & \\
\hline \multicolumn{6}{|l|}{ CONVOLVULACEAE } \\
\hline Ipomoea intrapilosa Rose & * & * & & * & \\
\hline \multicolumn{6}{|l|}{ CYCADACEAE } \\
\hline Dioon tomasellii De Luca, Sabato et Vázq.Torres & & & * & $*$ & \\
\hline \multicolumn{6}{|l|}{ ELAEOCARPACEAE } \\
\hline Sloanea mexicana Standl. & & & $*$ & & \\
\hline \multicolumn{6}{|l|}{ ERICACEAE } \\
\hline Vaccinium stenophyllum Steud. & & & * & * & \\
\hline
\end{tabular}




\begin{tabular}{|c|c|c|c|c|c|}
\hline Taxa & COL & GTO & GRO & JAL & MÉX \\
\hline \multicolumn{6}{|l|}{ ERYTHROXYLACEAE } \\
\hline \multirow{2}{*}{\multicolumn{6}{|c|}{ EUPHORBIACEAE }} \\
\hline & & & & & \\
\hline Manihot auriculata McVaugh & & & & $*$ & \\
\hline \multicolumn{6}{|l|}{ FABACEAE } \\
\hline $\begin{array}{l}\text { Aeschynomene amorphoides (S.Watson) } \\
\text { Rose ex B.L.Rob. }\end{array}$ & $*$ & & $*$ & $*$ & \\
\hline Coursetia madrensis Micheli & & & $*$ & & \\
\hline Dalbergia glabra (Mill.) Standl. & & & $*$ & & \\
\hline Lonchocarpus atropurpureus Benth. & & & * & & \\
\hline L. punctatus Kunth & $*$ & & $*$ & $*$ & \\
\hline \multicolumn{6}{|l|}{ FLACOURTIACEAE } \\
\hline Homalium senarium Sessé et Moc. ex DC. & & & $*$ & $*$ & \\
\hline \multicolumn{6}{|l|}{ JUGLANDACEAE } \\
\hline Carya ovata (Mill.) K.Koch & & $*$ & & & \\
\hline & & & & $*$ & $*$ \\
\hline \multicolumn{6}{|l|}{ LAURACEAE } \\
\hline Persea hintonii C.K.Allen & $*$ & & $*$ & $*$ & $*$ \\
\hline \multicolumn{6}{|l|}{ MALVACEAE } \\
\hline Abutilon rzedowskii W.R.Anderson & $*$ & & & $*$ & \\
\hline \multicolumn{6}{|l|}{ MELASTOMATACEAE } \\
\hline Conostegia icosandra (Sw. ex Wikstr.) Urb. & & & $*$ & & \\
\hline Miconia langlassei Standl. & & & * & & \\
\hline \multicolumn{6}{|l|}{ MENISPERMACEAE } \\
\hline Hyperbaena mexicana Miers & & & $*$ & & \\
\hline \multicolumn{6}{|l|}{ MIMOSACEAE } \\
\hline Acacia amentacea DC. & & * & & $*$ & * \\
\hline Acaciella rosei (Standl.) Britton et Rose & $*$ & & & $*$ & \\
\hline Cojoba arborea (L.) Britton et Rose & & & * & & \\
\hline Inga flexuosa Schltdl. & & & & $*$ & * \\
\hline \multicolumn{6}{|l|}{ MONIMIACEAE } \\
\hline Siparuna andina (Tul.) A.DC. & $*$ & & $*$ & $*$ & \\
\hline \multicolumn{6}{|l|}{ MYRSINACEAE } \\
\hline Ardisia compressa Kunth & $*$ & & $*$ & $*$ & $*$ \\
\hline Parathesis cubana (A.DC.) Molinet et M.Gómez & & & * & & \\
\hline P. macronema Bullock & & & $*$ & & \\
\hline \multicolumn{6}{|l|}{ MYRTACEAE } \\
\hline Eugenia crenularis Lundell & & & * & $*$ & $*$ \\
\hline E. rekoi Standl. & $*$ & & $*$ & $*$ & \\
\hline E. salamensis Donn.Sm. & $*$ & & & & \\
\hline \multicolumn{6}{|l|}{ NYCTAGINACEAE } \\
\hline Guapira macrocarpa (Miranda) Miranda & & & & * & \\
\hline \multicolumn{6}{|l|}{ OLACACEAE } \\
\hline Ximenia americana L. & * & & * & $*$ & \\
\hline \multicolumn{6}{|l|}{ OLEACEAE } \\
\hline Forestiera tomentosa S.Watson & & $*$ & & $*$ & \\
\hline \multicolumn{6}{|l|}{ ONAGRACEAE } \\
\hline Hauya rusbyi Donn.Sm. et Rose & & & $*$ & & \\
\hline \multicolumn{6}{|l|}{ PIPERACEAE } \\
\hline Piper amalago L. & & $*$ & $*$ & $*$ & $*$ \\
\hline P. diandrum C.DC. & & & $*$ & & \\
\hline P. marginatum Jacq. & & & $*$ & & \\
\hline P. pseudofuligineum C.DC. & * & & & * & \\
\hline P. psilorhachis C.DC. & & & $*$ & & \\
\hline P. sanctum (Miq.) Schltdl. ex C.DC. & $*$ & & & $*$ & \\
\hline
\end{tabular}




\begin{tabular}{|c|c|c|c|c|c|}
\hline Taxa & COL & GTO & GRO & JAL & MÉX \\
\hline \multicolumn{6}{|l|}{ POACEAE } \\
\hline Otatea fimbriata Soderstr. & & & & * & \\
\hline Rhipidocladum racemiflorum (Steud.) McClure & & & & * & \\
\hline \multicolumn{6}{|l|}{ POLYGONACEAE } \\
\hline Coccoloba liebmannii Lindau & * & & * & * & \\
\hline C. schiedeana Lindau & & & * & & \\
\hline \multicolumn{6}{|l|}{ RHAMNACEAE } \\
\hline Colubrina macrocarpa (Cav.) G.Don & & & * & & * \\
\hline \multicolumn{6}{|l|}{ ROSACEAE } \\
\hline Prunus erythroxylon Koehne & * & & * & & \\
\hline P. ferruginea Steud. & & & & * & \\
\hline P. tetradenia Koehne & & & & * & \\
\hline \multicolumn{6}{|l|}{ RUBIACEAE } \\
\hline Genipa americana L. & & & * & & \\
\hline Gonzalagunia panamensis (Cav.) K.Schum. & & & * & * & \\
\hline Machaonia acuminata Humb. et Bonpl. & & & & * & \\
\hline Randia obcordata S.Watson & * & & & & \\
\hline \multicolumn{6}{|l|}{ RUTACEAE } \\
\hline Amyris sylvatica Jacq. & & & & * & \\
\hline $\begin{array}{l}\text { Zanthoxylum limoncello Planch. et Oerst. } \\
\text { ex Triana et Planch. }\end{array}$ & & & & & $*$ \\
\hline \multicolumn{6}{|l|}{ SALICACEAE } \\
\hline Salix hartwegii Benth. & & & & & $*$ \\
\hline \multicolumn{6}{|l|}{ SAPINDACEAE } \\
\hline Cupania macrophylla Mart. & & & * & & \\
\hline \multicolumn{6}{|l|}{ SAPOTACEAE } \\
\hline Sideroxylon celastrinum (Kunth) T.D.Penn. & $*$ & & * & & \\
\hline S. stenospermum (Standl.) T.D.Penn. & & & & * & \\
\hline \multicolumn{6}{|l|}{ SIMAROUBACEAE } \\
\hline Simarouba glauca DC. & $*$ & & * & & \\
\hline \multicolumn{6}{|l|}{ SOLANACEAE } \\
\hline Cestrum laurifolium L'Hér. & & & * & & \\
\hline C. oblongifolium Schltdl. & & * & * & & $*$ \\
\hline Lycianthes manantlanensis A.Rodríguez et O.Vargas & & & & * & \\
\hline Solanum asperum Rich. & & & * & * & \\
\hline S. hazenii Britton & & & * & * & \\
\hline S. mitlense Dunal & & & * & & \\
\hline S. rudepeanum Dunal & & & * & * & \\
\hline \multicolumn{6}{|l|}{ STERCULIACEAE } \\
\hline Chiranthodendron pentadactylon Larreat. & & & * & & $*$ \\
\hline Helicteres guazumifolia Kunth & & & * & * & * \\
\hline \multicolumn{6}{|l|}{ THEACEAE } \\
\hline Cleyera mexicana (Turcz.) Planch. ex Hemsl. & & & & & * \\
\hline Ternstroemia sylvatica Schltdl. et Cham. & & & * & & * \\
\hline \multicolumn{6}{|l|}{ TILIACEAE } \\
\hline Heliocarpus appendiculatus Turcz. & & & * & & \\
\hline H. donnell-smithii Rose & * & & * & * & \\
\hline H. reticulatus Rose & & & & * & \\
\hline H. velutinus Rose & & & * & * & \\
\hline Triumfetta heliocarpa K.Schum. & & & & & $*$ \\
\hline \multicolumn{6}{|l|}{ ULMACEAE } \\
\hline Celtis reticulata Torr. & & & & * & \\
\hline \multicolumn{6}{|l|}{ URTICACEAE } \\
\hline Urera baccifera (L.) Gaudich. ex Wedd. & $*$ & & * & & $*$ \\
\hline \multicolumn{6}{|l|}{ VERBENACEAE } \\
\hline Citharexylum hexangulare Greenm. & * & & & $*$ & \\
\hline
\end{tabular}

